



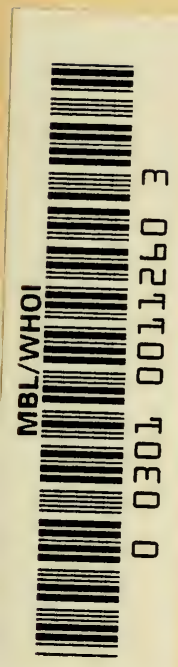



CONCERNING EVOLUTION 


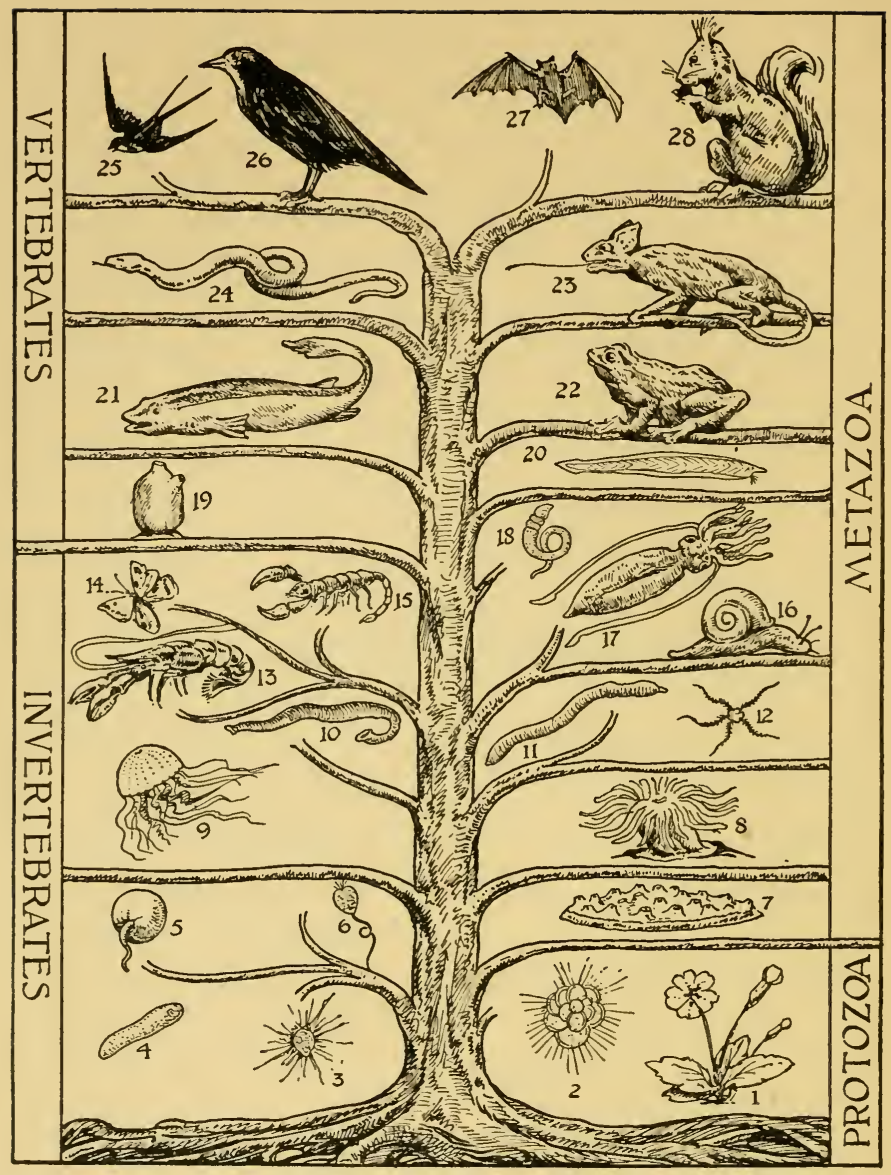

\section{SUGGESTION OF A GENEALOGICAL TREE OF ANIMALS}

1: A plant, indicating that the roots of this animal genealogical tree are connected with those of a corresponding plant genealogical tree. 2: Foraminifer, with threads of living matter. 3: Another Rhizopod Protozoön. 4: A parasitic Sporozoön. 5: Noctiluca, a luminescent Infusorian. 6: The Bell-Animalcule. 2-6 are unicellular animals,-Protozoa. 7: Crumb-of-Bread Sponge. 8: Sea-Anemone. 9: Jellyfish. 10: Leech. 11: A ringed worm or Annelid. 12: A Brittle-Star (Echinoderm). 13: Lobster. 14: Butterfly. 15: Scorpion. 13-15: Arthropods. 16: Snail. 17: Squid. 18: Balanoglossus, pointing on to Vertebrates. 19: A Tunicate or Ascidian. 20: Lancelet or Amphioxus. 21: Fish. 22: Toad. 23: Chamæleon (a Lizard). 24: Snake (another reptile). 25: Swift. 26: Rook. 27: Bat. 28: Squirrel. 


\title{
CONCERNING EVOLUTION
}

\section{BY}

\author{
J. ARTHUR THOMSON \\ M.A., LL.D.
}

PROFESSOR OF NATURAL HISTORY IN THE

UNIVERSITY OF ABERDEEN

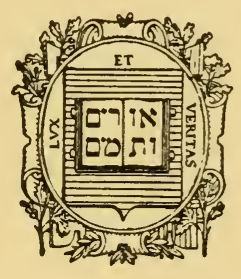

NEW HAVEN · YALE UNIṼERSITY PRESS

LONDON - HUMPHREY MILFORD - OXFORD UNIVERSITY PRESS

M DCCCC XXV 
Copyright 1925 by Yale University Press Printed in the United States of America 


\section{PREFACE}

T N 1924, the Corporation of Yale University did 1 me the honor of asking me to deliver the first series of Dwight $\mathrm{H}$. Terry Lectures. I have to thank the Corporation for this fine opportunity and for the many kindnesses shown to me during my visit to Yale.

I was led by the widespread discussion of Evolution to devote the three lectures to different aspects of evolutionist inquiry. They deal with the Making of Worlds, the Evolution of Organisms, and the Emergence of Man. My object was to show that evolutionist description is not inconsistent with religious interpretation. Indeed the evolutionist view of $\mathrm{Na}$ ture and of Man makes for enrichment and encouragement. The lectures are not systematic expositions of evolution in the domain of things, the realm of organisms, and the kingdom of man: they are intended rather to show how evolutionary science may illumine the religious outlook. The lectures are published almost as they were spoken, except that the second has been much expanded. I am greatly indebted to Professor J. H. McGregor of Columbia University for his permission to use a photograph of three of his remarkable restorations.

J. Arthur Thomson. 



\section{CONTENTS}

Illustrations

Page ix

Chapter I. The Making of Worlds

Page 1

$\S 1$ Laplace's Nebular Hypothesis. §2. Difficulties of the Old Nebular Hypothesis. §3. Spiral Nebulæ. §4. The Tidal Theory. §5. Planetesimals. §6. General Agreement as to the Nebular Origin of the Solar System. §7. The Old-time Religious Wonder. §8. Three General Impressions. §9. The Evolution of Matter. $\S 10$. The Unification of Energies. §11. The Fashioning of the Earth. §12. Making a Home for Life. §13. Criticisms. §14. A Possible Picture.

Chapter II. Organic Evolution

Page 39

$\S 1$. The Emergence of Life. §2. Note on Photosynthesis. §3. Outlook on Animate Nature. §4. Evidences of Evolution. §5. The Rock Record. §6. Geographical Evidences. §7. Anatomical Arguments. §8. Embryological Evidence. §9. The Living Past. §10. Experimental Evidence. §11. General Conclusion. §12. The Gist of Darwinism: (A) The Web of Life. §13. (B) The Struggle for Existence. §14. (C) Variability. §15. (D) Selection. §16. As Regards Heredity. §17. Habits and the Possible Entailment of Their Results. $\$ 18$. Evolution Not a Chapter of Accidents. §19. Evolution in Its Religious Aspect.

Chapter III. The Evolution of Man . Page 193

$\S 1$. The Tax on New Knowledge. §2. What Darwin Proved. §3. Factors in Man's Origin. §4. Recoil from

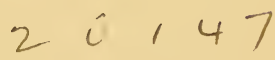


viii

Contents

the Evolutionist View. §5. Emergent Evolution. §6. Man's Emergence. \$7. Factors in Man's Evolution. $\S 8$. Neanderthal Man. §9. The Continuance of Man's Evolution. §10. The Danger of Biologisms. §11. Religious Interpretation.

Index

Page 243 


\section{ILLUSTRATIONS}

Suggestion of a Genealogical Tree of Animals

Frontispiece

PAGE

Figure 1. Saturn and Its Ring

Figure 2. Nebulæ

Figure 3. The New Zealand "Lizard"

54

Figure 4. Skeleton of Extinct Reptile, Iguanodon bernissartensis

Figure 5. Indication of Pedigree of Elephants, as Shown in a Series of Skulls

Figure 6. Amphioxus or the Lancelet

Figure \%. Skeleton of Right Whale

Figure 8. Peripatus: An Archaic Type

76

Figure 9. Balanoglossus, a Connecting Link

Figure 10. Evolution and Development of Nerve Cells

Figure 11. Appendix Vermiformis in Rabbit and in Man

Figure 12. Young Form of Rosy Feather-Star

Figure 13. Evolution among Poultry

Figure 14. Evolution among Pigeons

Figure 15. Evolution in Paludina

96

Figure 16. Hypothetical Ancestor of Birds

98 
Figure 1\%. Development of Antlers of Red Deer 128

Figure 18. The Leaf-Butterfly, Kallima, Illustrating Protective Coloration 134

Figure 19. Leaf-Insect, Phyllium 136

Figure 20. Adaptations in Barnacle 138

Figure 21. A Chamæleon on a Branch 142

Figure 22. Third Eyelid in Man and Bird 198

Figure 23. Darwin's Point in Man's Ear 200

Figure 24. Man's Genealogical Tree 208

Figure 25. Pithecanthropus, Neanderthal Man, and Crô-Magnon Man facing page 211 


\section{CHAPTER I}

\section{THE MAKING OF WORLDS}

§1. Laplace's Nebular Hypothesis.

§2. Difficulties of the Old Nebular Hypothesis.

§3. Spiral Nebula.

§. The Tidal Theory.

$\$ 5$. Planetesimals.

\$6. General Agreement as to the Nebular Origin of the Solar System.

§7. The Old-Time Religious Wonder.

§. Three General Impressions.

\$9. The Evolution of Matter.

\$10. The Unification of Energies.

\$11. The Fashioning of the Earth.

\$12. Making a Home for Life.

§13. Criticisms.

§14. A Possible Picture. 



\section{THE MAKING OF WORLDS}

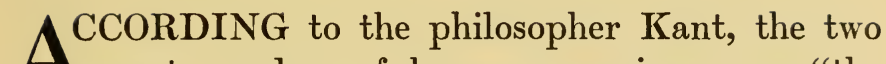
A great wonders of human experience are "the starry heavens above and the moral law within"; and it is interesting to remember that he was one of the first (1755) to try to give a firm picture of the manner in which the solar system might have attained to its present form from a state of diffused and cold material particles. Kant was one of the pre-Darwinian evolutionists, and his evolutionism has now been extended from the stars above to the moral law within. Kant was doubtless prescient enough to know that this would happen, and wise enough to be assured that it does not affect the dignity of anything to have its history unravelled.

\section{§1. Laplace's Nebular Hypothesis.}

UNAWARE of Kant's speculations, the mathematician and astronomer Laplace published in 1796 certain tentative suggestions of a cosmogony which became widely known as the Nebular Hypothesis. Laplace did not himself take his hypothesis too seriously, for he speaks of his suggestions somewhat apologetically, as "conjectures which I present with all the distrust which everything which is not a result of observation or of calculation ought to inspire." What Laplace pictured was a vast, very hot gaseous mass, rotating as a whole like a solid body, and filling more than the 


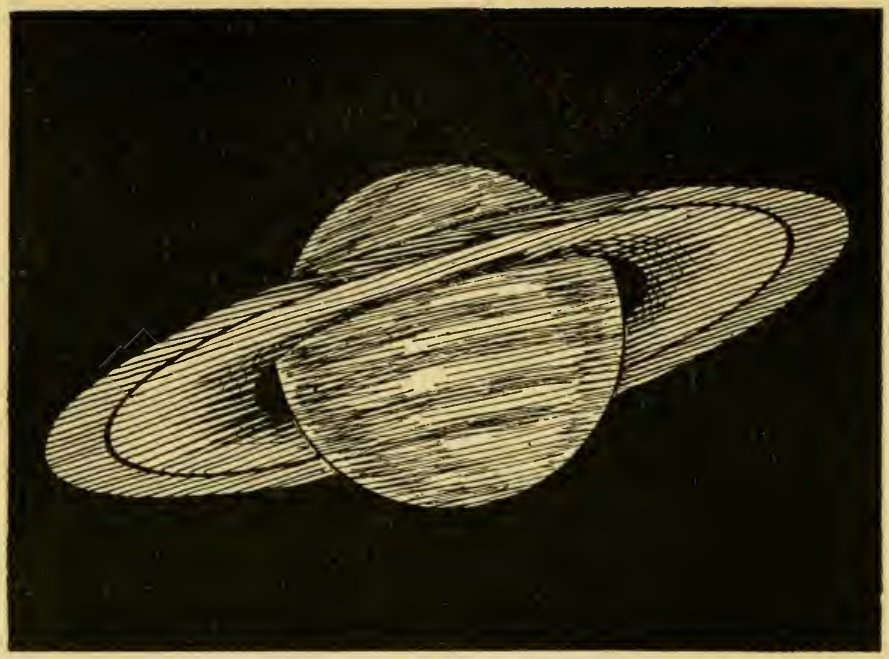

FIGURE NO. 1

\section{SATURN AND ITS RING}

Saturn, the planet with an orbit between that of Jupiter and that of Uranus, is marked by a ring, which is distinctly separable into three parts, probably consisting of a multitude of small satellites in rapid revolution around the planet. Outside the ring there are larger satellites, the largest almost as big as Mars. 
space now occupied by the solar system. As this great mass lost heat into space, it contracted and its speed of rotation increased. As the speed of rotation increased, the mass would tend to become less spherelike and more lens-like. Eventually, according to Laplace's suggestion, the great mass of gas would cease to be able to retain its integrity. A ring or zone would be separated off at the equator when the centrifugal force of rotation got the better of the centripetal force of gravitation. The detached rings went on revolving on their own, but under various conditions they condensed into planets, which might again project off rings like Saturn's, or satellites like Jupiter's.

§2. Difficulties of the Old Nebular Hypothesis.

IT has often been pointed out that there are lensshaped nebulæ to be seen to-day in the heavens, rotating about an axis perpendicular to the plane of their slight flattening. If these rotating masses are throwing off material from their equatorial planes, then they are behaving like Laplace's hypothetical nebula. But this confirmation of the original form of the Nebular Hypothesis is badly damaged by the conclusion of the experts that those apparently lenticular nebulæ are ordinary spiral nebulæ seen edgewise.

We are not competent to discuss the great technical difficulties in the way of Laplace's theory that the planets arose by the rotational separation of successive rings which subsequently condensed; but to avoid vagueness we must mention two or three reasons 

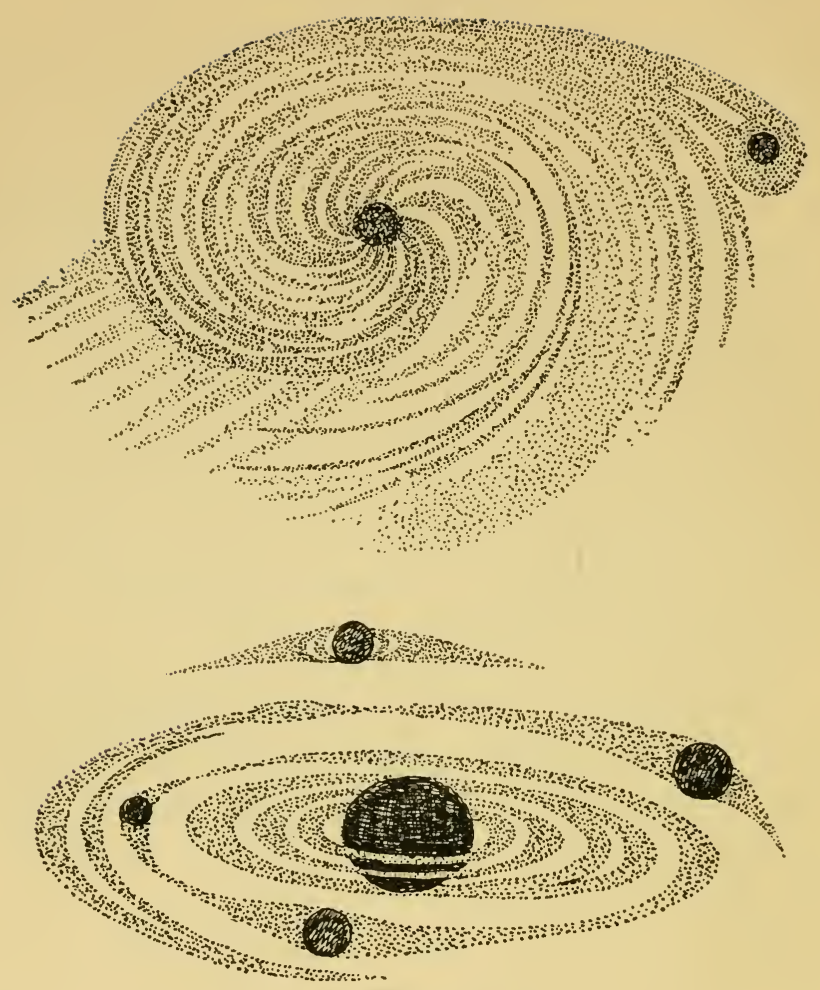

FIGURE NO. 2

\section{NEBULÆ}

The lower figure gives a diagrammatic indication of Laplace's nebular hypothesis. The center of the rotating nebular mass forms the sun. Successive rings are separated off, each concentrating into a planet.

The upper figure gives a diagrammatic indication of a two-armed spiral nebula. 
why the original form of the Nebular Hypothesis has been abandoned. The four inner planets should have possessed greater masses than the four outer ones, which is very far from being the case. The residual sun, the heart of the nebula, should be revolving on its axis much more quickly than it actually doesonce in twenty-five days. And, again, the equatorial plane of the sun ought, on Laplace's hypothesis, to lie precisely in the mean plane of the planets' orbits, whereas it is inclined seven degrees to such a mean plane. Let these difficulties suffice.

\section{§3. Spiral Nebulae.}

THE characteristic nebula observable in the heavens to-day seems to be a whirling mass of gas with a central nucleus and spirally-twisted ejected arms emerging symmetrically from opposite ends. Condensations in the arms of these whirling nebulæ are stars, as Dr. Jeans says, "in the process of birth." When these condensations began to move as detached bodies, vast clusters of stars may have arisen, great systems like the Milky Way, each system born out of a gigantic rotating nebula. "In the spiral nebula," Dr. Jeans writes, "we are watching, not the birth of planets, which Laplace attempted to explain by his nebular hypothesis, but the birth of the stars themselves. The process is, in its main outlines, identical with that imagined by Laplace, but on a more stupendous scale."

It might be supposed that the separated stars, set free from a giant nebula, like sparks from a Cath- 
erine-wheel firework, would proceed to repeat the process on a small scale, thus forming planets. But the experts on cosmogony, like Dr. Jeans, say No. The matter ejected from a giant nebula might readily form more stars than we can see on a clear night, but a small mass will give off only one condensation or none at all. The matter ejected from a small mass might dissipate into space, or it might form an atmosphere around the residual star, or it might in favorable conditions form a companion star. And such a binary or occasionally multiple type is well known in the heavens. But it seems that a solar system like ours could not arise in this way.

\section{§4. The Tidal Theory.}

THE gist of Laplace's theory is that the solar system arose by the rotational break-up of a great nebula. But the difficulties in the face of this theory seem to be very great, and they are not removed by starting with a giant spiral nebula like those to be seen to-day, which may even now be forming worlds. Thus there has arisen, especially in the ingenious minds of Professors Chamberlin and Moulton, a novel theory of great attractiveness-the tidal hypothesis. The sun and the moon raise tides on the earth to-day, and there is evidence that they were once much higher. It is not difficult to conceive of tides of colossal magnitude on the sun itself.

Similarly it is thinkable that a sun, arising perhaps from the condensation of a nebula, or as a knot on a spiral arm, might come to be subject to intense 
tidal forces because of the near approach of a passing star. A great jet or gaseous mass might be lifted off from the sun by the gravitational attraction of the passer-by, might be drawn out beyond possibility of recall, and might break into vast fragments which became our present planets. They would at first describe orbits under the combined gravitational action of the sun and of the star which caused the cataclysm, and this, as Jeans suggests, may account for the two planes of the solar system-the plane which contains the orbits of the outer planets, and the plane of the sun's equator and the orbit of Mercury, inclined at about seven degrees to the other. But as the passing star receded, the planets would be left in obedience to the parent-sun.

In a metaphorical way, then, we may think of the earth and the planets having a bi-parental origin, the one parent being the sun and the other a passing star. This seems almost too accidental to be true, but we suppose the passing of the star need not be thought of as in any way fortuitous, but rather as an integral part of the scheme of things-the Order of Nature, in other words. If the theory is true, it suggests that sequence of events in the Order of Nature must have been very well thought out. The mere fact that it led on eventually to the evolution of astronomers who devised such an ingenious theory seems enough to show that the star was not passing at random. Even hard-shelled physicists are agreed as to the incomprehensibility (not impossibility) of our cosmos emerging from chaos and chance. 


\section{§5. Planetesimals.}

'THe tidal theory, as stated by Professors Chamberlin and Moulton, postulates a sun due to the ingathering of a primal nebula. The close approach of another star is supposed to draw out a secondary nebula of spiral form with great rotational energy. It should be borne in mind that our present-day sun sometimes shoots out gaseous solar prominences to heights of nearly 300,000 miles and at velocities ranging up to 300 miles per second. What may it not have done long ago when provoked by a passing star!

It is supposed that in the arms of the secondary or spiral nebula there appeared knots which condensed to form the cores of the future planets. The earthmoon knot is supposed to have been double. The liquid or solid cores proceeded to gather in the likewise revolving outer residual material of the arms and the still finer dust-like particles which Chamberlin calls planetesimals. In the case of the earth's growth it is believed that the accretion of planetesimals has been of great importance. According to Chamberlin the earth was built up as a solid body, not fluid or viscous after the condensation of the knots into a core.

§6. General Agreement as to the Nebular Origin of the Solar System.

ThE cobbler should stick to his last, but we have ventured, under guidance from Yale and elsewhere, to enter fields beyond the domain of our personal studies. For it is the purpose of these lectures to 
present an outline picture of evolution as a whole, and then to submit general reflections thereon.

It is obvious that only high-brow mathematicians can pronounce on the validity of these difficult theories of the making of worlds, but it is important that the outsider should realize that such theories are advanced by competent experts and that the less stable, like Laplace's, are being eliminated.

The general significance of the experts' pictures is clear; they all point back to a nebula. The general thought that cannot be repressed is that if the potentiality of our earth and all that it contains was in a knot on the spiral arm of a nebula there must have been in the nebula more than met the eye-or than would have met the eye had there been any faroff astronomers to see.

The story goes that Napoleon asked Laplace what room there was for God in his celestial mechanics, to which the astronomer answered that he "had no need of that hypothesis." This is sometimes misunderstood as an irreverent or atheistic declaration, but it was neither. Laplace meant that the august concept of God was foreign to the astronomer's "universe of discourse." He meant that the words "God" and "Gravitation" must not be used in the same breath. He meant that the system of the stars is autonomous, that it does not require any underpinning. It is not like a clock that requires continual winding-up and continual regulation, though it may well be that the religious mind is right in believing that the world is the embodiment of a Divine Thought and that it 
would all disappear if God ceased to keep it in mind. But the relation of God to His world is plainly beyond man's understanding.

We cannot look at a wonderful piece of mechanism, such as a linotype machine or a steam-engine, without an admiration for its author, and if we were told that this triumph has not been directly made, but was the outcome of a simpler mechanism that went before it, and so on backwards, our admiration would be increased, not decreased.

A work of art expresses an idea or an emotion in significant form, and when we study a great painting we get some revelation of the artist's mind. So it should be in regard to the physical universe; it should tell our religious consciousness something of its author, especially if we do not think of Him as an Artificer, but as One who made things make themselves. Then we shall say: "The heavens are telling the glory of God."

\section{§7. The Old-Time Religious Wonder.}

THE question is whether we cannot regain something of the old wonder and reverence, without in any way losing our scientific foothold.

"Lift up your eyes on high, and behold who hath created these things, that bringeth out their host by number; he calleth them all by names by the greatness of his might; for that he is strong in power, not one faileth."

The grandeur of the picture was almost overwhelming. 
Soon as the ev'ning shades prevail, The moon takes up the wondrous tale, And, nightly to the list'ning earth, Repeats the story of her birth; While all the stars that round her burn, And all the planets in their turn, Confirm the tidings as they roll And spread the truth from pole to pole.

In Reason's ear they all rejoice, And utter forth a glorious voice; For ever singing as they shine, "The hand that made us is divine."

Addison's hymn may sound a little quaint to us, and perhaps we feel almost nearer the simpler words of the psalm that inspired them-not less so because it expresses astonishment that man should be crowned amidst all the splendor of creation.

When I see the work of thy fingers,

Moon and stars which thou hast fashioned,

What is man that thou shouldest think of him,

Or one of earth's race that thou shouldest befriend him?

In seeking to recapture something of the old religious wonder, we should not attach too much importance to the size of the canvas. But it is very impressive. Before Galileo the stellar universe consisted of less than five thousand visible stars; the telescope raised the number to hundreds of thousands; the photographic plate to hundreds of millions. And besides these there are the thousands of dark stars! 
The sun is about 93 millions of miles away, a distance which light takes eight minutes to traverse. Many people nowadays make the grand tour round the world, about 24,000 miles, in about sixty days. Sir Richard Gregory writes: "In order to travel as many miles as separate us from the sun it would be necessary to make nearly four thousand such journeys, and if a traveller started on his circuit as soon as he was born, he would require to live about 650 years to finish his task. . . A sensation travels along the nerves at the rate of about a hundred feet in a second. Imagine a man could stretch out his arm and reach to the sun so as to burn his finger; the sensation would start on its journey, but 160 years would elapse before it had reached his brain and made him realize the pain" (The Vault of Heaven, 2d ed., 1923, p. 24). Without wishing to make too much of huge dimensions, we feel that there is a basis for reasonable wonder. Light travels 186,000 miles per second, and the distance of six million million miles traversed in a year is called a "light-year." The nearest star is Alpha Centauri, but a flash from it to the sun takes four years to reach its destination; and the light we receive from Vega left that star twentyseven years ago. Sir Richard Gregory writes: "Most of the stars seen in the sky without telescopic aid are at such a distance that the light we now analyze left them about the time of Galileo (d. 1642); and there are others whose rays, though rushing with lightning speed through the depths of space, only reach us 
after a journey counted in thousands of years" (The Vault of Heaven, 2d ed., 1923, p. 147).

According to Einstein and others the universe is finite though boundless, and the astronomer De Sitter has estimated its circumference at about 100 million light-years-about ten times the possible distance from the earth to the farthest spiral nebula visible in the telescope. De Sitter estimates the mass of the universe at about a quintillion quadrillions $\left(10^{54}\right)$ of grams, and the number of electrons at a quintillion octillions $\left(10^{78}\right.$ ) (see Arthur Haas, The Nere Physics, 1923).

We cannot think of such vastnesses without feeling that we are citizens of no mean city, but perhaps we should be more impressed by the order and the uniformity of the heavens. Even the comets have their courses, and though there have been cataclysms in the course of ages a new order rises out of the old. Clerk Maxwell's declaration is familiar: "Though in the course of ages catastrophes have occurred and may yet occur in the heavens, though ancient systems may be dissolved and new systems evolved out of their ruins, the molecules [or atoms, we should say] out of which these systems are built- the foundation-stones of the material universe-remain unbroken and unworn. They are this day as they were created-perfect in number and measure and weight." The discovery of radio-activity necessitates some change in the wording, but not in the idea. The world is one and orderly. 
We must think also of the complexity of movements - the earth rotating on its axis and the sun doing the same; the earth revolving in its orbit; and the whole solar system moving, at the rate of about twelve miles a second, towards a point in the sky in the direction of the bright star Vega, the "apex of the sun's way." We must also think of the enormous liberation of sub-atomic energies continually going on in sun and star.

From finite experiences we cannot make a transcendent inference, but we see some point in the saying, "The undevout astronomer is mad." We cannot but be impressed by Newton's quiet declaration: "This most beautiful System of the Sun, planets, and comets could only proceed from the counsel and dominion of an intelligent and powerful Being."

\section{§8. Three General Impressions.}

Three large thoughts rise in the mind. The first is of man's masterfulness, who weighs and measures the heavenly bodies, who analyzes their chemical composition and unravels their complex movements, who predicts the return of the comet, who even deciphers the life-histories of systems. What masterfulness-

When science reaches forth her arms

To feel from world to world and charms

Her secret from the latest moon!

The second thought is expressed by the mathematician Poincaré (The Foundations of Science, 1913, p. 289): "Think how diminished humanity 

would be if, under heavens constantly overclouded, as Jupiter's must be, it had forever remained ignorant-of the stars. Do you think that in such a world we should be what we are? I know well that under this sombre vault we should have been deprived of the light of the sun, necessary to organisms like those which inhabit the earth. But if you please, we shall assume that these clouds are phosphorescent and emit a soft and constant light. Since we are making hypotheses, another will cost no more. Well! I repeat my question: Do you think that in such a world we should be what we are? The stars send us not only that visible and gross light which strikes our bodily eyes, but from them also comes to us a light far more subtle, which illuminates our minds."

Poincaré's point is that "without the lessons of the stars, under heavens perpetually overclouded," man would have been slow to attain to a knowledge of Laws of Nature, from which there is no escape and with which there is no possible compromise. Perhaps there might have been no science if man had not observed the stars. It looks as if Nature were Nature for a purpose.

The third thought is one to which we must return at a later stage in the argument. If the solar system emerged from a spiral nebula, and if living creatures are children of sunlit water, earth, and air, and if man is the crown of creation, how well-conceived, humanly speaking, must the institution of the Order of Nature have been! 


\section{\$. The Evolution of Matter.}

To our picture of the making of worlds must be added that of the evolution of matter. It is now known that the radio-active substances are continually producing from themselves other chemical elements. 'They cannot be stopped doing so or provoked to do so; therefore while the unchangeableness of the elements has been overthrown, their unchangeability remains, as Professor Soddy says, in a limited sense true.

In some cases a chemical genealogical tree is known. Uranium may produce ionium, which produces radium. Or uranium may produce protactinium, which produces actinium. From thorium may be produced lead, and from radium another lead, and from actinium yet another lead.

The epoch-making conclusion has been reached that the atoms of the different elements are not different in essential nature, but are constituted out of different numbers and arrangements of similar units. The atom is a planetary system in which the planets are represented by electrons (unit charges of negative electricity) circulating around a central body, which consists of hydrogen nuclei or protons and more electrons. Many authorities declare that the hydrogen nuclei or protons are just positive charges of electricity. All the world is one.

Here is a unification not less overpowering than the unity of a solar system or a galaxy of stars; we have come close to the stuff out of which worlds are 
spun, and we find that in spite of all its multitudinous diversity it is all the same.

The qualitative differences between different kinds of things turn out to be quantitative, since they depend on differences in the number and orbits of the revolving electrons and on the number of hydrogen nuclei or protons in the center of the atom. This must not lead us to overlook the fact that newness in the truest sense may emerge from new collocations of the same components. Out of Carbon, Hydrogen, Oxygen, Nitrogen ( $\mathrm{C}, \mathrm{H}, \mathrm{O}, \mathrm{N})$-the "Big Four" elements-may be made a poison or a tonic, an explosive or a food, a medicine or an aroma. Out of the same bricks and mortar-and a few girders-you may build a street of hovels or a Westminster Cathedral.

\section{§10. The Unification of Energies.}

Another great unification of recent times concerns the energies. Benjamin Thomson or Count Rumford was one of the early investigators to grasp at the idea that heat is a mode of motion. Motion gives rise to heat and heat gives rise to motion. It was plain that part of the energy of an incandescent body may be given off as light, and it was reserved for Faraday and Clerk Maxwell to discover the electromagnetic nature of light. Thus light, electricity, magnetism come into one series of energies. But a further great unification follows from Einstein's theory,-for gravitation also comes into line with the other powers, - and the world is unified in its energy as well as in its matter. 
\$11. The Fashioning of the Earth.

As we have seen, there is among astronomers a general acceptance of the proposition that our solar system had its origin in a great nebula.

As Tennyson wrote:

They say

The solid earth whereon we tread

In tracts of fluent heat began,

And grew to seeming random forms,

The seeming prey of cyclic storms

Till at the last arose the man.

Or, again, in Psyche's lecture in The Princess:

This world was once a fluid haze of light, Till toward the center set the starry tides, And eddied into suns, that, wheeling, cast The planets.

Secondly, the modern theory of the constitution of matter has given vitality to the idea of inorganic evolution. By expelling electrons and protons the atoms of radium may eventually produce lead, and so does thorium, and so does actinium, but the three leads, though identical chemically and spectroscopically, are yet different from one another and from common lead. To a certain extent the transmutation of elements has been observed, and, as we have seen, the different kinds of matter differ not in their stones and mortar (if such static words may be allowed for a moment), but in the numbers, proportions, and positions of the constituent electrons and protons. When we hear of Sir Ernest Rutherford knocking 
hydrogen and helium out of the nitrogen atom, we know that inorganic evolution is at our doors.

It-is at any rate possible to think of a nucleus of hydrogen gathering electrons about it and becoming an atom, of atoms uniting into molecules, and of molecules forming chains. In any case we hear one of the leaders of modern chemistry speaking of "the evolution of matter."

The cosmographic picture of the making of worlds is still in the mist; the evolution of matter is still a young idea; but both are very convincing. A third chapter, where the tone is more assured, is the fashioning of the earth. Difficulties in detail abound, but there is no great difficulty in principle. We may or may not accept such a novelty as Wegener's theory of the drift of continental masses away from the Poles, and from east to west; we may not believe that America is going west faster than Europe; but there is no dubiety in any mind as to gradual genesis of the earth by a series of slow changes the outcome of which has been great beauty. How admirable is this sentence from James Hutton's Theory of the Earth (1785): "No powers are to be employed that are not natural to the globe, no action to be admitted of except those of which we know the principle, and no extraordinary events to be alleged to explain a common appearance."

In his Landscape in History, Sir Archibald Geikie tells how he "found the splintered slabs of stone [on the wind-swept summit of Slieve League in Donegal] to be full of stems of fossil trees. Here, two thousand 
feet above the sea, lay a cake of the carboniferous rocks called millstone grit. This little remnant on the highest ground of the district demonstrated that a sheet of millstone grit once stretched over that remote part of the island, and may have extended much farther westward over tracts where the Atlantic now rolls." But no matter how strata have been upheaved and broken, folded and piled and thrust over one another, no one doubts the continuous operation of natural factors more or less similar to those seen in operation to-day.

What a fine vision Tennyson had of the age-long breaking-down and building-up, disintegration and reintegration!-

There rolls the deep where grew the tree.

$\mathrm{O}$ earth, what changes hast thou seen!

There, where the long street roars, hath been

The stillness of the central sea.

The hills are shadows, and they flow

From form to form, and nothing stands;

They melt like mist, the solid lands;

Like clouds they shape themselves and go.

\section{§12. Making a Home for Life.}

The earth was for long ages far too hot to be tenanted by any living creatures like those we know, and there is no use in talking of any others. Only the mythical salamander could have lived in the earth of long ago. But there was gradual cooling and the formation of a more or less substantial crust.

In his illuminating Origin of the Earth (Chicago, 
1916) Professor Chamberlin tells us how the young earth, more or less cooled down, became enwrapped in an atmosphere laden with "planetesimal" dust which sank gently on to the surface and drifted about in billowy, changeful dunes. By its early "ultra-Krakatoan" atmosphere, containing little free oxygen, but abundant carbon dioxide, water-vapor, and nitrogen, "the young earth was blanketed against intensities of radiance from without (a younger, more intensely radiant sun) and from inequalities of radiance from within." This curtaining and blanketing atmosphere was the first positive preparation for the emergence of living organisms, and we recognize its importance more clearly when we remember that the average living creature is adapted to mild temperatures and gentle reactions. Life is a tender plant, ill suited for violent vicissitudes.

Time passed, and from the growing atmosphere water began to condense on the cooling earth. It was absorbed by the dusty mantle, till by and by in the hollows among the dunes there appeared the gleam of pools and lakelets, from which grew lakes and sea. Perhaps the waters covered the earth with a universal sea. In any case, to the atmosphere there was added a second "preparation" for life, a hydrosphere.

In his Order of Nature (Harvard, 1917) Professor Henderson has worked out the panegyric of water. It can dissolve a larger variety of substances in greater concentration than any other liquid; it is a very mobile vehicle; it can split things up in hydrolytic cleavage. An enormous quantity of heat is 
necessary to evaporate away a lake or pond, and a very large quantity of heat must be lost before such a body of water entirely freezes.

Moreover, the relations between water and carbon dioxide made for progress. At temperatures consistent with the presence of a hydrosphere, the carbon dioxide "must always be somewhat evenly distributed between the air and the waters of the globe. Water can never wash the carbonic acid out of the air, nor the air extract it from the water." So much the better for land plants and water plants that get all their carbon supplies from carbonic acid. Furthermore, the presence of carbonic acid in the rain enabled the waters of the earth to mobilize in moderation the resources locked up in minerals. We need not prolong the panegyric of water save in recalling that living matter itself contains at least 75 per cent of water.

Another significant fact is that the surface of the young earth must have shown an abundant presence of carbon, hydrogen, and oxygen in combination. These three elements form, we may almost say, a great triumvirate. "Of all the chemical elements," Professor Henderson reminds us, "hydrogen, carbon, and oxygen possess the greatest number of compounds and enter into the greatest number of reactions." They tend, if we may say so, to join hands, to form rings and groups. The atoms of carbon possess the power of uniting in long chains which form large molecules, and it is this power which has made the compounds of carbon so numerous, so complex, and so important. 
Now all living creatures are essentially built up of proteins and other carbon compounds in a colloidal state, that is to say with ultra-miscroscopic particles and immiscible droplets in suspension or dispersion in a medium which, in the case of living matter, is very watery. Only in that colloidal state could materials have the pliancy and permeability which are characteristic of organisms, and that "energia" of which Thomas Graham wrote in 1861 that it "may be looked upon as the probably primary source of the force appearing in the phenomena of vitality." It is what we now call "surface energy." Now there is a notable readiness on the part of complex chemical substances to pass into this "dynamical state," as Graham called it, and thus was life prepared for. The argument runs thus: abundant presence of carbon, hydrogen, oxygen on the surface of the young earth; the unique properties of "the Big Three"; the tendency to form complex compounds under suitable provocation; the readiness of these to form colloids, which are characteristically necessary for the make-up and continuance of living creatures as we know them.

Another "preparation," if the non-scientific question-begging term is permissible, has been emphasized by Professor Chamberlin, and that was the making of a soil. Let us suppose for the moment that processes of chemical synthesis were going on; the pores of the growing soil would afford "an adequate mechanism for holding, protecting, and preserving the products of each successive step in such a way as to 
favor the next synthetic step." There is an intricate maze of capillary spaces and air-ducts in the soil.

Whether the soil was a cradle for emergent organisms or not, it has been, throughout the ages, of incalculable importance in the persistent circulation of matter and in what is called the meteorological cycle.

Water-vapor is drawn up from the sea and with the help of dust-particles forms clouds which the wind seems to shepherd across the sky. They condense on the cold rocks of the mountains and the springs are fed. With the help of the entrapped carbonic acid the water filches mineral matter from the rocks, and the streamlets form rivers which feed the sea. And then the mist rises again.

This unending cycle regulates the temperature on land and sea, it mobilizes and disperses raw materials, it canalizes the earth and gives approximate constancy of composition to the waters of the ocean. "Perhaps," as Professor Chamberlin says, "there is no fact in the earth's career more remarkable than the fidelity with which the very narrow ranges of temperature, and the not less narrow ranges of atmospheric constituents essential to the evolution of life, have been maintained, while oscillations within these permissible ranges have freely prevailed. These limits and these oscillations were perhaps as imperative for life's origin as for its prolonged maintenance." In the course of ages the changes of climate have often supplied a spur and 
often a restraining bridle, but the remarkable feature has been the general steadiness of the physicochemical environment. As we read the earth's history with imagination kindled, we almost hold our breath when a great period of aridity sets in, or a long succession of ice-ages, but in spite of local eliminations the ascent of life continues. The meteorological cycle is the scientific rainbow in the sky: a token of a covenant, we say in all reverence, between the physical Cosmos and Life. "While the earth remaineth, seedtime and harvest, and cold and heat, and summer and winter, and day and night shall not cease." Without a "meteorological cycle" there might possibly have been other kinds of living creatures on this earth of ours, for life is defiant of circumstances as many a strange habitat shows. But there could not have been the advancement of life that we know, nor the climax represented by man at his best.

Our point, then, is that a multitude of "preparations" conspired together to make the earth a home for life: the making of an atmosphere and a hydrosphere, the properties of water and carbonic acid gas separately and together, the properties and abundance of carbon, hydrogen, and oxygen in combination near the surface of the cooling earth, the ready assumption of a colloidal state by complex carboncompounds, the characters of the porous soil, and the regulative influence of the meteorological cycle. The constitution of the inanimate world is in many unique ways uniquely favorable to the interests of living 
creatures. It is plain that we have passed beyond science-which is true to itself in having nothing to do with significance or "increasing purpose." But science is not the be-all and end-all of our outlook on the world and estimate of our place in it. From a broader basis we say that it looks as if Inorganic Nature was as it is with a purpose.

Perhaps our position may be made clearer if we take the particular case of the freezing of water. As we all know, water has the almost unique property of expanding near the freezing point, instead of contracting as is usual with cooling bodies. For 280 days in the year the water near the bottom of a pool or pond is colder than the water near the surface, and this works out most appropriately well for many aquatic animals that like moderate coolness. But for 85 days in the year the water near the bottom of the pool or pond is warmer than that at the surface, and this is also well. When the frost's fingers go deep, the water near the floor of the pool begins to get very cold, and it reaches its maximum density at $4^{\circ} \mathrm{C}$. When it becomes still colder it expands, whereas every ordinary fluid contracts; and this expansion raises it to the surface, where it freezes and adds to the thickness of the blanket of ice. In this way it is difficult for a pool to freeze solid, and this means a preservation of the fresh-water fauna during the winter in North Temperate countries. From this far-reaching consequences follow. It seems as if it were well thought out! 


\section{§13. Criticisms.}

LET us now allow the critic to have his innings. He may urge that the facts we state are true enough, but that the phrase "preparations for life" is quite unscientific. The arrangements that came about were necessitated by the nature of the materials. Thus the widespread abundance of Carbon, Hydrogen, and Oxygen elements on the surface of the cooling earth probably had to do, as Mendeléeff suggested, with their small atomic weights. Surely, there is something in the molecular structure of water which forces it to expand as it is about to freeze. To this we must frankly agree. The idea of "preparations for" is not in the strictest sense a scientific idea; it is not a description, but an interpretation; it means seeing the pre-conditions in the light of the results. But perhaps we sometimes carry methodology too far. As long as we are studying non-vital phenomena in themselves, and without thought of their outcome, the question "Why?" does not ever suggest itself. But when we pass from things to living creatures, the question "Why?" becomes insistent. Not the philosophical "Why?" as to ultimate meaning; but a scientific "Why?" objectively teleological. Thus, in studying the development of an animal we feel bound to say: Look how stage $\mathrm{D}$ paves the way for stage $\mathrm{E}$; look how these varied factors conspire in the production of an eye. Perhaps, therefore, it is not quite illegitimate to say: See how the properties of water facilitate the emergence and continuance of Life. In any case, 
they did this and do this; and one is not restricted to the abstract scientific outlook.

But again the critic may say: "Yours is a very pious opinion, but are you not repeating the mistake of the naïve old lady who saw providential design in the way so many fine rivers flowed through so many large towns? Was it not simply that chemico-physical Nature gave rise to living creatures, which are naturally enough such that they find their environment friendly?" This seems good sense. The chemical elements that are constituents of living matter are the common elements of earth and air; and if the living creatures that evolved had not had abundant supplies at hand, and had not been viable in the given conditions, why, they would not have been there, that's all. But we are not sure that this does justice to the big fact that the chemical and physical conditions of Nature have been conspicuously favorable to the order and progress of organisms. It is easy to assert that with other elements, with other properties, there might have been other living creatures, very different from those we know, yet just as well adapted to their environment, just as marvellous and beautiful. But no one has substantiated this assertion.

\section{§14. A Possible Picture.}

Venturing frankly beyond science, we hold to the idea of a Creation, an institution of the Order of $\mathrm{Na}$ ture-consisting of the irreducibles such as electrons and protons and of their psychical correlates. At first it was but an implicit Order of Nature-a 
nebula and the elusive spirit thereof. But the irreducibles-the stuff out of which worlds were spunhad a nature such that in certain conditions a solar system, one out of many, established itself ; and a unit in it, one out of many, became our earth. And the nature of things was such that changes occurred which made living organisms possible in an environment which was not fatally unfriendly to them. Unfriendly to some, no doubt, but there was always a remnant; and that viable remnant has now covered the earth and filled the sea with victorious insurgent life.

But preparing a home for life was not all, and favoring the emergence of bio-psychical creatures was not all; for far in the future was the rational mind of man, prying into the facts, puzzling over them, in part understanding them, and if this also was an outcome of natural evolution, in other words of the marvellous endowment which the elements had in the beginning, then there is no way, even if we wished, of escaping the conclusion that what we call material is also psychical, for there can be nothing in the end which was not also present in kind in the beginning. Therefore, we say, in the beginning was the Logos; in the beginning was Mind.

"Still," the critic may urge, "you are clogged by anthropomorphism. Your words suggest a Creator who is like unto one who prepares a vessel for a long voyage, with stores of energy, with devices to meet emergencies, and with self-steering gear. Your words suggest the leader of an expedition who thinks out 
everything beforehand, and foresees possible crises and anticipates them. Your words suggest a Creator who thinks out the cosmic process which is his imagining, and endows the raw materials with such capacities that he can safely leave them to make themselves." This is a very anthropomorphic cosmology, and little more than a sending out of tendrils of ignorance. But the point is that these tendrils are seeking not for supports which may be scientifically provided, but for something beyond that altogether - a transcendental interpretation. Cosmography becomes clearer every year; but what of a cosmology which is philosophical or religious?

When we pass from the Lowest Common Denominators of scientific description to the Greatest Common Measure of philosophical or religious interpretation, we must be very humble, seeking for Vision. His ways are not as our ways, nor his thoughts as our thoughts. They are, as was also said long ago, like paths in a wood thick with trees through which we see for only a little way.

\section{Summary.}

1. The philosopher Kant had a theory (1755) of the genesis of the solar system. Independently of this the mathematician and astronomer Laplace published his famous Nebular Hypothesis in 1796. From an immense, very hot, gaseous mass, rotating as a whole like a solid body, rings or zones were separated off, he supposed, which condensed into planets.

2. Laplace's general idea was that the planets 
arose by the rotational separation of successive rings from a contracting nebula. This theory is confronted by serious difficulties; thus the residual sun is not rotating so quickly as it ought to do if Laplace's theory is right. Moreover, the equatorial plane of the sun ought to lie precisely in the mean plane of the planets' orbits, whereas it is inclined seven degrees to such a mean plane.

3. The characteristic nebula in the heavens to-day is the spiral nebula, consisting of a central nucleus and spirally-twisted ejected arms emerging symmetrically from opposite ends. Condensations on these arms might form stars, systems of stars, but the separated stars would not proceed to repeat the process, thus forming planets. According to the experts a solar system like ours could not arise in this way.

4. Thus has arisen the tidal hypothesis, that the sun, arising perhaps from the condensation of a nebula, or as a knot on a spiral arm, might come to be subject to intense tidal forces because of the near approach of a passing star. A great jet or secondary nebula drawn out beyond recall might break into fragments and condense into knots which became the planets and our earth. Some of the sun's prominences to-day rise to heights of nearly 300,000 miles.

5. Residual materials of the arms might be subsequently gathered into the knots, along with more dust-like particles called planetesimals, which are regarded by Chamberlin as making important contributions to the young earth. 
6. Details apart, there is general agreement as to the nebular origin of the solar system. If so, there must have been more in the nebula than met the eyenamely, the promise and potency of mind. We must hold by the Aristotelian idea that there is nothing in the end which was not also present in kind in the beginning. Therefore we say: In the beginning was mind. We cannot comprehend the relation of God to His world, but it is difficult to think of the world being launched in any such state of imperfection that it required subsequent underpinning and subsidies. Like Dame Nature in Kingsley's Water-Babies, God made things make themselves.

7. It should be possible to regain something of the old wonder and reverence in the contemplation of Nature without losing our scientific foothold. When we consider the grandeur, the intricacy, the simplicity, the flux, the order, the progressiveness of the physical world, we find a basis for reasonable wonder. "The undevout astronomer is mad."

8. Three general facts are impressive: man's intellectual masterfulness; the dependence of science on the possibility of seeing the stars in heavens not constantly overclouded; and the way in which the Order of Nature has admitted of advance from stage to stage. It looks as if the Creation had been, as we should say in human affairs, "well thought out."

9. Modern investigation has shown the possibility of an evolution of matter. The ninety-two elements form an orderly series, differing from one another quantitatively; namely, in the number and disposi- 
tion of the component electrons and protons. One kind of element may in certain cases give rise to another. A transmutation of elements does sometimes occur. There has been a unification of the different kinds of matter.

10. Similarly, there has been a startling unification of energies. Thus light, electricity, and magnetism come into a series, and Einstein has shown how gravitation may be brought into line with the rest. The energies have been unified and matter tends to be swallowed up by electricity.

11. The story of the fashioning of the earth has been well worked out, mostly in terms of processes at present operative.

12. A succession of events made the hot earth a possible home for living creatures. Taken together, these events may be philosophically spoken of as a "preparation" for life, but that is not a scientific concept. The cooling was followed by the establishment of an atmosphere and a hydrosphere. The importance of water and its circulation is fundamental. The surface of the young earth must have shown an abundant presence of carbon, hydrogen, and oxygen in combination, and these, along with nitrogen in the air, are the requisites for the physical basis of life. These carbon compounds readily tend to form colloids, which are characteristically necessary for the make-up and continuance of living creatures as we know them. The making of the soil with its maze of capillary spaces and air-ducts was another "preparation"; it may have been a cradle for incipient or- 
ganisms; it was of incalculable importance in the persistent circulation of matter and in the establishment of the regulative meteorological cycle. The constitution of the inanimate or inorganic world has been and is in many ways uniquely favorable to the interests of living creatures.

13. The arrangements that came about were no doubt necessitated by the nature of the materials, and the term "preparations for life" is going a little beyond science. Yet the word may stand for a quite legitimate philosophical or religious interpretation; it means seeing the pre-conditions in the light of the outcome. One must not make the mistake of discerning providential arrangement in the way fine rivers flow through large towns, but it looks as if Nature were Nature for a purpose.

14. The first picture is of a nebula and the elusive spirit thereof. The irreducibles are electrons and protons with electro-magnetic and other waves spreading through space, perhaps through the continuous medium of the ether. Behind the kinetic, however, was the primordial metakinetic, behind the physical the psychical. The irreducibles were such that a more differentiated cosmos arose. The Order of Nature was such that out of a few threads a wonderful fabric was woven. There seems to have been an integrative urge in things which led to the fashioning of an earth suitable to become a cradle and home of life. What science gives us is a descriptive cosmography, which seems to be congruent with a philosophical or religious cosmology. There is 
nothing inconsistent, so far as we can see, between empirical formulation in terms of Lowest Common Denominators, like electrons and feelings, and transcendental interpretation in terms of the Greatest Common Measure, which is God. But when we pass from scientific description to religious interpretation, we must be very humble, seeking for Vision, for his ways are not as our ways, nor his thoughts as our thoughts. 



\section{CHAPTER II \\ ORGANIC EVOLUTION}

§1. The Emergence of Life.

§. Note on Photosynthesis.

§3. Outlook on Animate Nature.

\$4. Evidences of Evolution.

§5. The Rock Record.

\$6. Geographical Evidences.

\$7. Anatomical Arguments.

§. Embryological Evidence.

\$9. The Living Past.

\$10. Experimental Evidence.

$\$ 11$. General Conclusion.

\$12. The Gist of Darwinism: (A) The Web of Life.

\$13. (B) The Struggle for Existence.

§14. (C) Variability.

$\S 15$. (D) Selection.

§16. As Regards Heredity.

\$17. Habits and the Possible Entailment of Their Results.

\$18. Evolution Not a Chapter of Accidents.

§19. Evolution in Its Religious Aspect. 



\section{CHAPTER II}

\section{ORGANIC EVOLUTION}

THE making of worlds implies the transforming

1 of material from one shape to another, and even when there has been an evolution of diverse elements from homogeneous primordial units and of one chemical element from another, it has been the same material throughout. There has been no succession of generations as in Animate Nature, and no picking and choosing of survivors or elimination of the doomed. Thus there is much to be said for using some word like "genesis" for the inorganic world, keeping evolution for the racial change of organisms, usually from simpler to more differentiated and integrated types. The term "development" should be kept for the becoming of the individual, while "history" remains the best word for organic and social changes in the kingdom of man.

Speaking of words, we may notice here that in our use of the convenient phrase "Animate Nature" to include all plants and animals and their interrelations, we are not to be held as implying that there is no "anima" in the domain of the non-living. For it is part of our personal metaphysics that there is throughout the inorganic or non-living world a metakinetic aspect, the analogue of the "mind," which struggles for expression in plants and in the lower animals, and finds a considerable degree of freedom in the higher reaches of life, notably among birds 
and mammals. We use the contrasted terms "Animate" and "Inorganic" simply because we cannot find any better.

\section{$\S 1$. The Emergence of Life.}

Aт some time or other, in the history of the earth, when the conditions had become more hospitable than at first, living creatures emerged. How are we to think of this? How did living creatures begin to be upon the Earth? (1) The first answer seizes on the marvel and mystery of life, and says, "Protoplasm is a handful of dust that God enchants." But perhaps this might also be said of the dewdrop and the diamond; and, however true it is, it is not a scientific answer. It implies a premature abandonment of the scientific quest, though it will not be affected by any scientific answer that may be found.

(2) The second position is an agnostic one, that of the scientific inquirer who refuses to commit himself. "Ignoramus." This answer emphasizes the difficulty of the problem, the uniqueness of life and the fact of experience to-day-omne vivum $e$ vivo. It suggests a doubt whether we are putting the question in the right way; are we even sure that life ever began? Perhaps the particular secret of life is as old as electrons and protons, and no one worries much over their origin. The long and the short of it is: "We do not know." Perhaps this is too superior, for while it expresses the truth that it may be too soon to answer a question, it is a little apt to suggest that it may be too soon to ask it. 
(3) The third answer, associated with the names of Kelvin and Helmholtz, Richter and Arrhenius, and therefore not to be smiled at, is that minute living organisms may have come to earth from elsewhere, ensconced in a meteorite or wafted with cosmic dust. There is the difficulty of understanding the survival of germs after passing through extremes of temperature, but that would depend on how they were wrapped up, and Becquerel's experiments show that simple and quiescent forms of life can endure extremes of heat and cold. The chief objection to this answer is that it merely shifts the responsibility of the problem off the earth.

It should be recalled that dried seeds may retain their capacity for germinating even after four-score years. Parsnip seeds may germinate after two years in a vacuum. Some other seeds-e.g., of mustard and wheat-will endure being subjected for three weeks to the temperature of liquid air, and after that for seventy-seven hours to the temperature of liquid hydrogen, $250^{\circ} \mathrm{C}$. below zero. Under the combined influence of low temperature and great drought, the living matter passes out of its normal colloidal state, and yet the seeds show a high percentage of germinations. As Becquerel says, "life without water, without air, without gaseous interchanges, without colloid molecules in suspension in a liquid, appears paradoxical," but it is a fact, and it should be borne in mind in considering the suggestion that germs of life may have come to the earth from elsewhere. Small Nematode worms can remain in a state of latent life for 
fourteen years, and some more complex animals, such as Crustaceans and Rotifers, can endure desiccation for some years. In certain cases what survives is the entire animal, in other cases a surviving cyst is formed inside the dying body, and in a third set of cases the eggs alone persist. The state of latent life is very imperfectly understood; there are no signs of vitality, and yet death has not occurred. The flux has ceased, but the molecules of the protoplasm have not disintegrated.

We may be allowed to recall Becquerel's interesting suggestion that if the sun were extinguished and all the gases of our atmosphere were to vanish, there might still be a persistence of seeds and germs, eggs and spores of organisms, lingering for a long time on the surface of the "frozen, uninhabitable planet, wandering in the darkness of cosmic space." It is possible that under the influence of the radiations of a new system the frozen streams of protoplasm might thaw and flow again; it is possible that a shattering of the derelict by collision or explosion might sow new worlds with the seeds of old life. (See Thomson, Secrets of Animal Life, 1919, p. 182.)

(4) The fourth answer is the evolutionist one, that the living arose by synthesis from the not-livingperhaps from some colloidal carbonaceous slime activated by ferments. This answer is in line with evolutionist thinking, and it finds some support in the successes of the synthetic chemist, who builds up compounds like grape-sugar, oxalic acid, indigo, and caffeine. There is also suggestiveness in the way in 
which green plants, with the help of the sunlight, build up complex carbon compounds out of air, water, and-salts. The cogency of these two sets of facts is diminished by the fact that the ingenious chemist directs operations in the one case, and the living plant is the theater of operations in the other case.

There may be a hint in the fact that cyanogen (CN) and its compounds may be formed in incandescent heat, and might arise while the earth was still hot. The cyanogen compounds are unstable and might readily form linkages with other compounds, especially when water began to be precipitated on the cooling crust of the earth.

But greater interest attaches to the recent investigations by Professor Baly of Liverpool and his collaborateurs. There has been success in effecting artificially what a green leaf effects naturally-the synthesis of formaldehyde by the action of light upon water and carbon dioxide. The light used was that of a mercury-vapor lamp, which has very short wavelengths. As in the green leaf, the synthesis is accompanied by the liberation of oxygen. Light of a somewhat longer wave-length caused the molecules of formaldehyde to unite to form simple sugars ; Professor Baly also succeeded in bringing about a union of nitrites and formaldehyde in a test-tube subjected to the light of a quartz-mercury lamp. Here it may be remembered that a discharge of lightning through the air might lead to the fixation of nitrogen, which man now achieves with his powerful electric arcs. Rain might bring the fixed nitrogen to the earth in 
the form of nitrite of ammonia, or something similar. Thus the nitrogenous component is not difficult to account for in natural conditions.

It comes to this, then: that apart from life altogether (except as represented by the ingenious chemist), it is possible to use light-rays so as to produce formaldehyde, sugars, and nitrogenous organic substances. This is a very arresting result! As it is practically certain that formaldehyde is the first product of photosynthesis in the plant, we may venture to say that man has discovered at last how to mimic a green leaf.

It may be pointed out that the light of a mercuryvapor lamp consists of wave-lengths much shorter than those that occur in ordinary sunlight as it reaches the earth to-day. But perhaps the sunlight was not quite the same several hundred millions of years ago. The better answer is that in some more recent experiments Professor Baly has been able to bring about the reactions referred to by using ordinary light in the presence of certain "photo-catalysts" of a complex nature, which probably play a part analogous to that of part of the complex of pigments known as the "chlorophyll" of the green leaf. As it appears to us, Professor Baly's experiments suggest forcibly that the natural synthesis of the raw materials of the living organism is far from being out of the question.

Various objections may be urged against the hypothesis that simple living organisms may have 
arisen spontaneously upon the earth from a natural synthesis of non-living matter.

It may be said that, while there is reason to admire the achievements of the synthetic chemist who builds up carbon compounds with creative prodigality and artificially manufactures such subtle things as indigo, salicylic acid, and adrenalin, yet we do not necessarily get from them much light in regard to the possibilities of natural synthesis. In the first place the chemist uses means-often violent-which are impossible in Nature, and in the second place, what in Nature could correspond to the rational chemist, picking and choosing, ordering and directing? But the edge has been taken off this objection by such researches as Professor Baly's, which show how much might be effected by the action of sunlight on water and carbonic acid, with some complex photocatalyst to help. No one will object to having an occasional thunderstorm thrown in.

Another objection, well deserving consideration, is that our problem is not the origin of living matter or protoplasm, such as we might squeeze out of a sponge or some similar simple animal, but the origin of a living creature, an organism, a viable unity. What can one answer save that the tendency to integration manifested in the synthesis of protoplasm may have continued into the integration which led to the first organisms? These were probably very short-lived, perhaps only creatures of a day, dying in the cold of their first night. But their radical distinction was that they were going concerns, able to 
balance accounts for at least a short time. It is probable that it was during this integration of the first organisms that mind emerged in sparks at least. One may ask whether the difficulty of the problem of the origin of living creatures may not be due in part to the psycho-biological nature of the integration.

A third objection, also serious, is that as a matter of fact we cannot find a trace of synthetic processes going on in the physico-chemical world apart from life. If there was in the dim and distant past a natural synthesis of carbohydrates and even nitrogenous compounds, why has it altogether stopped? To this, what can one answer save that we must not be too sure that the process has stopped, and, secondly, that the original integration may have required a specially happy combination of favorable circumstances? We have given prominence to the most serious objections that we know, but we must confess that the general trend of evidence is strongly in favor of belief in a continuity of process from nebula to earth and from cooling earth to awakening life, always supposing, however, that mind is the warp to matter's or electricity's woof ; for in the beginning was mind, and that same mind is the light of men.

\section{§2. Note on Photosynthesis.}

To appreciate the importance of Professor Baly's work, we must bear in mind that photosynthesis has been and is the most important process in the world. It is the activity by which the green plant utilizes the energy of the sunlight-notably the orange- 
yellow rays-in building up carbon compounds from the carbonic dioxide absorbed from the air and the water absorbed by the roots from the soil. The whole economy of Animate Nature depends on this process, for, in the long run, animals depend on the plant world for their food.

Chlorophyll is a complex of four pigments, and is characteristic of almost all plants except the Fungi. It absorbs light and, in some way not clearly understood, it enables some of this radiant energy (a small fraction of the whole that floods the leaf) to be utilized in reducing carbon dioxide in solution, so that oxygen is liberated and carbon is retained to help in forming organic compounds. The first product is in all probability formaldehyde, but this never accumulates, being changed immediately into higher molecular compounds-namely, sugars and starch. Reactions are set up between the carbohydrate products and the nitrates which are brought to the leaf in the sap-current or transpiration-current, and these result in the higher steps of synthesis which culminate in the production of proteins. These proteins always form an essential part of the living matter in all organisms.

The fundamental importance of this photosynthesis is well summed up in Dr. MacGregor Skene's masterly work on The Biology of Flowering Plants (1924, p. 79). "The organic matter of which the green plant is formed, and from the oxidation of which it derives energy, the organic matter which parasitic plants obtain from green ones, and all the organic 
food of the animal kingdom is synthesized in the first place from carbon dioxide and water through the action of light on chlorophyll. The major part of organic matter available on the land surface is the product of the flowering plants. Ruskin's 'vast family of plants, which, under rain, make the earth green for man, and under sunshine give him bread,' must be extended from the grass to the plant in general, and from man to the animal kingdom. Nor must a secondary effect almost as important be overlookedthe elimination from the atmosphere of the carbon dioxide constantly poured into it, naturally by the respiration of living things, and, one might say artificially, by combustion; and its replacement by oxygen. The warring processes, as is well known, keep the amount of carbon dioxide in the atmosphere roughly constant at about 3 parts in 10,000. It was in searching for the process responsible for keeping the air 'good' that the great chemist, Joseph Priestley, made the first discovery of this activity of the green plant in 1771."

Now it is this fundamental process of photosynthesis that Professor Baly and his collaborateurs have been able to imitate artificially, apart from life altogether. A clear account of their work up to 1922 is given in Dr. E. J. Allen's Presidential Address to the Zoölogy Section of the British Association meeting at Hull, and some of the original papers by Professor Baly and his fellow workers will be found in the Journal of the Chemical Society, Volumes 119, 120, 121, 122. We have lingered over this matter because 
the investigations in question throw light on the great step from the non-living and inorganic to the living and-organic, the methods utilized in the synthesis being not far removed from those that came into operation in Nature when organisms first emerged.

\section{§3. Outlook on Animate Nature.}

As we look around us in the world of living creatures -multitudinous and yet orderly, balanced and yet changeful, plastic and yet insurgent-we cannot but be filled with admiration. As Aristotle said: "In all these physical things there is something wonderful

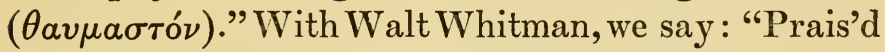
be the fathomless universe, for life and joy, and for objects and knowledge curious."

But through our admiring wonder there rises the irresistible question: How has all this come to be as it is? Whence and how has this system of Animate Nature come into being? The old answer, before science got into its stride, was that living creatures arose after a fashion which cannot be scientifically formulated: "And God said, Let the earth bring forth grass; . . . Let the waters bring forth abundantly the moving creature that hath life." There is a certain nobility in this answer, for it suggests some recognition of the fundamental mysteriousness of Nature and of the splendor of what we see; and it also suggests what to many is an open secret, that if we wish to ascribe the visible universe to a source behind which we cannot think, we must say: "In the beginning was Mind, and that Mind was with God, 
and that Mind was God. The same was in the beginning with God. All things were made by it: and without it was not anything made that was made. In it was Life. ...."

But noble and true as this answer may be, it is a transcendental answer. That all came from and continues to express the Will of God, is part of a philosophical or religious creed; and it does not satisfy the restlessly inquisitive, continually scrutinizing, and probing spirit of man. To be content with the religious answer-always apt to become a soft pillow to the easy-going-is to abandon the scientific problem as insoluble, and there can be no greater impiety than that. It is surrendering our birthright-not for a mess of pottage, it is true, but for peace of mind. Therefore man is true to himself when he presses home the question: How has this marvellous system of Animate Nature come to be as it is? Divine in origin, divine in continuance, divine in its progressivenessthese are religious truths; but in other moods we are bound to ask whence came these birds and beasts, these flowers and trees, and what was the manner of their coming.

It is unnecessary to occupy time in re-telling a story often finely told-and never more effectively than in Yale-but let us briefly illustrate the facts that rewarded the questions which began to be pressed with insistence from the eighteenth century onwards, by men like Buffon, Erasmus Darwin, and Lamarck. 


\section{§4. Evidences of Evolution.}

THE root-idea of organic evolution is that the present is the child of the past and the parent of the future. Our present-day fauna and flora must be regarded as arising by natural processes out of an antecedent fauna and flora, on the whole somewhat simpler and more generalized, and so on backwards through the ages until we lose clue after clue and find ourselves in the thick mist of life's beginnings. Apart from occasional simplifications and relapses and what might be called "eddies," there has been an age-long progression from the simple to the complex, a general advance in differentiation and integration, and a frequent emergence of the distinctively new. It is not merely that one type of crocodile evolved from another, as the rock records show very clearly; there has also been an occasional appearance of great novelties, such as birds are when compared with their dimly descried ancestors among the extinct dinosaurian reptiles. The Proteus leaps as well as creeps!

It is not difficult to verify the law or descriptive formula of gravitation; it is not difficult to give an approximate experimental proof of the laws of the conservation of matter and the conservation of energy; but it is not possible to give this kind of demonstration of the validity of the evolution theory. Yet we do not know of any competent naturalist who has any hesitation in accepting the general doctrine. All naturalists are dissatisfied with their knowledge of the factors that have operated and still operate in 


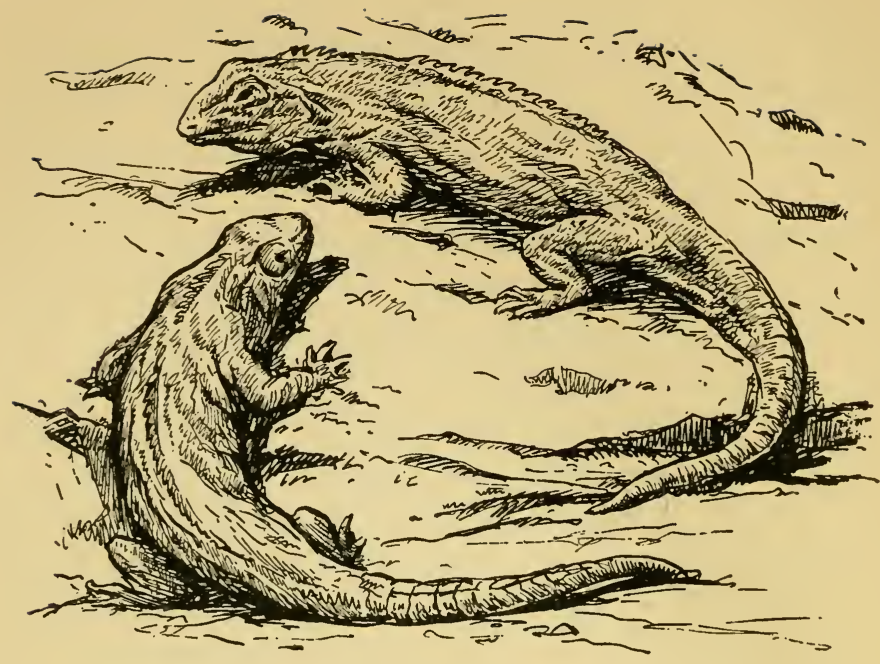

FIGURE NO. 3

\section{THE NEW ZEALAND "LIZARD" \\ [Sphenodon or Hatteria]}

This animal may well be called a "living fossil." It is the sole survivor of an ancient group of reptilesthe Rhynchocephalia, a very generalized group, not very far off the aboriginal stock of reptiles from which all other groups took their origin. The animal is one to two feet in length; it persists in some small islands off the New Zealand coast; it hides in holes during the day and hunts for small animals at night. It is the last of its race. Its pineal body shows distinct evidence of being or having been a median, upward-looking eye. 
bringing about evolutionary change, but no one has any hesitation in regard to the fact. The reason for this-is that the evolution formula-rehich defines a certain mode of becoming-fits all the observed data. It is a key that opens all the locks-only, however, to disclose other locks; namely, the precise course of events involved in an evolutionary change, such as the emergence of birds from extinct reptiles, or of mammals from extinct reptiles. And behind these are other locks; namely, the causal factors that brought about each step.

When one says, "The elephant of to-day acquired its long trunk (the nose and part of the upper lip) as the entailed result of the use that antecedent elephants made of their shorter trunk," one is stating a Lamarckian theory of the factors operative in a particular case. Many zoölogists would refuse to accept this theory, but no one of them has any doubt that the modern elephants evolved from smaller and simpler ancestral Proboscideans of which, happily, much is known. Similarly, when one says that the whiteness of some snow-animals is the result of $\mathrm{Na}$ ture's sifting (the Natural Selection) of the fitter among the many inborn heritable variations-good, bad, and indifferent-that are always cropping up, one is stating the Darwinian view of the factors operative in a particular case. Many zoölogists have their doubts as to the satisfactoriness of this causal theory, but it is intellectually dishonest or intellectually dull-witted to use any such confession of scientific 


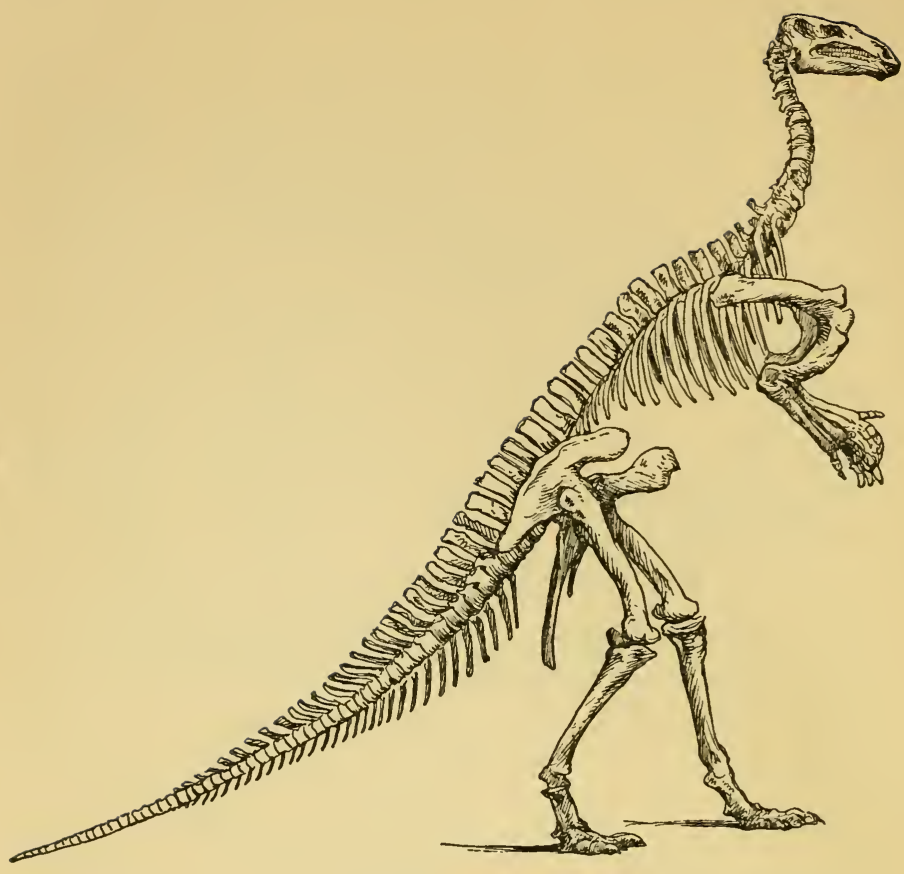

FIGURE NO. 4

SKELETON OF AN EXTINCT REPTILE, IGUANODON BERNISSARTENSIS

(After Marsh)

Iguanodons were Dinosaur Reptiles, of terrestrial and herbivorous habits. Their remains are found in the Wealden (Upper Jurassic), in England, Belgium, and Germany. There are related North American types. The length of the skeleton figured is nearly thirty feet. The Iguanodons were highly evolved reptiles, which have left no direct descendants. 
scepticism as an argument against accepting the general idea of evolution-that the present is the child of the past and the parent of the future.

\section{§5. The Rock Record.}

The fossil-bearing rocks are "the graveyards of the buried past," and they disclose a gradual advancement of life which testifies eloquently to the validity of the evolution idea. It is usual to speak of these illustrative facts as "evidences of evolution," and after the saving clauses of the previous paragraph the useful term may be retained.

The rock record, battered and incomplete as it is, shows clearly that as the earth grew in æons there was a successive emergence of nobler and finer forms of life. There was a time when the only backboned animals were the fishes in the waters under the earth. Ages passed, and Amphibians appeared, with fingers and toes, lungs and a voice, and many other new acquisitions. Then came the Golden Age of Reptiles, confirming the conquest of the dry land which Amphibians had begun. For a long time these Reptiles represented the topmost branches of the genealogical tree, for there was no hint of birds or mammals. Eventually these appeared, and the ascent continued, until at last arose the man.

In early Darwinian days the gradual emergence of more differentiated and more integrated forms of life was recognized as a great fact; and detailed fossil series were discerned of snails and cuttlefishes, of 
horses and elephants. And everyone remembers how Darwin digging fossils on the pampas was impressed by the resemblance between the extinct and extant sloths and ant-eaters. "This wonderful relationship," he wrote, "in the same continent between the dead and the living will, I do not doubt, hereafter throw more light on the appearance of organic beings on our earth, and their disappearance from it, than any other class of facts." This was a prophetic utterance. The palæontologist has not only deciphered a very difficult ancient record, he has thrown the light of the past on the present.

What a thrill there must have been in the world of naturalists when Archæopteryx was discovered in Jurassic strata in Bavaria-an extinct bird linking the creatures of the air back to the reptiles of the earth. For it had teeth in both jaws, a long lizardlike tail, and a half-made wing. It is by no means true that connecting links are always missing.

There is something eloquent too in the persistence of what may be called "living fossils," creatures like the king crab (Limulus), the lungfishes (Dipnoi), and the New Zealand "Lizard" (Sphenodon), sole survivors of ancient races which were once abundantly represented. Of the ancient order of fringedfinned fishes (Crossopterygii) which were abundant in the Old Red Standstone Age, and are included by some in the ancestry of Amphibians, only two remain in modern times-Polypterus and Calamichthys, in African rivers. 


\section{PEDIGREE OF THE ELEPHANT}

It may be more profitable to select a particular pedigree, and that of the elephants is eloquent. Millions of years ago in the Eocene epoch, when the climate was hot-house like and the vegetation luxuriant, there lived in North Africa a primitive hoofed animal called Mœritherium. It was about the size of a small donkey, and it was a pioneer on the elephant line of evolution. It had, like the tapir, a short snout, useful in gripping the herbage. Ages passed, and in the Lower Oligocene there appeared alongside of Mœritherium a larger creature called Palæomastodon, standing from four to six feet high. The snout had lengthened, the nose-opening was farther back, the canine teeth had disappeared, and likewise the front teeth, except two pairs of tusks. Moreover, the big grinding molars showed three transverse ridges. More ages passed, and in the Miocene there appeared the triumphant Tetrabelodon, as large as a mediumsized elephant. The nostrils were still farther back, the upper tusks were stronger, the grinding teeth had more ridges, and there was a more marked development of air-cavities, lightening the heavy skull. The neck was becoming shorter and the snout was turning into a flexible trunk. Ages passed, and in the Pliocene epoch there appeared the elephant proper, in some ways linked back to Tetrabelodon by the Mastodons. The chin-region had shortened, the lower tusks were gone, the back teeth were more complicated, the upper tusks were much stronger, 

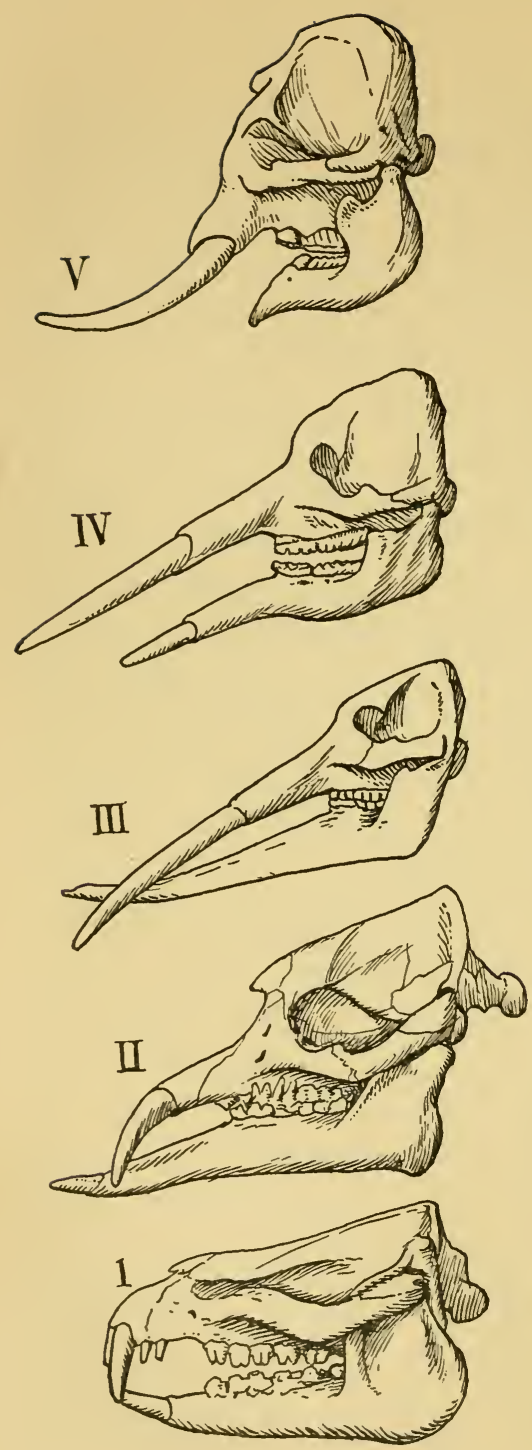

FIGURE NO. 5

INDICATION OF PEDIGREE OF ELEPHANTS, AS SHOWN IN A SERIES OF SKULLS NOT DRAWN TO SCALE

(After Andreros and Lull)

I. Skull of Mœritherium. Upper Eocene. II. Palæomastodon (lengthening chin). Lower Oligocene. III. Tetrabelodon (long chin). Lower Miocene. IV. Tetrabelodon (shortening chin). Upper Miocene. V. Elephas (short chin). Upper Pliocene to Recent. 
and the trunk was much longer. To support the tusks and the great grindstone molars, and to afford insertion-surface for the muscles of the prehensile trunk, able to lift a tree, there was need of an enormous skull, but the tendency to an overincrease of weight was counteracted by the extraordinary development of air-cavities in the bones. This is but the outline of a long story, which has been very carefully worked out. There is a reasonable pedigree of elephants; the fossils cannot be read in any other way. By slow processes of adding on and lopping off, complexifying and simplifying, moulding and modifying, a type like Mœritherium has been transformed into the modern elephant.

\section{§6. Geographical Evidences.}

As we have mentioned, Darwin was greatly impressed by the fact that there were numerous extinct groundsloths (Megatheriums and Glyptodonts in the order Edentata) to be unearthed in South America, and that the same geographical region was one of the modern headquarters of members of the same sloth and ant-eater order. There are other instances of the same correspondence between the extinct and the extant in the same area. It is no coincidence!

Remains of extinct marsupials are found in many parts of the world, such as Europe and America. The order was once widely represented, but the marsupials seem to have gone to the wall before the higher placental mammals, which had better brains. Except the arboreal opossums of North and South America, 


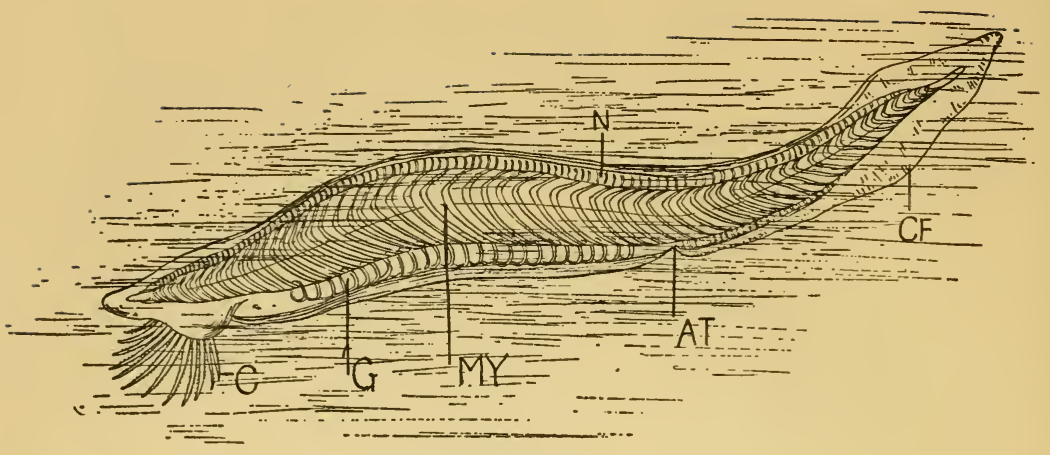

FIGURE NO. 6

\section{AMPHIOXUS OR THE LANCELET}

Near the beginning of the Vertebrate or Chordate series, there is a class (Cephalochorda) of very primitive animals - the lancelets. There are several different kinds, and, like many old-fashioned types, they have a wide geographical distribution. They are found in many seas, spending much of their life buried in the fine sand, the only part protruding being the ciliated cirri (C) around the mouth. The cilia waft in microscopic organisms. At times the lancelets bestir themselves and swim with an undulatory movement in the water, utilizing their 62 or so muscle-segments or myotomes (MY). They have the following Vertebrate characters:- a dorsal nerve cord (spinal cord), a dorsal supporting axis or notochord $(\mathrm{N})$, numerous gillslits, a segmented body (MY), numerous kidney-tubes or nephridia. But they are in many respects primitive, e.g., in having no skull, no jaws, no limbs, no brain, no heart. There are 26 pairs of reproductive organs or gonads $(\mathrm{G})$. AT is the breathing aperture or atriopore; $\mathrm{CF}$, the caudal fin. 
and the shy selvas (Cœnolestes) of South America, the marsupials are now confined to Australasia. It is a reasonable hypothesis that they had established themselves in part of Australia while that region was connected with the continent of Asia by a great landbridge across the Java Sea, and that insulation occurred before any of the placental mammals appeared on the scene. Thus, through no virtue of their own, but by a geological subsidence, many of the marsupials were isolated in Australia, and thus saved from a competition for which they were not equal. They have evolved in Australia in many different directions. Geography and evolutionism join hands.

As everyone knows, there are two kinds of islands in the sea. First, there are oceanic islands, which are usually of volcanic origin. They have a peculiar fauna and flora which can be accounted for, as Alfred Russel Wallace showed, by fortuitous contributions borne by water-currents, wind, and birds. Thus there are no amphibians on oceanic islands, for it is very unusual for an amphibian to be able to endure any trace of salt. Secondly, there are continental islands, which are isolated pieces of an adjacent continent, and they always have a fauna and flora with a predominant resemblance to those of the mainland. The faunistic and floristic differences between oceanic and continental islands are readily intelligible to the evolutionist.

Another interesting fact in regard to geographical distribution is the widespread representation of some of the primitive types. The lung-breathing fishes or 
Dipnoi are very archaic, and all are extinct save three; it is striking to find that one of these (Ceratodus) occurs in Queensland, another (Lepidosiren) in the Amazons, and a third (Protopterus) in certain African rivers. Similarly the primitive pioneer Vertebrates known as lancelets (Amphioxus) have a wide distribution near the coasts of warm and temperate seas. The ancient king crab (Limulus) lives in shallow water off sandy shores from Maine to Florida; it occurs in the West Indies, and also off the Molucca Islands in the Far East. We shall refer later to the wide distribution of the old-fashioned or primitive types known as Onychophora and Enteropneusta.

\section{THE GALAPAGOS ISLANDS}

Instead of making more general statements let us take a particular case that is very instructive in more ways than one-the case of the Galápagos Islands, studied by Darwin on his Beagle voyage, and recently by Mr. William Beebe, traveller-naturalist to the New York Zoölogical Society.

Long before the beginning of the age of man, a great peninsula stretched from Central America southwards into the Pacific. It was an Ultima Thule except that it lay in the wrong direction, not northwards but verging on the equator. It was a land of volcanoes and far from hospitable. Ages passed, and the great land-bridge was broken; the peninsula became an island, five hundred miles or so west of Ecuador. The subsidence continued and the island became an archipelago, with the tops of the cold 
volcanoes rising out of the sea. Thus arose a group of about sixty islands and islets, discovered by Europeans in 1535 and called "The Enchanted." Exactly three hundred years later they were visited by Charles Darwin, who was then twenty-six years of age, in the course of his Beagle voyage, one of the great "Columbus voyages," for it disclosed a new world. The islands were by that time called Galápagos, which means tortoises. Even the discoverer-the Bishop of Panama-had called attention to the giant tortoises, big enough to carry a man; but what impressed Darwin more than the size was the fact that each island seemed to have its own kind, so that he felt himself "brought near to the very act of creation." Ten different kinds of tortoise on ten adjacent islands, and five kinds in different corners of the largest island, which is called Albemarle-what could it mean but that isolated groups of an original stock had varied in slightly different directions on the various islands, and that isolation had prevented any pooling of the new departures? It should be noticed that these tortoises (Testudo) are thoroughly terrestrial, and cannot swim from island to island. They are the descendants of an original stock which was geologically marooned, so to speak, in Galápagos land, and then isolated in small groups. They form an object-lesson in the potency of isolation as a factor in evolution, and it is deplorable that this object-lesson has been already in great part spoiled by the ruthless and impious extermination of the tortoises on some of the islands. 
Another striking inhabitant of the Galápagos Island is the unique Sea-Lizard (Amblyrhynchus), of which Darwin gave a good account, which must, however, be supplemented by the pictures in Mr. William Beebe's Galápagos: World's End, a stately volume forming a sumptuous appendix to Darwin's few pages. What are the remarkable features? The animal is large for a lizard, up to four feet in length. It is laterally compressed in its hind parts, especially in the tail, and this is plainly an adaptation to swimming, which is altogether of the undulatory type. The giants are gregarious on land, but individualist in the water. They graze on the short, succulent seaweeds more or less exposed at low tide, and if they are covered by a wave they hold on tightly with their twenty claws. Mr. Beebe did not see any spontaneous diving, though the sea-lizards are usually credited with this power. There seems, indeed, to be little reason why they should dive, for the food is abundant on the shallow-water rocks. Captain Colnett's statement, quoted by Darwin, that "they go to sea in herds a-fishing," is not very happy.

During the night the sea-lizards lie in burrows or in deep lava crevices; during their leisure time by day they bask in the sun; when the tide is suitable they graze among the seaweed, showing a marked preference for quiet places. Darwin was much interested in the fact that he could not induce the Amblyrhynchus to enter the water. He could throw one in by force, but it immediately clambered out; and when he chivied one on to an overhanging point of rock it 
would rather be lifted by its tail than jump into the sea. Darwin wrote: "Perhaps this singular piece of apparent stupidity may be accounted for by the circumstance that this reptile has no enemy whatever on shore, whereas at sea it must often fall a prey to the numerous sharks. Hence, probably, urged by a fixed and hereditary instinct that the shore is its place of safety, whatever the emergency may be, it there takes refuge." Mr. Beebe does not deny that sharks occasionally come close to the shore, or that they now and again take toll of swimming lizards, but he seems inclined to lay more stress on the fact that the sealizards cannot stand rough water. They would be smashed by big breakers, and though they may be seen feeding in the surf they prefer the quiet waters of the coves.

The Galápagos Islands are not overrun with visitors, and the sea-lizards are not in the least afraid of man. They allow themselves to be stroked, to be caught in a noose and swung in the air, and to be lifted by the tail, which never breaks off. They do not try to bite man, and if they scratch, it is by mistake. They follow the visitor with interested eyes. Their reactions are few; they clutch the rough volcanic rocks with their talon-like claws; they inflate their body when excited, and send out from their nostrils a double jet of watery breath. When two adult males meet on the road they raise themselves high on their front legs and nod vigorously two or three times; they sniff and pass on. In the same dignified way the male approaches his desired mate. The eggs, about 
three inches long, are buried in the sand near the beach. The youngsters have been seen playing together like puppies. Sea-lizards seem to be very selfcontained animals, without much in the way of inter-relations, but Mr. Beebe saw one creeping over a sea-lion as indifferently as over a rock, and he saw another allow a big red crab to come crawling over his scale-covered body and pick off three ticks. The dull black and gray coloring makes them very inconspicuous in spite of their large size, and the camouflaging is perfected by the rough clinker-like scales on the head and the long row of tooth-like scales which extend along the middle dorsal line of body and tail. But we have no right to use the word "camouflaging" in regard to an animal that has no enemies save man. All that we can say is that the sea-lizards are as congruent with the lava as with the seaweedcovered rocks.

One of the characteristics of living creatures is their ability to make the most of niches of opportunity. In these sea-lizards this is well illustrated. They are large Iguanids of a thoroughly terrestrial stock; they have a near relative (Conolophus), also of large size, and also confined to the Galápagos Islands. But while Conolophus has remained on dry land and has learned to feed on cactuses and the like, Amblyrhynchus has found its chance of survival among the seaweeds of the shore. The two kinds are near relatives, as we have said; they are probably scions of a common stock, geologically marooned long ago on the Galápagos land. But one has become par- 
ticularly adapted to life in a very unpromising inland environment, while the other has, so to speak, gone to sea. Thus have animals blazed the trails which man has followed. Another point of evolutionary interest is that, while there are many different species of giant tortoise on the different Galápagos Islands, illustrating the influence of isolation in evolution, there is only one kind of sea-lizard, for it differs from the tortoises in being able to swim from island to island, and is thus untethered in its inter-crossing. Who can wonder that Darwin was prompted to evolutionist thinking by his visit to the "Enchanted Islands," as they used to be called?

\section{\$7. Anatomical Arguments.}

THE anatomist has also made his contributions to the "evidences," showing how the same fundamental material-say, that used in the making of fore-limbs - is moulded and shaped into diverse forms. As Darwin said: "How inexplicable is the similar pattern of the hand of a man, the foot of a dog, the wing of a bat, the flipper of a seal, on the doctrine of independent acts of creation! How simply explained on the principle of the natural selection of successive slight variations in the diverging descendants from a single progenitor!"

Structures that resemble one another in fundamental structure and in the way in which they develop are said to be homologous, and the tracing out of homologies speaks of evolution at every turn. A bird's wing is at first sight conspicuously different from the 
fore-limb of a lizard, and yet we find that the bones, muscles, nerves, and blood-vessels are fundamentally the same. Similar material is, as it were, built into different styles in different types. Experts on musculature tell us that in fishes, where the fore-limbs are usually balancing fins, there are the fundamental blocks of muscle that are found specialized in connection with the fore-limbs of reptiles and higher Vertebrates. The bird has a quite unique ankle-joint, for after embryonic development the two rows of ankle-bones (tarsal elements) are quite unrecognizable. It is as different as possible from the ankle-joint of, let us say, a crocodile, where there are as usual two rows of ankle-bones. But when we work into the development of the bird's ankle we find that it began like a reptile's, and that it remains in spite of appearances curiously like a reptile's, for it is an inter-tarsal ankle-joint. The plane of movement is between the proximal and the distal row of ankle-bones, though no separate bones are left. This may seem a pedantically trivial matter, but it is a straw which shows very clearly how the evolutionary wind has blown. The mammal's ankle-joint has diverged on a line of its own; it is cruro-tarsal, not inter-tarsal.

The anatomist also discloses one of Nature's ways, so to speak, of making apparently novel things out of what is very old. The beautiful three-linked chain of little bones or ossicles by which the vibrations of the drum are conveyed to the inner ear-why, it was once part of the commonplace framework of the jaws. The elephant's trunk is a long nose and a pulled-out por- 
tion of the upper lip; the serpent's fang is a channelled tooth, and its poison-gland is usually a specialization of one of the salivary glands. At the hind end of a spider's body there is a cluster (usually three pairs) of spinnerets. Each is somewhat like the rose of a watering can and bears numerous minute apertures (spinning spools) through which there issues a multiple jet of liquid silk, hardening instantaneously into a thread. A study of the development of these spinnerets shows that they are transformed abdominal limbs. This is Nature's way; the old becomes the new. The sting of a worker-bee is a transformed ovipositor or egg-laying organ and therefore absent from the drones or males. The milkglands of mammals, great novelties in their daywhat are they but transformations of the commonplace glands of the skin?

The anatomist also points to the dwindling vestigial organs which are to be seen in many an animal's body, like unsounded letters in words, like functionless buttons on our clothes-relics that reveal the past. No teeth cut the gum in the whalebone whales, and yet there are two sets of teeth. Whales have no visible hind-legs, yet many show useless vestiges, buried deep below the surface, with bones, cartilages, and even unmoving muscles. In the inner upper corner of man's eye there is a vestige of the third eyelid, which is large in many mammals and useful for cleaning the front of the eye. It is absent in whales and their relatives, where the window of the eye is continually washed with water; it is vestigial in 


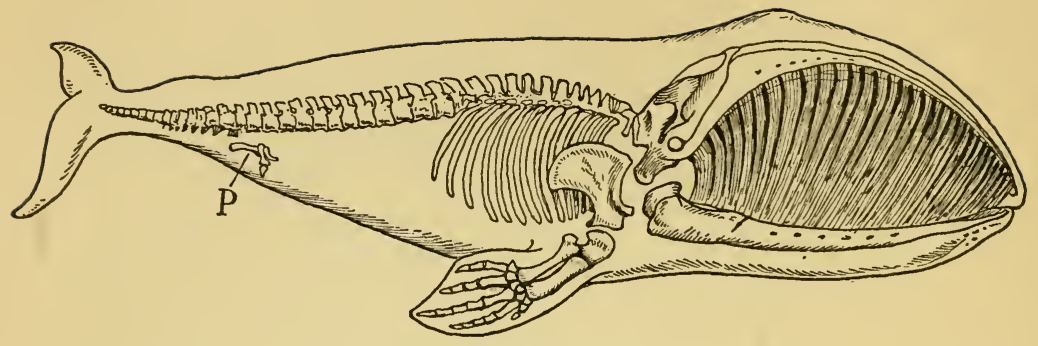

FIGURE NO. 7

\section{SKELETON OF RIGHT WHALE}

\section{[Balana mysticetus]}

This whalebone whale is about 60 feet long. At $P$ are shown the vestiges of the hip-girdle and hind-limb, buried deep within the flesh, and useless. The fore-limb is turned into a balancing flipper, yet the ordinary bones are all represented. The flukes of the tail and their muscles form the propelling organ. From the palate there hang down the dark plates of whalebone. 
monkeys and man, where its place is taken by the upper eyelid, which is much more mobile than in ordinary mammals. Behind the eye of the skate there is a large hole, opening into the back of the mouth. It is called the spiracle and is the first of the gill-clefts. It serves for the entrance of the water which washes the gills and passes out by the five pairs of ordinary gill-clefts on the ventral surface. The spiracle is therefore of much use; but when we look into it we see a little comb-like structure which is plainly a vestigial gill. The minute teeth of the comb correspond to the filaments of a gill, but they are too small to be of any use in respiration. The comb is clearly a vestigial gill. It may be noted that the spiracle of the skate and other Gristly Fishes or Selachians becomes the Eustachian tube in Amphibians, Reptiles, Birds, and Mammals-a tube running from the outer earpassage past the inner ear to the back of the mouth. This is a good example of change of function in the course of evolution.

Another point of interest is that many Gristly Fishes have below the vestigial gill a patch of peculiar cavernous tissue, which is said to be of importance in the destruction of worn-out blood-corpuscles and in the making of new ones to take their place. We see, then, that the spiracle itself is not vestigial: it is a cleft for the entrance of water; and the tissue below the comb is not vestigial: it has hæmolytic and hæmopoietic functions; what is vestigial is the dwindling comb. True vestigial structures are minute traces of what they once were and have dwindled out of use. 
They must be distinguished from structures which have dwindled, yet have been transformed into something else that is useful. As we have mentioned, the sting of a worker-bee or wasp is a small version of an ovipositor, but it cannot be called vestigial, since it forms a very effective weapon. The few hairs sometimes seen on a whale's upper lip are in a sense "relics" of the hairy covering which the ancestors of whales probably possessed, but individually they are anything but vestigial. They are very richly innervated and are doubtless important as tactile structures, like the vibrissæ on the cat's face.

At many levels in the Animal Kingdom there are living annectent types or connecting links which bind one group to another. This may be illustrated by the Mudfishes or Dipnoi, which are intermediate between Amphibians and ordinary fishes. Many new acquisitions were made when Amphibians emerged from a piscine ancestry, perhaps from a stock related to the fringed-finned fishes (Crossopterygii), and some of these acquisitions are partly anticipated by the Mudfishes. Thus the ordinary swim-bladder of fishes has become a genuine lung in the Mudfishes, which thus point onwards to the lunged Amphibians. An ordinary fish has unicellular skin glands; frogs and other Amphibians have multicellular skin glands; but these are also found in the Mudfishes. The heart of a fish is two-chambered, with a receiving chamber or auricle and a driving chamber or ventricle; the heart of an Amphibian is three-chambered, with two auricles and a ventricle; the heart of a Mudfish is in- 
cipiently three-chambered, but the partition dividing the auricle is not complete. In an ordinary fish the heart contains only impure blood; in the Mudfish some pure blood is brought to the heart, as well as impure blood; so is it also in Amphibians, though the heart of the larva-e.g., the tadpole of a frog-is for a while two-chambered just like that of an ordinary fish. These instances might be multiplied, but they may serve to show how the Dipnoi or DoubleBreathers (with lungs as well as gills) are intermediate between ordinary fishes and the Amphibians. They are annectent types. One must not jump to the conclusion that the Dipnoi of to-day or of any day are necessarily ancestral to the modern Amphibians, but it is certain that they represent a grade of organization through which the ancestors of modern Amphibians must have passed.

Of great evolutionary interest are the "synthetic types," as they have been called, which combine in their organization some of the characteristics of two quite different groups of animals. One of the best illustrations is Peripatus, an archaic animal somewhat like a permanent caterpillar, distantly related to insects and distantly related to worms. Along with some other genera it is included in the class Onychophora (claw-bearers) or Prototracheata. They are old-established animals, survivors of an ancient fauna, and an index to their antiquity may be found in their extraordinarily wide geographical distribution. They have had time to establish themselves in many different parts of the world, such as Tropical 


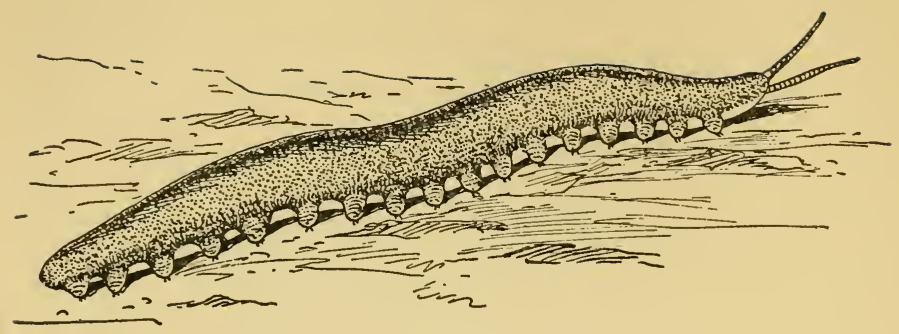

FIGURE NO. 8

\section{PERIPATUS: AN ARCHAIC TYPE}

The species of Peripatus and allied genera form a class (Onychophora) of somewhat caterpillar-like animals, linking segmented worms or Annelids to the insect alliance. They are annectent or synthetic types. Thus Peripatus has air-tubes or tracheæ and likewise kidney-tubes or nephridia. No other type has both tracheæ and nephridia. In several other characters the Onychophora are insect-like; in an equal number of characters they are worm-like. They may not be in the direct lineage between Annelids and Tracheate Arthropods, but the point is that they are connecting links. They are shy, nocturnal creatures, frequenting damp places under leaves and among rotting wood. They . feed on insects which they catch by squirting out jets of slime. They are viviparous. 
America, Chili, Tropical Africa, South Africa, Tibet, Indo-Malay, Australasia, and New Britain. They are cryptozoic defenceless animals, shy and nocturnal, hiding in damp places under leaves and among rotting wood. They feed on small insects, which they catch by the ejection of slime from little papilla-like appendages in the mouth. They are viviparous, and the newly born young one is already a miniature of the parent. There is a long ante-natal period, somewhat over a year in the case of Peripatus capensis from South Africa. This helps to reduce the chances of death.

But we are taking Peripatus and its allies to illustrate what is meant by a "synthetic type." Peripatus is like a ringed worm or Annelid in having numerous regularly arranged kidney-tubes or nephridia, which never occur in insect-like types. It has air-tubes or tracheæ, like simple forms of those by which Centipedes and Insects breathe, but there is never anything of this sort in worms. It has a body-wall musculature like that of worms, stump-like legs, and simple eyes; on the other hand, in having two pairs of appendages in the service of the mouth, in its heart and circulation, in its salivary glands, and in its feelers, it resembles an insect. The point is that Peripatus and its relatives have many Annelid characteristics and many Insect characteristics, and while they are not to be regarded as the actual connecting links between segmented worms and air-breathing jointedfooted animals, there can be little doubt that the ancestors of insects passed through a grade of or- 


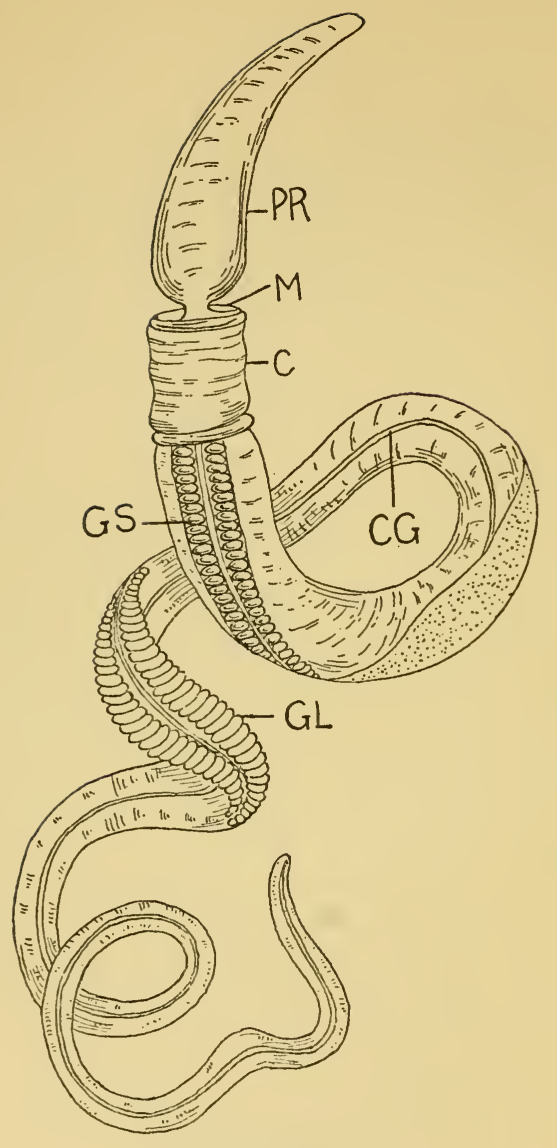

FIGURE NO. 9 


\section{BALANOGLOSSUS, A CONNECTING LINK}

\section{(After Spengel)}

Widely distributed in the sand of many seas are the Enteropneusts (i.e., gut-breakers), which help to link backboneless (Invertebrate) and backboned (Vertebrate) animals. Are they Vertebrate-like worms or worm-like Vertebrates? They are connecting links, though it does not follow that they are directly ancestral to the Vertebrates we know. The proboscis $(P R)$ is used for burrowing in the fine sand; $M$ shows the position of the mouth; $\mathrm{C}$ is the region called the collar; GS are numerous gill-slits opening from the food-canal to the exterior, a Vertebrate feature never seen in Invertebrates; CG, a slight ciliated groove along the dorsal middle line; GL, glandular sacculations on the food-canal, shining through the skin. The animal figured is about six inches long. In several ways there are distinct hints of Vertebrate affinities. 
ganization not far removed from that represented by Peripatus.

Then the anatomical classifier comes with his species and shows us that while each is a distinct entity, itself and no other, they can often be arranged in series, and linked together by divergent variants. Sometimes he can make a plausible genealogical tree, and though his critic promptly proceeds to cut it down, this will not continue indefinitely. The possibility of making a "natural" classification spells evolution.

\section{§8. Embryological Evidence.}

The embryologist joins in and shows how the individual development reads like a condensed recapitulation of presumed racial evolution, how the past lives on in the present, how circuitousness in the individual becoming may receive historical interpretation-how, in short, in a general way, the individual animal climbs up its own genealogical tree.

For some days the embryonic development of a bird is so like that of a reptile that one may think of the two as proceeding along the same (Sauropsidan) highway together, until they come to the parting of the ways, when the reptile goes to the right and the bird to the left (see the Genealogical Tree). It is very striking to take three or four very young embryos of mammals that are not nearly related to one another, simply to see how close the resemblance is in the early stages. But microscopic examination of sections of these embryos shows that there is con- 
siderable specificity even in the early days of development, and this soon becomes more and more accentuated.

The embryo of a reptile, bird, or mammal always shows a number of gill-clefts on the side of the neck, minute openings from the pharynx to the exterior. They are gill-clefts or visceral clefts. The first seems to become the Eustachian tube, from the outer earpassage to the back of the mouth, and the thymus gland is developmentally connected with another; but the rest of them are useless and soon pass away. Occasionally in adult life there may be just a trace left, but that is an abnormality. Now, there can be no doubt that these gill-clefts are echoes of the past. They are recapitulations of the gill-clefts which are used in the respiration of tadpoles, of fishes, of lampreys, and of still more primitive Vertebrates like lancelets. The evolutionist account of the useless gill-clefts of the higher Vertebrates is the only one that makes sense. They are relics of ancestry, and it is very striking to learn from Dr. Boyden (1918) that in the embryos of the chick and of some reptiles there are not only gill-clefts but dwindling and transient traces of gills.

In a primitive backboned animal like the lancelet, or even in the much more advanced lamprey, the dorsal supporting axis of the body is called the notochord. It is a skeletal rod folded off from the median dorsal line of the embryonic gut; it therefore belongs to the inner germ-layer or endoderm. In fishes it often persists to a large extent, but it is being more or less 


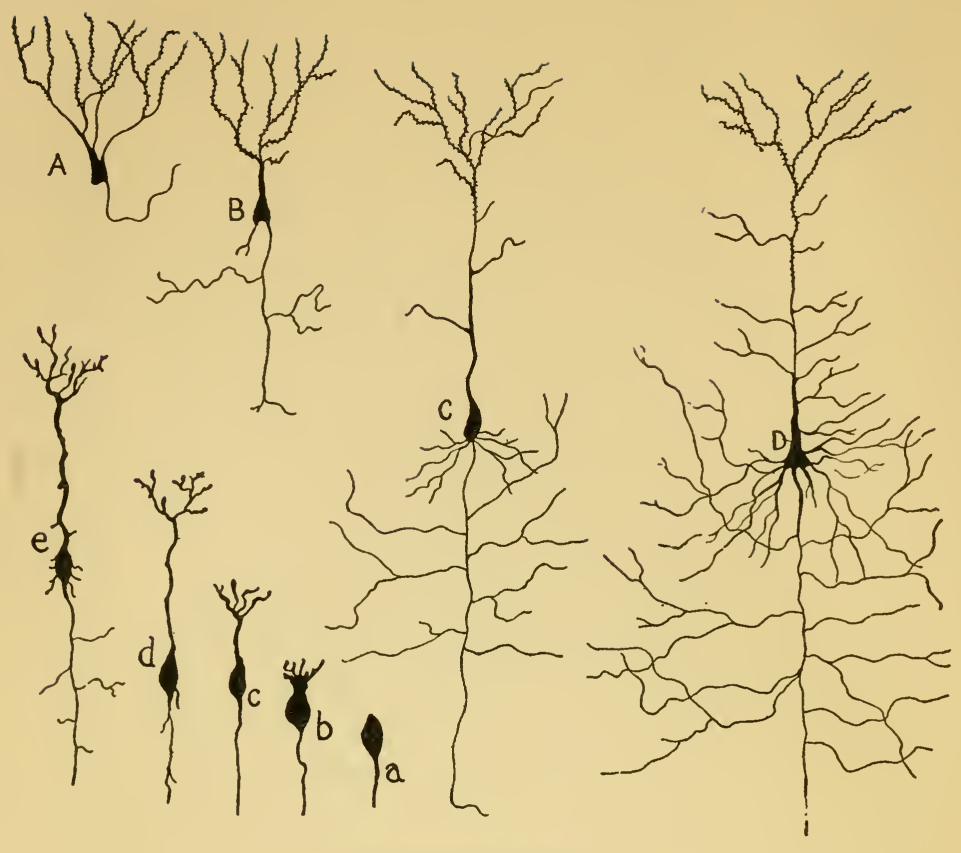

FIGURE NO. 10

EVOLUTION AND DEVELOPMENT OF NERVE-CELLS

(After Ramon y Cajal)

A-D, nerve-cells or neurons from four Vertebrate animals :-A, a fish, B, a reptile, C, a bird, D, a mammal. The evolution is marked by increased complexity in the branching of the nerve-fibres. But the figures a-e show five stages in the individual development of the neurons of a bird. The individual development recapitulates the racial evolution. 
replaced by its substitute, the backbone. This develops from the mesodermic sheath of the notochord, and may perhaps utilize the notochord as a sort of scaffolding during the time of formation. Among the different types of fishes we can find every stage in the replacement of the endodermic notochord by the mesodermic backbone; but in Amphibians, Reptiles, Birds, and Mammals the notochord is an embryonic structure with only vestiges left after development has been completed. The remarkable fact is that on to man himself the notochord continues to appear in development, though it never comes to anything above the level of fishes. It is a veritable antique; it has its short day and passes. But it is never absent, and this would be unmeaning if we had not the evolutionist interpretation.

In the individual's building up of important structures such as the brain, the skull, the heart, the kidneys, the foundations are laid on old-fashioned lines, often not directly suggestive of what is to follow. The individual development recapitulates in modified form the racial evolution. There is always specificity; each embryo is itself and no other; yet the old paths are to some extent re-trod, even if it means circuitousness. Often, however, the progress of a hundred thousand years is condensed into one day.

The bony flat-fishes, such as plaice, flounder, sole, and turbot, are very peculiar in many ways. They rest and swim on one side, on the floor of the sea. Plaice, soles, lemon soles, dabs, flounders, witches, 


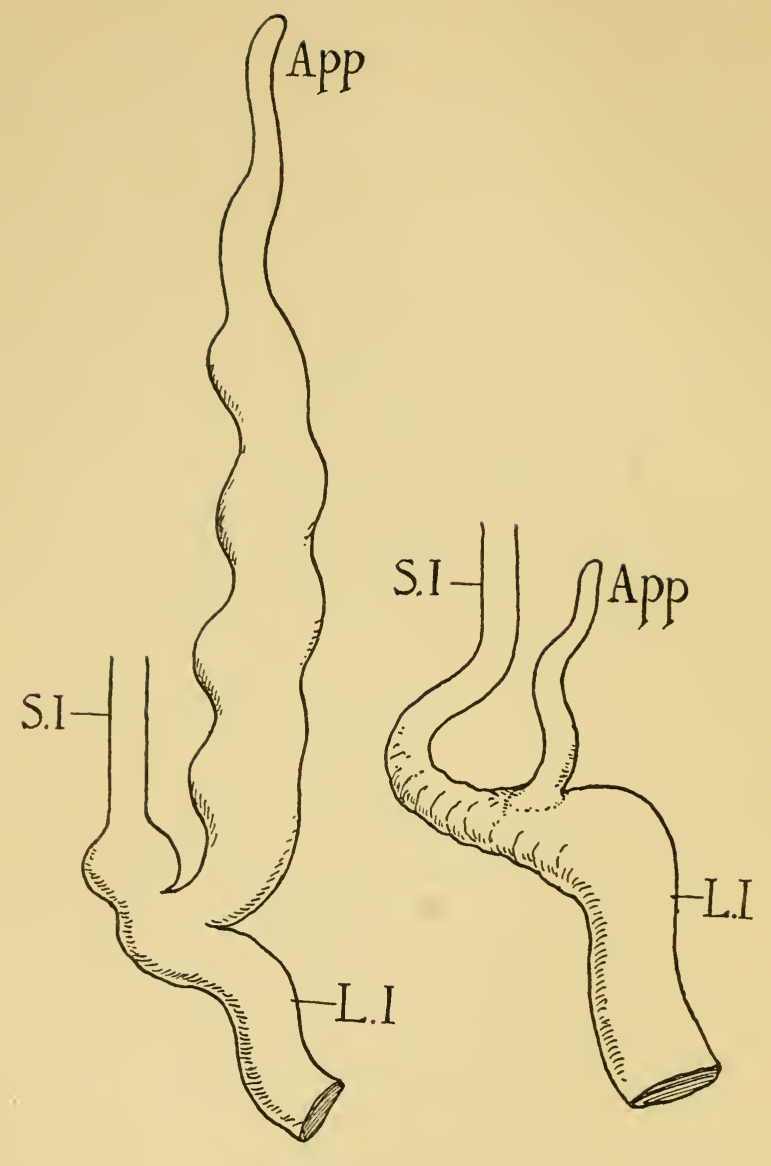

FIGURE NO. 11 


\section{APPENDIX VERMIFORMIS IN RABBIT AND IN MAN}

The diagram to the left shows part of the intestine of the rabbit. S. I indicates the small intestine coming from the stomach. Its lower end is expanded into a roundish sac, the sacculus rotundus. Here is given off the large blind gut or cæcum, a cul-de-sac, which ends in the finger-shaped vermiform appendix (App.). The cæcum is full of partly digested food which is thus delayed on its downward passage, before passing into the large intestine (L. I).

The diagram to the right, not drawn to scale, shows similar parts in man:-S. I the lower end of the small intestine; L. I the beginning of the large intestine; App. the vermiform appendix, reduced to a vestige. The part corresponding to the large blind gut of the rabbit and of many other mammals is unrepresented save by the vestigial appendix, which is the seat of inflammation in appendicitis. 
halibuts, and the long rough dab swim on their left side; turbot, brill, and megrims on their right side. The down-turned side is always the heavier. Its surface is silvery white, and that implies that there is no pigment, the whiteness being due to crystalline spangles of a waste product called guanin. On the floor of an aquarium in which young flounders were developing, Mr. J. T. Cunningham placed a mirror throwing the light upwards, and the result was that eleven out of thirteen of the metamorphosing flounders developed pigment on the down-turned, as well as on the up-turned, side. Another peculiarity of the flat-fishes is that both eyes are on the up-turned side - an obvious advantage since an eye on the downturned side would be not only useless but a source of danger, as it would be very liable to be scratched. The eye on the down-turned side travels round or in part through the margin of the head. In these and in other ways the bony flat-fishes are very peculiar; but there is no alternative to the view that they originated from an ordinary symmetrical stock. This is practically proved by the life-history, for the newly hatched forms are quite symmetrical and swim near the surface in the ordinary position of other fishes. As they go on developing a marked lopsidedness sets in; they seem to lose their poise; they begin to sink towards the floor of the sea. We cannot make sense of the story except on the evolutionist interpretation that the young flat-fishes are recapitulating the history of their race. 
§9. The Living Past.

The drowsy dog turns round and round, making itself comfortable in the imaginary herbage of the hearth-rug. What its wild ancestors - whether they were wolves or jackals-did ten thousand years ago, or more, it is doing to-night. The past is living still. And the horse that shies at a sudden movement in the hedgerow sees the snake that bit its ancestor's heel! Cows transported from very conventional conditions in Scotland to the wilder environment of a ranch in California have been known to hide their calves in a thicket while they grazed in the open-a sudden return to a habit older than domestication. In many different ways the past lives on in the present. Let us take an instance where this idea illumines a life-history.

Everyone knows that the Common Eel has a very remarkable history. Its life begins far out in the Atlantic, where the knife-blade-like transparent larvæ swim and drift in the open waters. The American species goes westwards, the European eastwards, for their birthplaces overlap, perhaps recalling a time when the continents were nearer one another than now. When the European forms are in their third year they are approaching the coasts and they change into cylindrical elvers, the length of our first finger and the thickness of a stout knitting needle. They ascend the rivers in the well-known "eel-fare"; they reach the slow-flowing stretches and the ponds. In the course of from four to seven years they have 


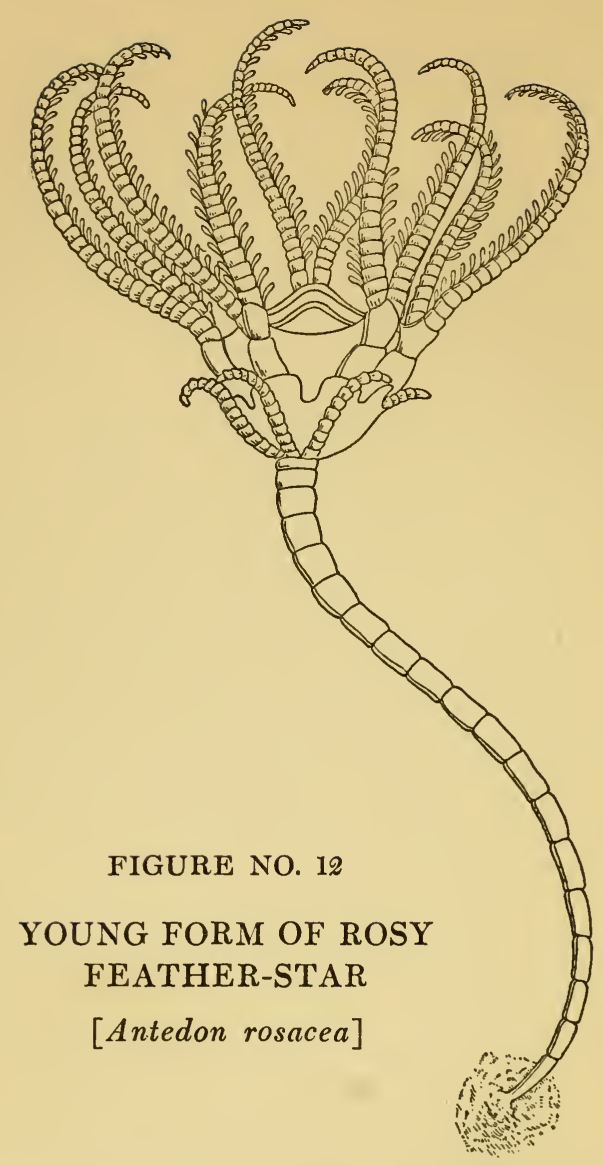

Most of the adult feather-stars or sea-lilies (Crinoids) were fixed forms, with the cup and the arms borne on a stalk. The same is true of some of the present-day forms. The common Antedon, however, moves about freely, and can swim by bending its pinnate arms. It is interesting to find that after its free-swimming larval stage is over, the developing Antedon passes through a sedentary phase, here represented. The individual recapitulates racial history. On attaining a certain size the Antedon, still very small, drops off the top of the stalk. 
grown into large eels which begin to become lusty. A restlessness seizes them; they descend the river, sometimes after squirming through a meadow to find it; they reach the sea and swim out to a great distance and a considerable depth in the Atlantic. There they spawn and die; for the adults never return to fresh water, and they never spawn except in the sea.

This is but a glimpse of a long story, but it may serve as a picturesque illustration of the outlook of the new biology. We might refer, for instance, to the interesting "tropism" of the elvers as they push their way up the river, often against considerable obstacles, adjusting their body automatically so that the pressure of the current on the two sides is always the same. But for our present purpose it is more useful to refer to the restlessness of the full-grown eels which sets them a-roving. It has been pointed out that when the reproductive organs of the fish become ripe, they exert an influence on the everyday routine of chemical processes that go on in the laboratory of the eel's body. There are perhaps internal secretions to which we shall afterwards refer; in any case the composition of the blood changes; the proportion of carbonic acid increases, and this, acting on the nervous system, provokes restlessness. From the vague words we are forced to use it is plain that the study of the internal economy of the adolescent eel has only begun; but the general idea has come to stay, that periodic changes, such as the ripening of the gonads in the body, have by-effects which lead the creature to give new answers-back to external 
influences-e.g., the oxygenation, temperature, and currents of the water-which, again, are subject to periodic changes. Thus external changes punctuate internal changes, while the latter on their part may be prompting the creature as a whole to make some change in its environment.

Two extremes have to be avoided. On the one hand, the eel is not moved by any intelligent awareness that it must get to the sea if it is to spawn, or by any memory-images of its birthplace. On the other hand, the creature seems to be more than a collocation of little chemical laboratories which set one another going automatically and work out an effective total reaction. The animal cannot work without means, and we cannot know too much about the little chemical laboratories with their oxidations and reductions, hydrations and dehydrations, solutions and fermentations; but we must not overlook the central fact of their harmonious correlation. There are chemical tactics, but there is psychical strategy. There is some sort of registration in the nervous system which counts for something in the urge, probably giving a point of endeavor to the search after conditions of greater satisfaction. Such at least is our view, that while the study of the chemistry of the body is indispensable, it is not possible to give an adequate account of the eel's wanderings, or of any similar phenomena, without recognizing the animal as a historical being which enregisters past experience in a living way within itself. 


\section{§10. Experimental Evidence.}

THE story of domestication and cultivation is a long record of experiments in evolution. There are over two hundred well-marked breeds of domestic pigeon, but all have been derived under man's care from the blue rock-dove, Columba livia. Similarly there is very strong evidence that the multitudinous breeds of poultry (see Figure 13) are descended from the jungle fowl, Gallus bankiva, still found wild in some parts of India and Malay. The origins of most of our cultivated plants are unknown, but the evidence is strong for tracing most of the wheats to the wild wheat still growing on Mount Hermon, and for tracing the cauliflower, broccoli, Brussels sprouts, curly greens, and the like to the Wild Cabbage that grows by the shore. And everyone knows how the aristocrats of the orchard owe their origin to the plebeian crabapple of the wayside. Darwin's question was, If Man has been able to fix and accentuate this and that variety in a comparatively short time, what may not Nature have accomplished in a very long time?

There is suggestiveness also in what Man has been able to do within recent years by using the Mendelian clue in his practical transformism. He has been able, so to speak, to pick out desirable characters from one breed of animals or race of plants, and assemble them again in another which has some good points of its own. Very interesting also are those few cases, such as Professor Tower's experiments with potato-beetles, where man has been able to provoke heritable changes by some deeply saturating environmental change. In 


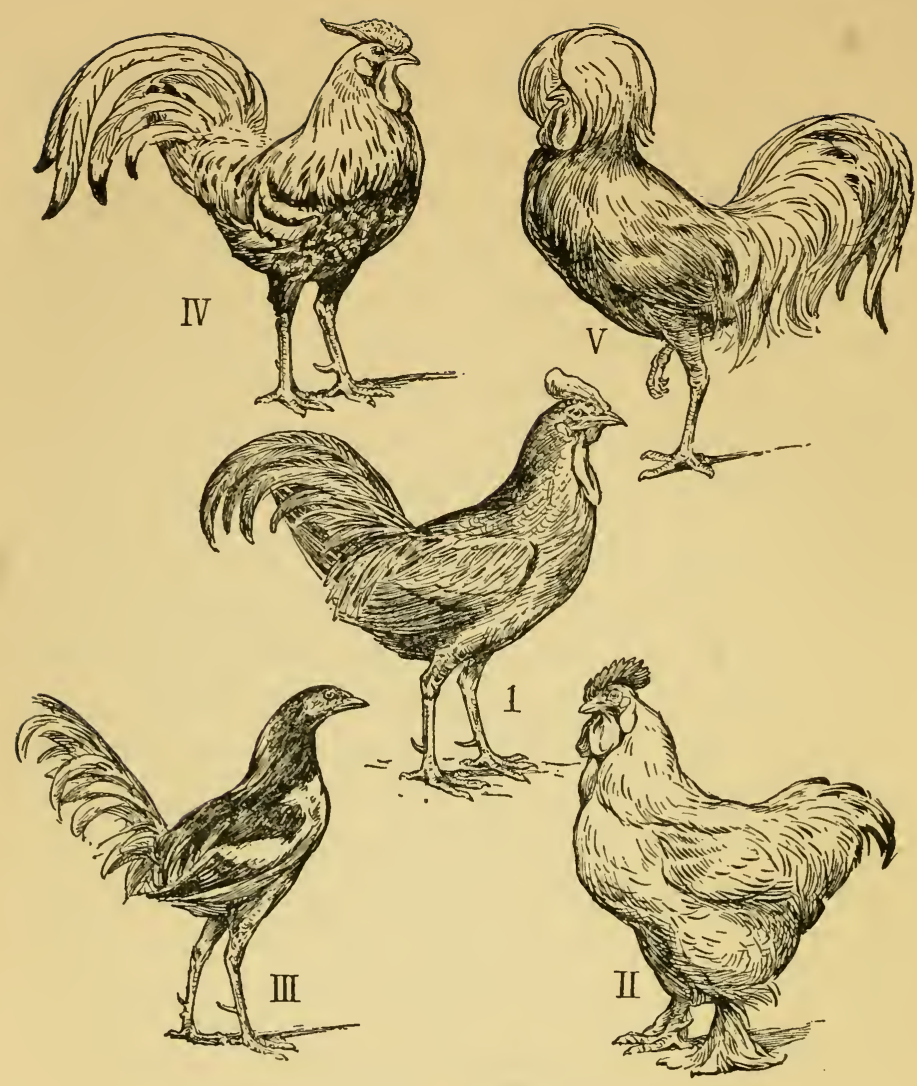

FIGURE NO. 13

\section{EVOLUTION AMONG POULTRY}

The figures II-V show four of the races of poultry which have been evolved under domestication, the progenitor of all being the wild Jungle Fowl (I), Gallus bankiva of India. Variations or mutations arise; man keeps them apart, pairing them with others like themselves; divergent or retrogressive individuals are eliminated; gradually there is established a stable race, breeding true. I. Ancestral Jungle Fowl. II. Cochin China race. III. Bantam. IV. Hamburgh. V. Poland. 
most instances, however, man can do little in the way of inducing heritable variations; he has to wait for what Nature supplies.

Experiments on the transfusion of blood have an interesting bearing on evolutionism. Friedenthal has shown that there is harmonious mingling of the blood of horse and ass, hare and rabbit, orang and gibbon, chimpanzee and man. The harmonious mingling indicates blood-relationship, near or distant. But when the blood of an animal is transfused into a quite different type, there is great disturbance and, it may be, much destruction of red blood corpuscles. It has been shown by Uhlenhuth and Nuttall that if the blood-serum of a rabbit which has had human blood injected into it be added to human blood, a precipitate is formed. When it is added to the blood of an anthropoid ape, it forms almost as marked a precipitate, thus indicating a blood-relationship between man and anthropoid. Let us follow the matter a step farther, using a terse paragraph from Professor G. Schwalbe's essay in Darwin and Modern Science, edited by Professor Seward (Cambridge, 1909). "The reaction to the blood of the lower Eastern monkeys is weaker, that to the Western monkeys weaker still; indeed, in this last case there is only a slight clouding after a considerable time, and no actual precipitate. The blood of the Lemuridæ (socalled 'half-monkeys') givès no reaction, or an extremely weak one, that of the other mammals none whatever. We have in this not only a proof of the literal blood-relationship between man and apes, but 


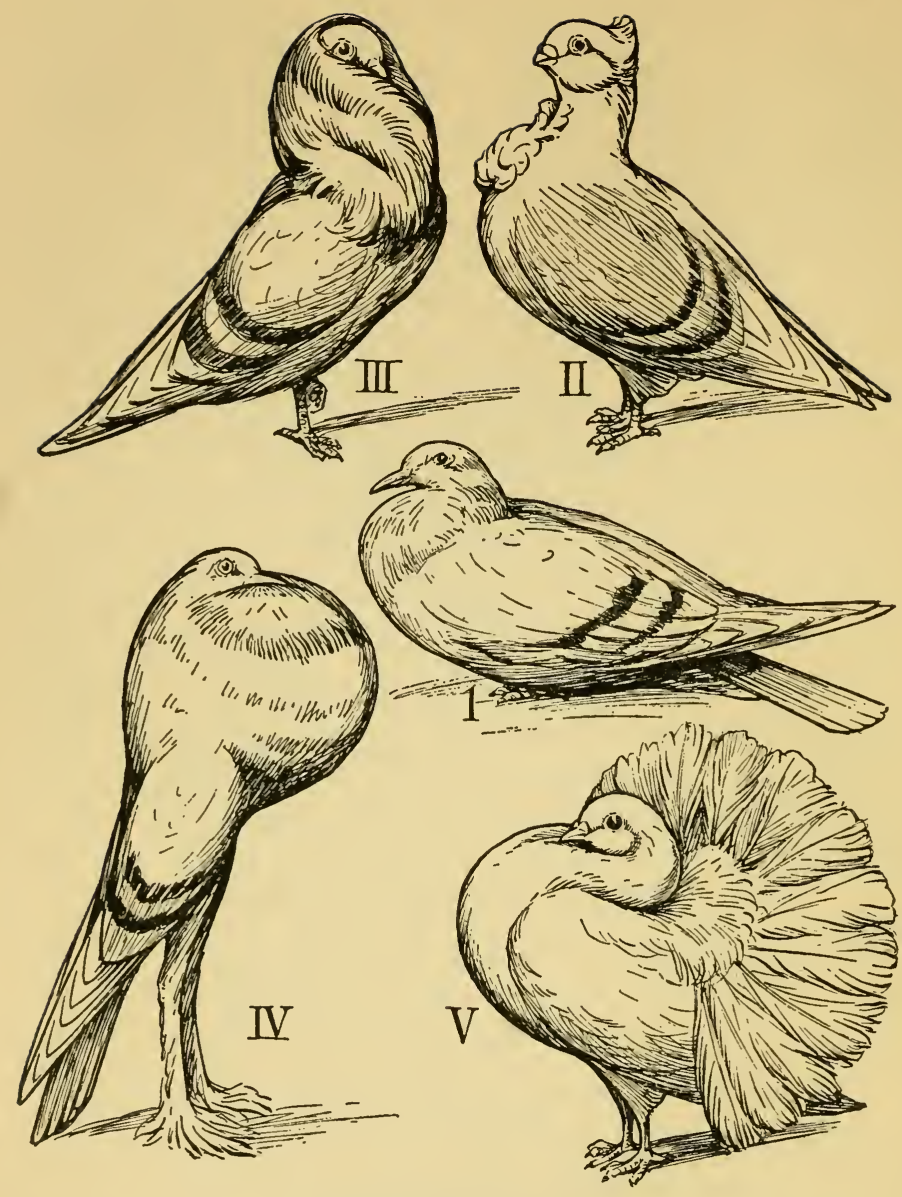

FIGURE NO. 14

\section{EVOLUTION AMONG PIGEONS}

This figure shows (I) the wild Rock Dove (Columba livia), the ancestor of all the races of domesticated pigeon, e.g. (II) Turbit, (III) Jacobin, (IV) Pouter, (V) Fantail. As in similar cases, man has selected mutations or variations that pleased him, and established stable races, breeding true. Similar mutations are paired together; divergent or reversionary individuals are eliminated. 
the degree of relationship with the different main groups of apes can be determined beyond possibility of mistake."

Speaking of blood reminds us of the striking correspondence between the proportions of the salts in our blood or any backboned animal's blood and the proportions of the same salts in the sea; especially, they say, the ancient Silurian sea in which the primitive fishes lived and had their blood well established. This looks like the past living on in the present!

\section{§11. General Conclusion.}

Considerations such as we have illustrated have led naturalists to accept evolution as a modal theory of racial becoming. It means little more than projecting on Animate Nature the idea of human history.

Continuity, however, is an essential part of the idea-a continuity of natural processes. Our presentday fauna and flora and their inter-relations have arisen without gaps, though not without leaps, from simpler antecedents which were their entire preconditions. There can be no dragging in of spiritual influxes to help the evolving organism over difficult stiles. It is a religious conclusion that a spiritual background is always there, and to that conclusion science can have nothing to say. But what is scientifically intolerable is the suggestion that the spiritual background is intermittently intrusive in the chain of natural events.

Organic evolution may be defined as a continuous natural process of racial change in a definite direc- 

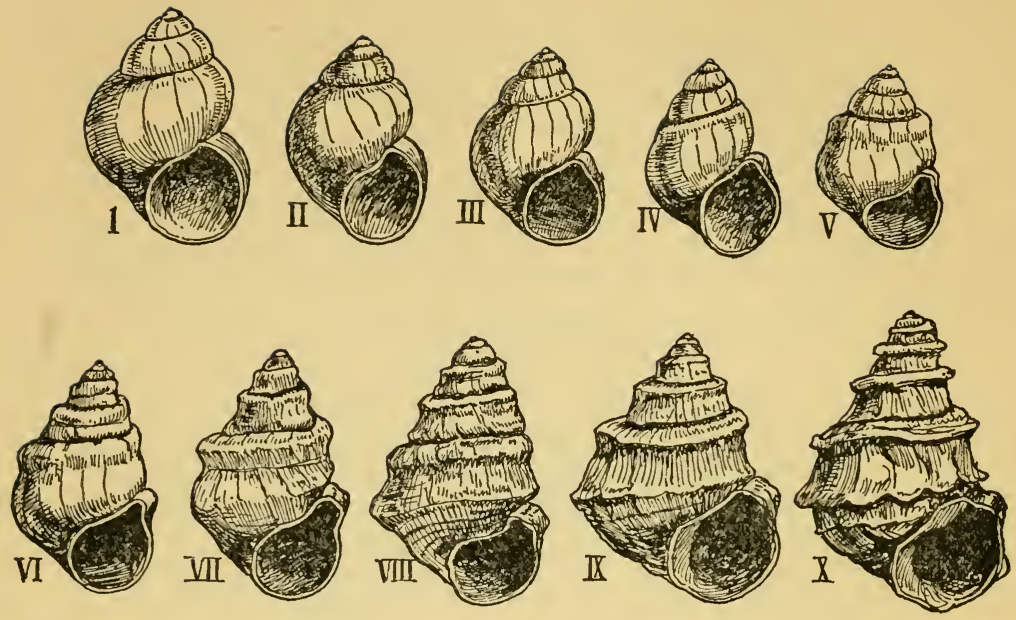

FIGURE NO. 15

\section{EVOLUTION IN PALUDINA \\ [After Neumayr]}

Here is shown a fossilized series of freshwater snails belonging to the genus Paludina. The oldest form (I), Paludina neumayri, is very different from the youngest in this series (X), Paludina hœrnesi. But the intermediate forms (II-IX) link them indissolubly by a gradual series of transitions. The idea of evolution leaps to the eye when we look at a series like this. 
Difficulties in the Evolutionist View 97 tion, whereby distinctively new individualities arise, take root, and flourish, alongside of or in place of the originative stock. This is a scientific description or formulation of the general way in which the system of Animate Nature has come to be as it is. As long as we do not inquire into the biological factors in the process, the evolution-formula remains entirely a modal theory. It does not, in the first instance, explain anything to say that it evolved; for that simply states the manner of its becoming, that it emerged in the course of a continuous natural process. This is a descriptive formula that fits all the facts and is not confronted by any contradiction. And yet the naturalists of to-day are not so intellectually comfortable as their fathers were in declaring a result to be "the outcome of evolution." Not that there is any dubiety in accepting the evolution-formula as the only scientific formula that we can think of, but there is a clearer appreciation of certain difficulties. Perhaps it may be of service to indicate briefly what these difficulties are.

The inquiries of evolutionists for two generations have been rewarded by some big discoveries, such as Mendelian Inheritance and the frequent occurrence of Mutations ; but there have been many disappointments. It is a fact, for instance, that many of the pedigrees that were hailed with much enthusiasm in early post-Darwinian days have not given satisfaction to the zoölogical College of Heralds. Lineages have turned out to be much more complicated than 


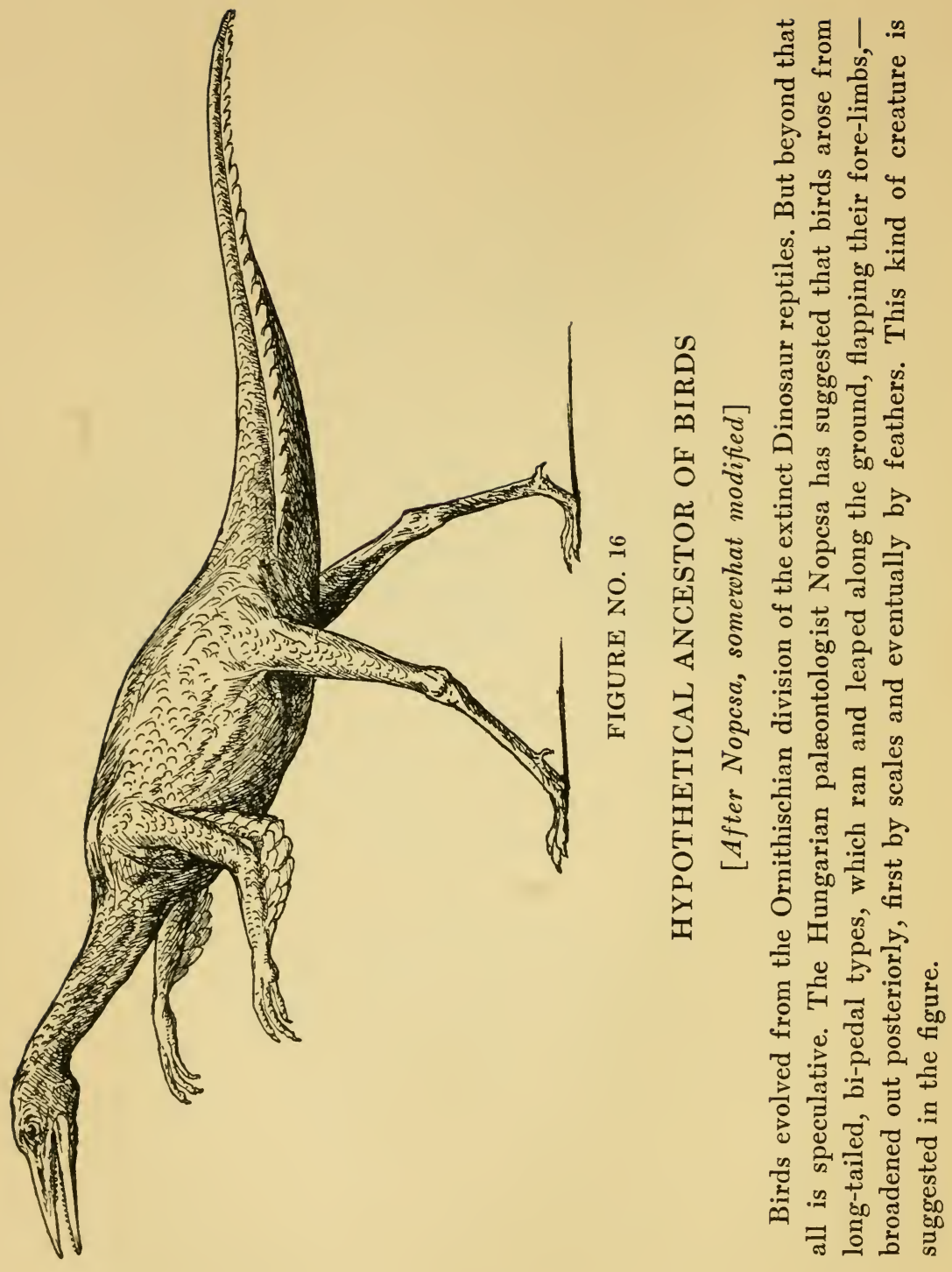


the palæontologists supposed. Many of the genealogical trees which Haeckel was so fond of drawing have fallen to pieces. Who can say anything, except in a general way, regarding the ancestry of Birds or even Vertebrates? We are only nibbling at the provisional description of how most of the great lifts in evolution may have been effected. The fact of evolution stands more firmly than ever; the uncertainties in regard to the factors are immense. The Origin of Species was published in 1859, but who to-day has attained to clearness in regard to the origin of any single species, i.e., a discontinuous group of similar individuals, breeding true (in the main) inter se, but not readily fertile with other species?

As Professor Bateson says in his Problems of Genetics (1913, p. 97) : "Ideas which in the abstract are apprehended and accepted with facility fade away before the concrete case. It is easy to imagine how Man was evolved from an Amœba, but we cannot form a plausible guess as to how Veronica agrestis and Veronica polita were evolved, either one from the other, or both from a common form. We have not even an inkling of the steps by which a Silver Wyandotte fowl descended from Gallus bankiva, and we can scarcely even believe that it did." Perhaps the agnosticism of this quotation from one of our leading investigators is extreme, but it is useful in suggesting the unpleasant truth that the confidence of the past, including our own, was "chiefly founded on ignorance."

In view of polemical disputations we must repeat 
that uncertainty in regard to the factors cannot be said to affect the validity of the modal concept of evolution, and it is entirely unfair to use confessions of ignorance in regard to the factors as if they implied doubt in regard to the fact. One authority declares that the Domestic Cat originated from the Caffre Cat of Egypt; another says that it is a scion of the European Wild Cat species; a third maintains a multiple origin; and none of the three can describe the actual steps in the transformation. But all are agreed that the Domestic Cats have evolved from wild ancestors. We must recognize how young active evolutionist inquiry is, that it is practically included in two generations. There is not the slightest reason for jettisoning the modal formula because we are still very ignorant in regard to the detailed steps and factors in the process.

It may be urged, however, that a modal formula is unsatisfactory until it is supported by a causal description; and that is true. It is possible that besides variation and heredity, selection and isolation, there may be some unknown factor in organic evolution. And this raises the question whether the unknown factor may not be of a providential order, some supermundane directive agency intervening at crises. This was the view of Alfred Russel Wallace, Darwin's magnanimous fellow-worker; we can only say that it seems to us to imply a premature abandonment of the scientific problem, and that it lands us in the confusion of trying to speak two languages at once. 
\$12. The Gist of Darwinism: (A) The Web of Life. 'THE general idea of evolution is that the present is the child of the past and the parent of the future. But what are the characteristics of the particular form of organic evolutionism that is familiarly called "Darwinism"? This is the subject of frequent misunderstanding. There are in "Darwinism" four great ideas. First, there is the image of the Web of Lifethe correlation of organisms, the linkages binding one living creature to another in a vital economy. Cats are connected, Darwin told us, with the success of next year's clover crop. Cats have also something to do with the incidence of the plague in India; and little fishes, by devouring mosquito larvæ, play their part in checking the dissemination of malaria. Water-wagtails in Britain have something to do with profitable sheep-farming, for they devour the freshwater snail that harbors the juvenile stages of the fluke-worm, responsible for the disease of liver-rot in sheep. Everyone knows what far-reaching harm the European sparrow has done in the United States. Earthworms have made most of the fertile soil of the world, and the white-ants or termites on the outskirts of the forests contribute to the making of the alluvium of distant valleys. Flowers and insects are fitted to one another as glove to hand; in many cases the flowers would probably disappear without their visitors and the insects without their flowers. As John Locke said, with his characteristic insight, nothing stands by itself ; everything is a retainer to some other part of nature. The circle of one creature's life cuts 
many other circles. The face of Nature is like the surface of quiet water on a summer evening when the touches of the May-Flies dimple it into a multitude of interacting circles. Or it is like the lea quivering with threads of fallen gossamer. To put it in the coldest way, there seems to be a tendency in Animate Nature towards the correlation of organisms. This is one of the central ideas of Darwinism, and if we ask how this stands to-day, the answer must be, "Clearer than ever." Every year brings fresh instances of the Web of Life. Nature is seen more and more vividly as a fabric. Let us take a number of vivid instances.

One of the plants most inimical to man's interests is the bracken, for it destroys good pasture and it is so sturdy and insurgent that it can conquer even the heather. The encroachments may be met by laborious cutting and by spraying with sulphuric acid, but it would be more promising to discover new uses for the fern. It makes excellent bedding, it has strong antiseptic qualities, it contains a considerable quantity of potash, and so on. A few experiments have shown that the fish-yield of fresh-water lochs can be greatly improved by pitching cartloads of cut bracken into the waters. Their slow decay promotes the multiplication of animalcules, on which small crustaceans and the like depend, and thus the fishes are fed. These experiments should be continued, for it may be that bracken cast upon the waters will return to us after many days in the form of trout.

Everyone knows that widely separated forms of 
life are often linked together by being the two hosts of one parasite. Remembering that the sheep and the little water-snail are the two hosts of the liverfluke, Dr. Leiper was able during the War to prove that the very formidable human parasite called Bilharzia spends part of its juvenile life inside freshwater snails. From these the microscopic larvæ pass into the water and swim freely. If an opportunity offers they enter man through cracks and weak spots in the skin. Every third child of the 30,000 born annually in Cairo is infected with Bilharzia, and the parasite is a serious menace to adults as well. Dr. Leiper not only traced the life-history of the worm; he has saved thousands of lives by showing that the dangerous intruders can be kept back by good filters, and that the free-swimming stages die within thirty-six hours in water that is kept drawn.

The subtleties of parasitology are often almost incredible. There is a remarkable fluke called Leucochloridium that lives in the intestine of singingbirds in European countries. The miscroscopic eggs are voided on the meadow and may be eaten by a small snail (Succinea), in whose stomach they hatch. Each larva gives rise to strange branched forms, with ramifications which extend up to the snail's horns, where they pulsate with great rapidity, sometimes twice a second. The swollen and agitated horns are all the more conspicuous because they have become banded with red and green pigment. They have been, so to speak, painted by the parasite. If a Blackcap or some similar perching songster is attracted by the 
snail on a leaf and pecks off the pulsating horn, the branch of the parasite, which is now full of larvæ of another generation, closes up automatically at its base, so that there is no loss of the multitudinous microscopic progeny. Now the investigators tell us that if the Blackcap swallows the horn then and there, nothing happens. The fluke-parasites are digested. But if the bird gives the tidbit to its nestling, which has a weaker digestion, then infection occurs and the extraordinary life-cycle begins again.

There are endless instances of the linking together of lives apparently far out of touch with one another. The malarial parasites pass from man to man by aid of the mosquito; the Trypanosome microbe, that causes sleeping sickness, is disseminated by the tsetse fly; bubonic plague is transferred from rat to man by the intermediation of the rat-flea. Some of the finest pearls appear to be formed in the pearl-oyster as the sepulchre of the minute parasitic larvæ of flukes and tapeworms.

One of the most striking biological facts in many parts of Britain is the success of the heather. It grows exuberantly on mountain and moorland where few other flowering plants can make a living. There is soil, but it is unready; there is water, but it is apt to be physiologically unavailable. How does the heather flourish so well? The answer is that it has entered into a very intimate partnership with a fungus, which penetrates through and through the heather, from root to stem, into every leaf, even into the flower and its seed. What an individual could not do, a firm 
achieves. The heather is a dual organism; it is like a flowering lichen! If it stood alone it would be a remarkable curiosity, but it is only an instance of a kind of partnership that is now known to be common, between the highest plants and the lowest. The list of flowering plants with fungi (mycorhiza) living in profitable partnership with their roots is already a long one. The root-tubercles of Leguminosæ, due to nests of symbiotic Bacteria, are familiar, and of considerable importance in agriculture. Familiar, we say, but it does not seem at all clear as yet how it is that the partnership enables the quiet-living plant to capture the nitrogen of the air-a feat which man accomplishes by harnessing waterfalls to electric machines and sending terrific lightning discharges through the air.

Considerable progress has been made with the physiology of animal luminescence. Indeed, the chemistry of the transformation of energy has outrun our knowledge of what the light means in the life of the creature. The gleams, so badly called "phosphorescent," may be lanterns, or lures, or dangersignals, or love-lights, or recognition-marks, or whatnot-speculation is rife because ecological observations and experiments have been few. As to the physiology, however, it seems to have been well established in the case of the firefly, the crustacean Cypridina, and the rock-boring bivalve, the piddock or Pholas, that a ferment-like substance, luciferase, acts on an oxidizable substance, luciferin, changing chemical energy into light. Our point, in connection with 
the linkages of organisms, is illustrated by the evidence that in some cases, such as luminous cuttlefishes, the light is produced by nests of Bacteria. They are like those that we see in the dark on the glistening surface of the haddock hung up to dry; but they are living in regularized partnership with the animal. In some cases, therefore, the luminescent animal shines with a borrowed light.

Many beetles eat wood, but that is Spartan diet. It is not surprising, therefore, that some of the beetles which habitually bore in fresh wood have learned to grow a mould that yields what is called "ambrosia." This fungus lives on the wood and its sap, and spreads over the walls of the tunnels that the beetles make. The fungus collects, concentrates, and prepares the food, making ambrosial bodies for the beetles and their grubs. In some cases the beetles never swallow the dust of the wood through which they bore; they feed on ambrosia. The fungus does not seem to form spores or propagative elements, so it is probable that the beetles infect a new tree with surplus vegetative ambrosia cells which have passed out undigested from the food-canal.

Sometimes there is a triple alliance. Thus certain gall-midges that attack flowers of mulleins, scrophularias, and capers, provoke strange galls, inside which an ambrosia fungus flourishes. Gall-midge, mullein, fungus - a triple alliance. The hollow petioles of the Tachigalia tree in British Guiana are the homes of certain little beetles that have established an alimentary partnership with minute mealy bugs. These 
share shelter with their hosts and yield food to them in response to quaintly urgent massage. Beetle, tree, mealy bug-a triple alliance.

In his Edge of the Jungle, Mr. William Beebe has recently given a vivid picture of the habits of the leafcutting ants, and verified an interesting linkage. When he took a pickaxe and broke into the underground city of the ants, into which they carry the semi-circles of leaf dexterously cut off from the branches, he disclosed a remarkable sight. For he saw hordes of worker-ants chewing at the leaves that had been brought in and making them into a green paste, which is the culture-medium for a particular kind of fungus not known elsewhere. This forms the sole food of the ants as long as they are beneath the ground. But there are wheels within wheels, for when a queen-ant leaves the community and rises high in the air on her nuptial flight, she takes with her a minute pill of the fungus, carrying it in a depression beneath her mouth. Eventually, she comes to earth again, settles down to maternity, and has a family of workers. When they are strong enough and numerous enough they bring in segments of leaves and begin to make the green paste; then the queen takes the fungus-pill from beneath her mouth, where it has been safely kept all this time, and starts a new culture. The story is almost too good to be true, but it is well documented. Animate Naturè becomes subtler under our eyes.

We must not linger over this seductive section of our subject, but a final illustration may be permitted. 
Everyone knows the little beetles called "deathwatches" that make tapping noises in the wainscot. The male thumps his head against the wood, signalling to his desired mate-speaking, therefore, of love, not of death. The larval death-watches bore in wood and other dry materials, including books-poor food! Now, it has been shown that at the beginning of the digestive part of the food-canal of the larval death-watch there are two minute pockets which are crammed with yeast-plants. These work on the unpromising wood pulp, and there is a little brewery inside the larval death-watch. Careful examination showed Professor Buchner that there were no yeastplants in the eggs; yet they were always present in the young grubs. The solution of this puzzle is almost incredible. Associated with the egg-laying apparatus in the female there are two minute reservoirs opening to the exterior, and these are full of yeast-plants. When an egg is laid, some yeast-plants are expelled along with it, and they adhere to the rough surface of the egg-shell. When the beetle-grub is ready to hatch out, it nibbles at the egg-shell, and thus its food-canal becomes infected with yeast-plants. A little leaven goes a long way with the death-watch. The details are interesting, but even more important is the general fact that a partnership of yeasts and insects has been demonstrated in scores of cases. It is no "curiosity."

The correlation of organisms is very important practically, for there cannot be an evolving control of life which does not give the intricacy of the web 
full recognition. But the fact is also of great importance theoretically, for the complex system of inter-relations forms an external registration of evolutionary gains, and a sieve by which new variations-sometimes subtle nuances, one might thinkare effectively sifted.

\section{ANTS AND ACACIAS}

In further illustration of the idea of the interrelations of organisms, we take the well-known linkages between ants and acacias - an old story on which recent inquiry has thrown fresh light.

When Dr. Hernandez was sent in 1570 by Philip II of Spain to investigate the resources of Mexico, he came across a "horn-bearing tree," and observed that "within the horns there are generated certain slender ants, tawny-colored and blackish, whose sting is hurtful, causing pain which persists for a whole day." The "horn-bearing tree" was an acacia, and the paired horns are the stipules at the base of the beautiful pinnate leaves. When the leaves fall off, the thorns remain, and they are very formidable.

Years and centuries passed, and, in 1872, Thomas Belt, author of the famous book The Naturalist in Nicaragua, was attracted to the "bull's horn thorn," another acacia. He observed that certain ants bore into a thorn and may even cut their way from one thorn to the opposite member of the pair, that they eat up the soft pulp and establish themselves in the excavated interior, that they multiply exceedingly, and that they form a standing army for the acacia, 
warding off browsing mammals and driving away the destructive leaf-cutting ants. He noticed that the standing army had barracks in the hollow thorns, and that they were well victualled by the plant. At the base of the midrib of each beautiful leaf there is a crater-shaped gland, secreting a honey-like liquid, of which the ants are very fond. Moreover, on the tip of each of the leaflets there is a little yellow body, like a golden pear, about a twelfth of an inch in length. When these little bodies are ripe the ants collect them and carry them into the hollow thorns. An ant transporting a single golden pear is as heavily laden as a man carrying a large bunch of plantains. "Belt's bodies," as they have been called, are very nutritious; they contain protein material, sugar, and oil globules.

There is no doubt that Belt, like Delpino about the same time, had the idea of a mutually beneficial partnership between the ants and the acacias. $\mathrm{He}$ thought that the "ant-loving" acacias had become in certain ways specially adapted to secure the persistent presence of their bodyguard of ants, just as many flowers are adapted to secure cross-pollination through the agency of their insect visitors. "Habitations full of food are provided for the ants to commence housekeeping with; and cups of nectar and luscious fruits await them every day." As a shrewd observer, however, Belt could not but notice the other side of the picture, conspicuous in the dry season. For then the glands cease to secrete sweetness, no fresh food-bodies are produced, the leaves of the acacia fall off, there is great scarcity among 
the ants, many of the thorns are depopulated. This seamy side awakens a suspicion that the fitness of the mutual benefit society may have been exaggerated. The ant-loving acacias and other plants are called "myrmecophilous," and the theory of myrmecophily is that certain peculiarities of the plants have arisen as adaptive answers-back to the very advantageous presence of the partner-ants. Professor Schimper and other botanists of distinction have lent support to this not unreasonable theory. The food-bodies seem to be transformed glands, but Schimper pointed out that they are "distinguished from all other known glands by definite characters which may, with reasonable certainty, be regarded as special adaptations for the ants' benefit, such as greater size, prolonged persistence, richness in albumen, and easy detachment when touched." Moreover the same peculiar food-bodies occur in some plants not related to acacias, and some of these have also partner-ants. Another interesting feature is that the crater-like nectary is away from the usual position of nectaries; it is extra-floral, situated at the base of the midrib of the leaf. These peculiarities are suggestive of special adaptive arrangements that have arisen in the course of evolution in response to the tenancy of the ants, and in relation to the broad fact, which many naturalists confirm, that the ants form an effective bodyguard, defending their host from men, cattle, and various kinds of insects.

But the results of recent investigation have rather shaken the theory of ant-loving plants. There is no 
doubt that the ants get food and lodging, but are the peculiarities of the acacias in any way the result of the presence of the ants? And are the ants as necessary to the acacias as was at first believed? One irreverent critic goes to the length of saying that "the plant has no more need of the ants than a dog of fleas." It is said that the ravages of the leaf-cutter ants have been much exaggerated, and it is loudly hinted that the protective prowess of the body-guard, in driving off the leaf-cutters, leaves a good deal to be desired. But it is in favor of the useful-partnership theory that the Javanese fruit-growers stretch ropes from one mango to another so that certain large red ants can spread from tree to tree and form a standing army to ward off the attacks of a very destructive beetle.

On the other side of the argument, however, is the contention that the "cups of nectar" that Belt spoke of do as much harm as good. They may victual the standing army, but they also attract sweet-toothed visitors who are anything but welcome. It is also argued that these extra-floral nectaries are bound up with the internal physiology of the plant-the working of the sugar-factory-and have no direct relation to the army of friendly ants.

It is certain that the ants eat and enjoy "Belt's corpuscles," but are these little food-bodies present because there has been for ages a partnership with ants? The truth will out, that many plants with no partner-ants have little stalked glands with a secretion containing protein, sugar, and oil. In some cases 
it has been proved experimentally that a tree, normally "ant-loving," can flourish without its army, and that the army can flourish without its rations from the tree!

In our judgment, then, it seems time to abandon the idea that the peculiarities of myrmecophilous plants have any causal relation to the ants which find habitual shelter there. But it is always extreme to empty out the baby with the bath. Ants are quick to profit by experience along certain lines; they are intelligent as well as instinctive; they show considerable plasticity of behavior; and there is nothing improbable in the view that they have thoroughly learned how to make the most of the acacias. Nor is it at all improbable that the acacias are in some places and times all the better for this linkage which has tied them up in the bundle of life with aggressive ants of a species that does the tree no harm. This is the grain of truth in the theory of myrmecophily, and it is not a microscopically minute grain!

\section{ANOTHER CORNER OF THE WEB OF LIFE}

The idea of the Web of Life is so fundamental to a true appreciation of Animate Nature that we venture to give another illustration which has been discovered very recently by Dr. N. A. Kemner. The story comes from Java, a land of many marvelswhere bamboos grow so quickly (over thirty feet in fifteen days) that even the veracious observer can see them growing; a land where "flying frogs" parachute from branch to branch and deposit their eggs 
in little aquaria among the leaves! The story concerns the alliance between a little moth called Wurthia and an ant called Polyrhachis. The linkage is called by the strange name HYphжNosymphiLy, which will be explained presently.

The ant in question is common in the coffee plantations, where it is in the habit of making its nest on or between the big leaves. This nest consists chiefly of a web of whitish half-transparent threads, and these are produced by the ant-grubs, just as in the case of the tailor-ants. A worker seizes a grub by the back and dabs its head against a leaf, whereupon the grub reels off a silk thread. This is wonderful enough, but it is familiar in the case of the tailor-ants, which use their larvæ in a similar way as animated gum-bottles; but now come the wheels within wheels. As Dr. Kemner was watching the combined labors of the workerants and the ant-grubs he noticed a larva that was working by itself, but at the same job. A second glance showed that it was not an ant-grub but a little caterpillar. That let the cat out of the bag! The caterpillar was helping in the construction of the ants' nest.

Further inquiry showed that various nests had their partner caterpillars, partners in the sense that they helped in spinning. The ants seemed to ignore them, and yet the caterpillars were feeding on antgrubs all the time. The toleration is the more remarkable since ants of this species show fierce and fatal resentment if stranger ants intrude. But the caterpillars are allowed to go on their way without let or 
hindrance. Sometimes a caterpillar insinuates itself within the cocoon or pupa-case of an ant (popularly called an "ant's egg"), and the workers carry the two about as if they did not notice anything wrong. When there is a migration from the nest, however, the caterpillars are not designedly flitted. But this does not matter, for, like the family ghost, they cannot be left behind. Little ones cling on to ants' cocoons, or larvæ, or clumps of eggs, and are transported to the new nest all unbeknownst. It is a noteworthy fact that the caterpillars appear to be very helpless when they are removed from the ants' nest.

In the course of time, having eaten many antgrubs, having grown and moulted according to rule, the caterpillar passes into the quiescent pupa or chrysalid phase. It makes a cocoon of snow-white silk fastened to the nest-wall where it joins the leaf. As there may be a dozen of these cocoons in one ants' nest, they contribute to the strength of the wall and lessen the risk of the two leaves being torn asunder by the wind or by an intruder. It seemed to Dr. Kemner that the nests with many cocoons were the most successful. Two of them contained between them 29 males, 42 females, and 364 workers; and this was not near the maximum.

The moth (Wurthia) is a little white creature that flies by day, without much rapidity or persistence. Another species has its caterpillars living in the nests of the common tailor-ant, but apparently as parasites rather than as partners. What characterizes the menage of the new species is its active share in spin- 
ning the web that makes the ants' nest; hence the strange word hyphænosymphily, for "symphily" means something like "friendly association" and "hyphæno" means "spinning." It is a mutually beneficial association, as the result of which the caterpillars secure shelter and food, and the ants secure assistance in nest-making. There is no trace of exudations which might give the caterpillars a pleasant fragrance or taste, as in many ants' guests; and the caterpillars have no disguise or invulnerability or quickness or protection of any kind. All that can be said is that the ants tolerate the caterpillars, whom they could devour in a very short time if they chose. It seems to us that the caterpillars have by far the best of the bargain.

It would be strange if an inter-relation like this stood quite alone; and it does not. Apart from the presence of the caterpillars of a species of Wurthia in the nests of the tailor-ant, where no assistance in spinning has as yet been observed, there is a case described by Jacobson where caterpillars of an unrelated moth (Batrachedra) live in the nest of another kind of Polyrhachis ant and strengthen the wall with their spinning. These ants are furiously intolerant of other caterpillars, but they shut their eyes to this one which devours their cocoons! There is also a very curious case where the caterpillars of another species of Batrachedra live in a friendly way with a gregarious South African spider and probably assist in the strengthening of the web. These instances are interesting, because they suggest steps in the evolution of 
the more subtle and perfect linkage described by Kemner.

We cannot pass from the subject without recalling the well-known linkage between the British "Large Blue" butterfly and a common ant. The eggs of the "Large Blue" are laid on the wild thyme, and the small caterpillars feed for a while on the flowers. When autumn approaches they go a-roving, and are picked up by ants and taken into the recesses of the nest for the winter. It is believed that the caterpillars have an exudation that is very agreeable to the ants, inducing them to wink at the unpleasant fact that the caterpillars eat their grubs all the winter through. When spring comes the well-fed caterpillars say farewell to their hosts, pupate in soft earth, and turn into the beautiful blue butterflies. This is a good instance of the subtle weaving of the web of life. What patterns there are!

\section{§13. (B) The Struggle for Existence.}

The second fundamental idea in Darwinism is that of the Struggle for Existence, which the great master realized with much more insight than some of his disciples have shown. By the struggle for existence Darwin meant not merely the jostling and elbowing around the platter of subsistence-like pigs at their trough; he meant also the endeavors that birds make to save their young ones in the cold spring or against the glare of an unusually strong sun. He meant not only the inveterate antagonism between the grasseating herds and the carnivores hungry for warm 
flesh, between the small rodents and the birds of prey; he thought also of non-competitive endeavors which animals make to cope with drought and cold. He included not only the cannibalism in the cradle which occurs in the egg-capsules of the Whelk, when the pioneers eat the laggards; he thought also of the mutual aid so deeply engrained among ants. He included not only the starving locust eating its neighbor and the fierce combats among rats in despair; he thought also of the mutual aid of gregarious and social animals. More clearly than anyone since, Darwin realized that the descriptive term "the struggle for existence" is to be used in "a large and metaphorical sense," that it includes endeavors to secure the welfare of the offspring as well as internecine competition for the necessities of life. How has this changed since Darwin's day?

There have been relapses, if we may so call them, as when Huxley pictured Nature as "a vast gladiatorial show" and "a dismal cockpit"; there has been a tendency to use too much red in the picture; there has been now and then a loss of Darwin's subtlety; but on the whole it has become clear that the Struggle for Existence is a formula for all the manifold efforts and answers-back that living creatures make when they find themselves up against environing difficulties and limitations. It includes all the reactions which secure the welfare of self and kin. The struggle may mean competition between fellows of the same kith and kin-rat against rat-or parrying the attacks of foes belonging to other races-herbivores against 
carnivores-or reactions against the callous fates of the physical world, such as the diverse ways of meeting the winter. The struggle may mean girding the loins or tightening the belt, trimming the lamps of the senses or quickening the pace, putting on a garment of invisibility and lying low, or, at its highest level, "intending the mind thereunto" and thinking out a problem. The struggle rises from internecine competition to an endeavor after well-being; the field-naturalist knows more of its subtlety than the zoölogist. Both are agreed that it is essential not only in making but in securing progress.

\section{HUNGER AND LOVE}

Everyone knows the poet's declaration: While philosophers are disputing, hunger and love solve the world's problems. But is it as wise as it looks? Do hunger and love solve the world's problems? Are they not problems themselves? And are not the disputings of philosophers what we need to help us to see life whole and do justice to egoistic and altruistic impulses alike? For sixteen hours on a summer day did a pair of Blue Tits gather hundreds of small caterpillars as food for their nestlings. Too much hunger from the caterpillar's point of view ; satisfaction of hunger from the nestling's point of view; but how much love on the parents' side! It is part of their meat and drink to gather càterpillars for their offspring; and the urge which they obey in doing this is quite as real as their own gastric urge which enforces snacks of food for themselves. 
120 Self-regarding and OTHER-REgarding

Was it not the same poet who asked: "Why do the people so strive and cry?" and gave as answer: "They will have food and they will have children; and they will bring them up as well as they can." Here we get down to bedrock-the two fundamental impulses of hunger and of love, the pivots on which life swings. From first to last-if one can talk of last-is not the business of life twofold-caring for self and caring for others? As Herbert Spencer said: "From the dawn of life altruism has been no less essential than egoism." "Self-sacrifice is no less primordial than self-preservation." Deep down in the abysses of evolutionary emergence, hunger and love may be hardly distinguishable; and on occasions all through the history of living creatures the egoistic and altruistic currents seem to merge and flow apart again; but cases of female spiders devouring their suitors cannot be regarded as typical! On the whole the two fundamental trends are clearly defined.

Hunger and love are the warp and woof of the web of life, with its evolving pattern; but it would be a terrible literalism to take this statement as meaning that the gastric "urge" and the reproductive "urge" persist throughout in their original simplicity. Hunger is a primary appetite, with which there have become associated, even among animals, many other impulses or inborn reaction-tendencies, such as selfpreservation, self-defence, self-assertiveness, and selfinterest. These are shoots of which hunger is the common root, and there are flowers, too, such as ad- 
venturousness and courage, though these may be blossoms of love as well as of hunger.

Similarly, it is one of the largest facts of biology that in the ascent of animal life the sex-urge becomes linked to joyous emotions, artistic expressions, and coöperative endeavors; that it joins hands with parental instincts and affections; that it broadens out into kin-sympathy and other raw materials of morals. Physical fondness is transfigured as psychical love, especially in monogamous animals; and $a$ fortiori this should be true of man. Even among animals the shoots of which sex is the common root bear flowers-affection, self-sacrifice, courage, and artistic self-expression. One has not to go beyond birds to find abundant evidence.

We are not, of course, suggesting that man's guidance in morals should be confined to a study of the animal kingdom-he has better guidance nearer home--but we are concerned to point out that selfregarding activities do not cover more than half of animal life. If we are to be realists, let us not be onesided. Other-regarding activities occupy a large part of the time and energy of a multitude of creatures, both on instinctive and intelligent lines. It sometimes happens, as among some insects, that an entire section of the creature's life is preoccupied with satisfying hunger, while another section is largely given over to love; it sometimes happens that there is a hunger season and a love season; but in the total woven fabric there is always the self-regarding warp and the other-regarding woof. The thoroughly indi- 
vidualistic animal is as much a fiction as is homo homini lupus. And many an animal has gone far in subliming the struggle for existence into an endeavor after well-being, which is the great task of civilization.

In the course of organic evolution, as we have said, the root-appetite of hunger has formed the groundwork of many shoots (reaction-tendencies, appetencies, desires, instincts, and so on) along the selfpreservative line of evolution. These have stood the test of Nature's sifting (Natural Selection), and they have blossomed into animal virtues, such as courage, alertness, pertinacity, and patience. That these have played their useful part in the competitive and environment-mastering modes of the struggle for existence is plain to every Darwinian naturalist. One of man's steps has been to make ideals of the self-preservative virtues, lifting fit behavior to the level of ethical conduct. That these self-preservative ideals are in the main justifiable in the light of higher values is as certain as the fact that Nature has consistently pronounced judgment against every form of slackness, every form of "the unlit lamp and the ungirt loin." And if the critic points to parasites, he must notice that they bear the stigmata of degeneracy in proportion to their surrender of independence.

Similarly the root appetite of sex has formed the groundwork of many shoots (reaction-tendencies, appetencies, desires, instincts, and so on) along the other-regarding line of evolution. These have stood the test of Nature's sifting and they have blossomed 
into animal virtues, such as affection, self-sacrifice, parental care, and kin-sympathy. That these have had "survival value" was emphasized by Darwin, and some of his disciples have followed him. One of man's steps has been to make ideals of these other-regarding virtues, just as of the others; and while he does not require Nature's sanction for his ethics, it is more than interesting to know that the momentum of integrative evolution is with us at our best. In the system of which we form a part the first places are given to creatures whose very name suggests mother. The rewards of survival and success, meaning especially a joyous, free, and masterful life-surely something of a satisfaction in itself-have come to creatures that balance self-realization with selfsubordination. Our finest British mammal, the otter, might be taken as a symbol of the virile virtues; but, on the other hand, what a climax of self-forgetfulness, on the maternal side at least!

The animals of the sea are sometimes divided into the Nekton and the Plankton, the swimmers and the drifters, and so it is also with mankind. The drifters exist casually ; the swimmers command their course by ideals. What the biologist would insist upon is that these ideals must include the other-regarding as well as the self-regarding virtues, and the self-regarding as well as the other-regarding. For man, unless he becomes one of the Plankton, it is impossible to give up ideals. That were a surrender of one of his prerogatives. The problem is to keep a balance between the hunger-ideals and the love-ideals, and to pitch 
them both high, till the trammels of protoplasm are transcended.

\section{§14. (C) Variability.}

THE third great idea in Darwinism is Variabilitythe mysterious welling up of novelties, so that children differ from their parents and two peas may be very far from like. These variations furnish the raw materials of evolution, and their origin is the most difficult problem in biology. Darwin relied chiefly on minute fluctuations, a little more of this and a little less of that; he was interested in brusque freakish novelties, but he thought they were bound to be swamped by inter-crossing. He confessed that he did not know how variations arose except in the case of those acquired novelties or modifications which are directly due to peculiarities in surroundings, food, and habits - which we now call modifications. Darwin called the inborn variations fortuitous, but he simply meant that the combinations of causes that give rise to a new departure remained obscure or beyond analysis. He thought of novelties as sometimes continuing along the same line generation after generation, and accumulating like compound interest, as he saw in his studies on domesticated animals and cultivated plants, but he was also aware of discontinuous variations which crop up, so to speak, without warning. Darwin had hold of the useful idea of correlated variations, that a change in one structure may have in its wake a change in another structure. One change may have several outcrops. 
What changes have come about since Darwin's day in regard to variations?

-(1) We know that variations are even more abundant than Darwin supposed; the fountain of change is copious.

(2) We know, what Darwin did not clearly realize, that novelties are due to permutations and combinations in the germ-cells. The bodily novelties are the expression of germinal changes.

(3) Most of us are very dubious in regard to the transmissibility of somatic modifications ("acquired characters") as such or in any representative degree. 'Though it is premature to shut the Lamarckian door, there are few who would now say that the giraffe's long neck is directly due to the efforts of its ancestors to reach up to the leaves of the acacia trees, or that the dwindling of our little toes is the nemesis of our great-great-grandmothers' tight boots.

(4) We know that discontinuous variations or brusque mutations are much commoner than was previously supposed and that they have great staying power in inheritance. A Greater Celandine with much cut-up leaves-Chelidonium majus laciniatum-appeared suddenly in an apothecary's garden in Heidelberg in the seventeenth century, and has bred true ever since. Hornless calves, tail-less cats, lop-eared rabbits, short-legged sheep, waltzing mice, copper beeches, weeping willows, thornless prickly pears, stoneless plums, and scores of other mutants are familiar in the short period of precise observation; 
how much mutation there may have been in many millions of years!

In some cases it is certain that the germinal representatives ("factors" or "genes") corresponding to brusque new departures or mutations, and to all or many of the discrete non-blending "unit characters" of the organism, lie in linear order-like beads on a string-in the nuclear rods or chromosomes of the germ-cells, and in a few cases something is known of their topography.

In the fruit-fly Drosophila there are about 7500 of these germinal "factors" or "genes," and a new light has been thrown on variability by the realization that these are like hereditary cards which are re-shuffled at the beginning of each new life. It has been shown that one hereditary factor may affect several adult characters (thus corroborating Darwin's idea of the correlation of variations), and that one adult character or quality may be the outcome of several hereditary factors.

From the study of some fossil series, such as certain lineages of Ammonites, Lamp-shells, crocodiles, and elephants, and also from some experiments, there is evidence that variations are sometimes definite or orthogenetic-i.e., occurring persistently in a particular direction. In other words, a variation may be congruent with what has already been enregistered in the organization of the creature. If an architect is asked to enlarge and improve a building, he cannot add at random, but only what is consistent with the given style. So it is unlikely that "anyhow" varia- 
tions are of common occurrence. An organism is a unity, even when it is an implicit organism, the germcell; the new must be congruent with the old.

\section{THE OPTIMISM OF PATHOLOGY}

In connection with new departures or variations we venture to follow for a short distance a line of thought that seems to give promise of illuminating views. One of the foundations of modern pathology was laid by Virchow about the time of the publication of The Origin of Species. He showed that many of the changes which are called diseases are exaggerations or inhibitions of normal processes. That is to say, constitutional diseases are not mysterious malignant intrusions, but disturbances of an everyday routine. A disease may be due to the invasion of the body by some virulent microbe or microscopic beast of prey or strength-sapping parasite. Or it may be due to some serious defect in the nutrition or to some radical unwholesomeness in habits and surroundings. But when we put aside these parasitic diseases and modificational diseases, there remain those that may be called constitutional, which are due to some initial perturbation in the germinal material-to some new departure which is on the wrong side of viability. What Virchow pointed out was that these new departures which spell disease need not be very far removed from those that are useful. A change that misses the target in one kind of living creature may be a bull's eye in another. Constitutional disease is metabolism that has got out of time, out of place, and 


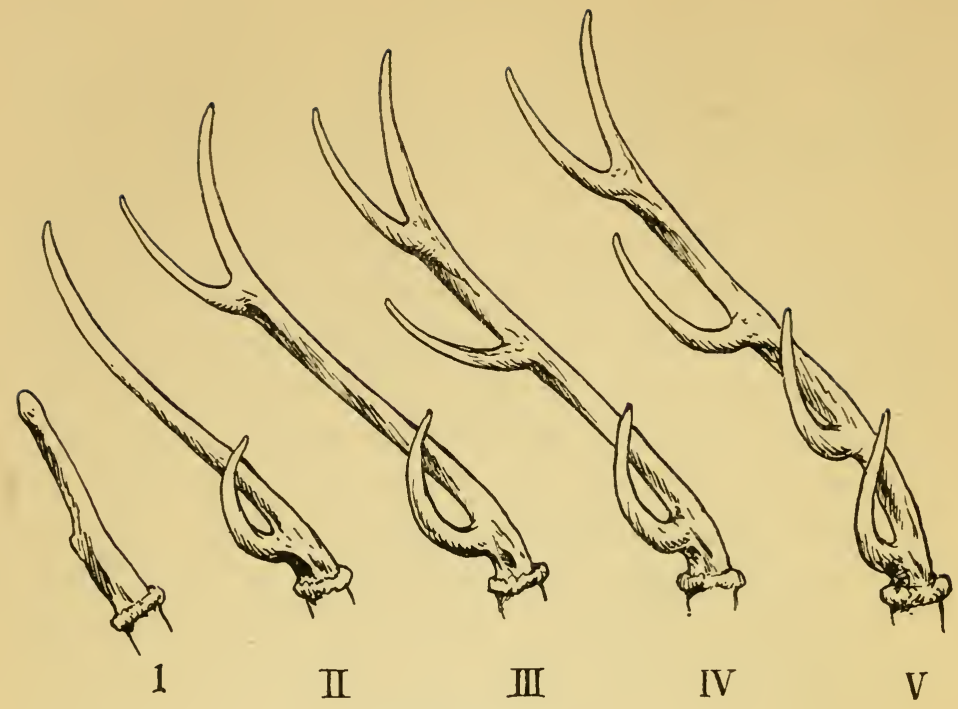

FIGURE NO. 17

\section{DEVELOPMENT OF ANTLERS OF RED DEER}

In the young buck of Cervus elaphus an outgrowth or pedicle grows out from the frontal bone in the course of the first year. This pedicle is a permanent structure. In the second year (I) there grows an antler with an unbranched stem. This falls off at the end of the season. Next year-the third-the second antler (II) grows, with a stem and one branch or tine. The thickened ridge at the base shows where the antler drops off each year. A new tine is added each year, e.g., III to V. No. V is an antler of the sixth year, with four tines. But while the figure shows individual development, it might also serve to show racial evolution, for the number of tines attained was gradually added to as the race grew older. This is shown by "rock-records" of ancestral species of deer. The individual development recapitulates racial evolution. 
out of proportion. What is disease in one animal may be regularized in another. Everyone admits the affinity of the lunatic, the lover, and the poet. What is normal at one time of life may be pathological at another. Disease-changes and health-changes are not so far apart as they seem at first sight; and Virchow's optimism of pathology was that the new departures which turn out to be disharmonious or even destructive are arrows that miss the target. They are not unnaturally associated with that vigorous organic archery which we call variability. Plus implies minus, the saint the sinner, and progressive evolution the possibility of the pathological. In wild nature, however, the radically disharmonious very rarely comes and never comes to stay!

The late Sir William MacEwen, in his suggestive study of the antlers of deer, pointed out that the multiplication of cells that leads to these extraordinary structures-as transient as they are exuberant -was comparable to that seen in a rapidly growing tumor. The yearly production of the stag's antlers is like a semi-pathological process that has become more or less normalized. Not less striking is the method by which the annual shedding of the antlers is effected. There is a dying away or necrosis of the bone which would be pathological elsewhere. As Virchow would have said, here in the stag are two pathological variations which have been brought into harmony with health.

At the breeding season the male stickleback bends pieces of seaweed or fresh-water plants into a nest. 
They are fastened together by delicate glutinous threads which exude from the kidneys. There are similar pathological products in the kidneys of higher animals, and there can be little doubt that the male stickleback has been able to make a weakness into a strength. Microscopic sections of the kidneys show that considerable changes away from the normal occur at the breeding season, yet these deviations have not crossed the line of safety. Virchow would have said: Here in this fish is a pathological change that has been normalized and turned into an advantage.

The familiar spectacle of the salmon leaping at the falls is a fine picture of the insurgence of life. They are seeking the spawning-grounds in the higher reaches of the river, and they show an admirable quality of persistence against the stream. It is a great gymnastic feat to hurl the heavy body clean out of the water, sometimes to a considerable height; and our wonder is not lessened by the fact that all the work seems to be done on an empty stomach. For the salmon is one of those creatures that show a very sharply defined alternation or see-saw between feeding and breeding. There is the nutritive life in the sea, when vast stores of chemical energy are accumulated; there is the adult's reproductive life in the fresh waters, where "hunger" has been eaten up of "love." We are not concerned at present to refute the view that hooked salmon disgorge the contents of their stomach. It is also possible that they may sometimes take a larval insect into their mouth, and 
squeeze out the juice at the base of the tongue. And we need not be ashamed of our inability to explain why salmon take the angler's unearthly lures. Our point at present is that the spawning salmon's feeding in fresh water is negligible, and that the foodcanal is below its normal vigor.

Speaking of food-canals, we recall the curious phenomenon of "pigeon's milk," which is produced in both sexes as the result of a degeneration and internal sloughing of the cells lining the crop. The creamy fluid is given by the parents to the young ones-a valuable aid to their gastric education, but it is not a secretion. It is much nearer an internal moulting. It is like a pathological process become normal. And do not the sea-swifts, which make snowwhite edible nests from the copious secretions of their mouths, suffer from supra-salivation? Is it absurd to suggest that chewing the cud may have begun in a normalizing of vomiting?

In processes of inflammation the wandering amœboid cells or phagocytes of the body do their best to deal with intruding microbes or irritant particles or poisons. The phagocytes are reacting to some quite abnormal stimulus, and their activity often saves the animal's life. But it is very difficult to draw a hardand-fast line between the rôle of phagocytes in inflammation and their rôle in assisting the re-growth of a lost part, or in some process of metamorphosis that leads from one style of architecture to another. In the life-history of many insects the phagocytes play an important part in breaking down the tissues 
of the larval body or in absorbing the products of their disintegration. Similarly not a few familiar changes, such as those involved in the disappearance of a tadpole's tail, would certainly be classed as pathological degenerative processes if we did not know that they turn out all right in the long run.

No good service is ever done by making different things seem the same, and we are not hiding the fact that disease-changes are self-contradictory and disintegrative, whereas health-changes make for greater harmony and unity of life. But our points are two(1) that what would be a disease-change in one organism may be normalized in another, and (2) that it is not surprising to find among the multitude of bull's eyes that some of the arrows of variation miss the target altogether. We call these misses constitutional diseases.

\section{§15. (D) Selection.}

The fourth great idea in Darwinism is Natural Selection. This means the sifting of the new departures that living creatures show, the winnowing of their experiments. The course of Natural Selection has been a long commentary on the maxim: Prove all things and hold fast that which is good. Yet Darwin warned those who followed his argument that Natural Selection was not such an easy idea as it looked. For the sifting takes place in the struggle for existence, and that, as we have seen, is complex and manifold.

living creatures are insurgent, urged by "a will to live"; they find themselves hemmed in by diffi- 
culties of diverse dimensions, and they answer back; the clash of the individual's new reactions against environing limitations is the struggle for existence. But in many cases there is an abundant crop of variations-good, bad, and indifferent-variations that can be entailed on the offspring. Those organisms that exhibit an advantageous variation will have an advantage; those that have not this character, or have some other that is disadvantageous, will be handicapped. Provided the novel character has some survival value, it is bound to prevail. Professor Punnett has made the interesting calculation: "If a population contains .001 per cent. of a new variety, and if that variety has even a 5 per cent. selection advantage over the original form, the latter will almost completely disappear in less than a hundred generations." Sometimes the sifting will be quick and sure: "Off with his head, and there's an end of it"; but sometimes it must be slow and subtle: A slightly shorter adult life, a somewhat smaller family, a little less success in launching them. In the course of time, however, the results of the quick and the slow sifting will be the same: the survivors will survive. They will survive-this is the whole point-in virtue of the possession of some advantageous character, including fertility; or because they are free from some weakness which is a fatal handicap to their fellows.

If it is one's ambition to possess a very fine lawn, like that of some of the Oxford Colleges, one may proceed by laboriously weeding year after yeareliminating the plants, including perhaps coarse 


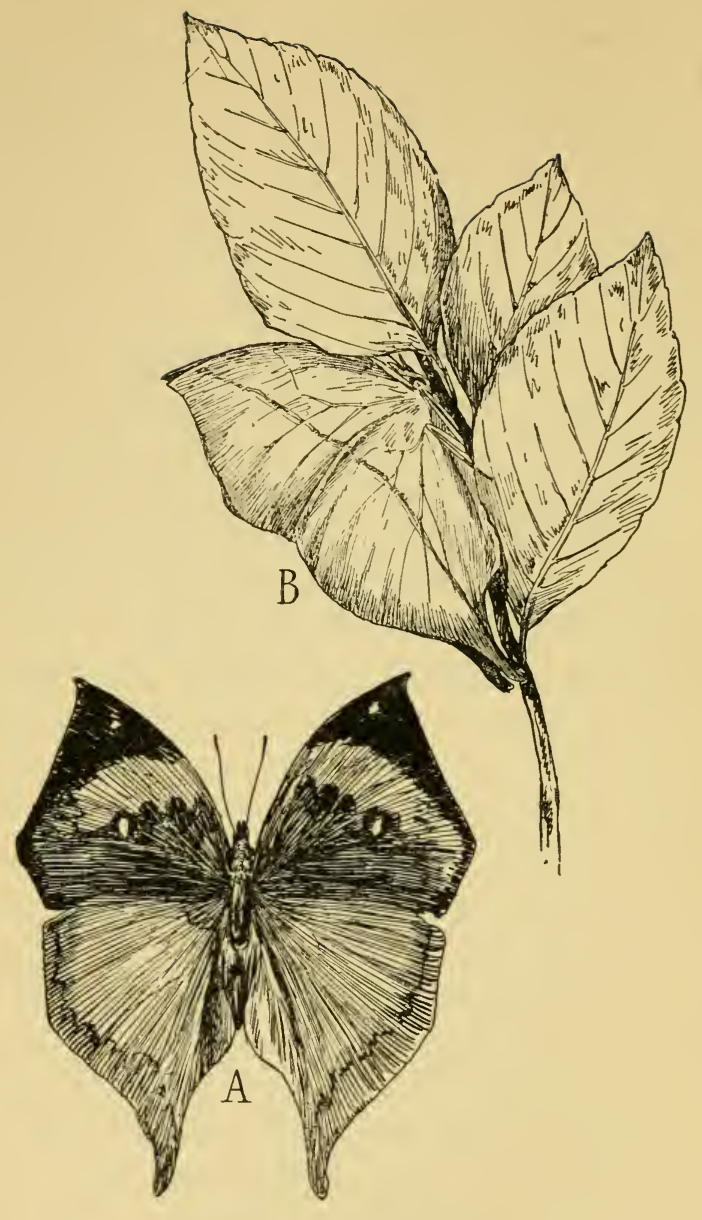

FIGURE NO. 18 
THE LEAF-BUTTERFLY, KALLIMA, ILLUSTRATING PROTECTIVE COLORATION

A. The butterfly with outspread wings, the upper surface of which is beautifully colored, with blue, orange, and other tints.

B. The butterfly has settled down on a twig, opposite three withered leaves, and it has, as is usual with resting butterflies, folded its wings together vertically. Thus the under surface, which is colored brown, is exposed. It harmonizes adaptively with the withered leaves. Moreover, the venation of the wings is like the venation of a leaf. This is a good example of adaptive coloration. The butterfly puts on a cloak of invisibility. 


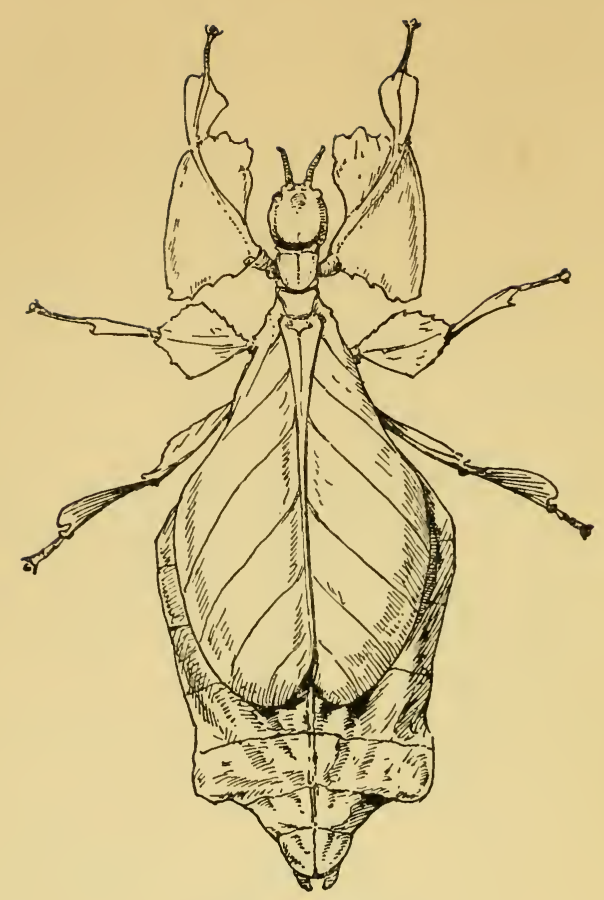

FIGURE NO. 19

\section{LEAF-INSECT, PHYLLIUM}

This insect, belonging to the cockroach-locust order, Orthoptera, is found in the East Indies, and bears an extraordinary resemblance to a leaf or a number of leaves. It is green in color and the venation of its wings suggests that of a leaf. Moreover, there is a strange flattening of the joints of the legs, suggestive of smaller leaves. A specimen exhibited in the Royal Botanical Gardens in Edinburgh deceived everyone by its resemblance to the plant on which it lived. It came to its end in this way, for "the visitors, sceptical as to its animal nature, insisted on touching it before they would be convinced." This is a good example of protective resemblance,- - though not against man! 
grasses, that are not wanted. This is an illustration of lethal selection, a process of pruning. But it is possible to work towards the perfect lawn in another way, by using a differential fertilizer. This promotes the growth and multiplication of the grass, but has no such influence on the weeds. The increase of the grass tends to smother the weeds. This is an illustration of what is called reproductive selection. The forms with the advantageous character may be helped to success if they have a fertility much greater than that of those that have not the character in question. In many cases lethal and reproductive selection may both be operative. There are other kinds of selection, such as germinal selection and sexual selection, but the present point is simply that while the logic or principle of the sifting remains the same, the modes of operation may be diverse.

The sifting will vary according to the nature of the "struggle," whether it is between fellows of the same kith and kin, or between foes quite different in nature; or it may be non-competitive-the organism pitting itself against the callous physical fates. Or the sifting will vary according to the need which brings about the clash. It may be for food, for foothold, for a place in the sun, for a mate or for a harem, or for room for a cradle. The struggle may be for luxuries; it may be for self-satisfaction and selfpreservation, or it may be concerned with the welfare of the offspring. Even among animals it may rise into an endeavor after well-being.

It is interesting to try to follow the changes in the 


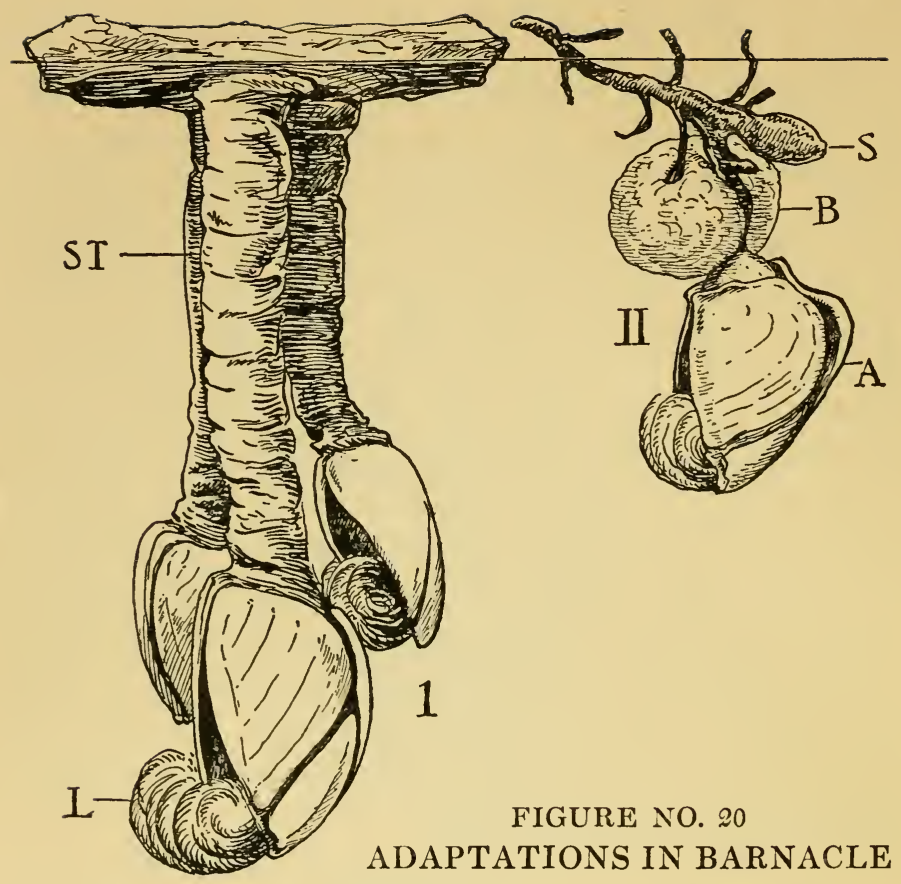

Fig. I shows three ordinary ship-barnacles, Lepas anatina, attached to a floating log. They are crustaceans, free-swimming as larvæ, which become adapted to sedentary life. The young forms fix themselves by the front part of the head, which grows out into a long flexible stalk (ST). From between the valves of an external shell of five pieces, something like an unopened pea blossom, six pairs of curled limbs (L) are protruded, which waft the microscopic food into the mouth.

Fig. II shows the floating barnacle, Lepas fascicularis, attached to a detached piece of seaweed (S), which its growing weight is dragging below the surface. But the barnacle has secreted a gelatinous buoy (B) with entangled gas, and this enables it to continue floating although its body (A) has become too heavy for the seaweed. This is an interesting physiological adaptation. It should also be noted that the shell pieces are very lightly built. 
criteria of survival from type to type and from age to age. This idea has been emphasized by Professor James Young Simpson in his striking and courageous book, Man and the Attainment of Immortality (1922). He points out that the determining factor may be at one time food, at another time family; in one age the criterion is muscle, in another it is brains. There are, of course, permanent indispensables, like health, which must always be winnowed for, if the creature is to live adventurously-one of Nature's lessons that man is apt to forget; but the emphasis shifts, in time and space and type, from speed to cunning, from armor to weapons and vice versa, from vigor of body to a capacity for self-effacement, from the art of lying low to the quality of swiftness. There is obviously an extraordinary variety in the survivalvalue qualities which may be the subject of Natural Selection or Nature's sifting; but there is another way of looking at the facts-namely, by inquiring into the evolution of the sieves.

The oldest of sieves is the quest for food; the living engine must be stoked if it is to continue working. In the case of radium the clock is persistently running down; the overcrowded atom disintegrates slowly into lead, and there is no winding up in the inorganic world as we know it. But it is characteristic of the vital Proteus that it can feed and recuperate itself for the losses of energy implied in all activity. This is the primordial question that Nature asks of her living children: "Can you feed yourself?" That is the first test- the pursuit of food, often under diffi- 
culties, often in desert places, often in circumstances where only a chemical genius could find nutriment. We understand why there should be perhaps ten distinct modes of nutrition, why the quest for food should illustrate great ingenuity of device, why in the same Galápagos Island one lizard has learned to eat seaweeds while its first cousin has learned to feed on spiny cactuses. We understand why an animal with many alternatives on its bill of fare has always an advantage over one that is a specialist in diet.

The second great sieve is the physical environment, which is very diverse in different places and at different seasons. The organism has to face peculiarities of temperature, illumination, pressure, humidity, composition of the medium, and so on. We have only to think of habitats so diverse as the lofty mountains and the abysses of the sea, the sun-baked desert and the subterranean river, the icy margin of the Antarctic Continent and inside the food-canal of an animal, to realize the variety of the meshes in the environmental sieves. One must think of the periodic siftings of winter and summer, of the recurrent Ice Ages when the meshes were very small, and of the change of sieve-pattern from one geological period to another. What a change there would be, for instance, when grass began to cover the earth with a garment!

A third sieve is the animate environment-the competitors, the neighbors, the partners, the parasites. This must be thought of as ever-new; it is an evolving sieve. A new enemy may be as testing as a new habitat. 
Flora and fauna are sieves to one another, and both show continually changing patterns. Perhaps we should recognize a special kind of sieve where there is something in the way of gregarious or social life, for the members are sifted according to their capacity for "give and take" and for "playing the game." Moreover, under the shelter of society there is a possibility of new departures which would be speedily eliminated by the sieves which apply to ordinary, more or less individualistic, life. At different levels of animal society there will be a different pattern of sieve.

Perhaps this is the place for special recognition of the sieve of courtship, to which Darwin attached so much importance. We refer not so much to cases where rival males fight with one another, like the stags in the forest glade; we are thinking more of the indubitable cases where the female animal holds the sieve and exhibits something like choice. Here again the meshes evolve, becoming finer and finer as æsthetic and other psychical considerations begin to tell. In preferential mating there is certainly an evolving sieve.

It is not necessary to give more illustrations, for we have said enough to suggest the complexity of Nature's sifting and what seems to us the very important idea that there has been in the course of ages an evolution of sieves as well as an evolution of the material to be sifted. Sometimes, no doubt, the width of the mesh has been increased, not decreased, and the result has been the survival of flabby and degenerate 


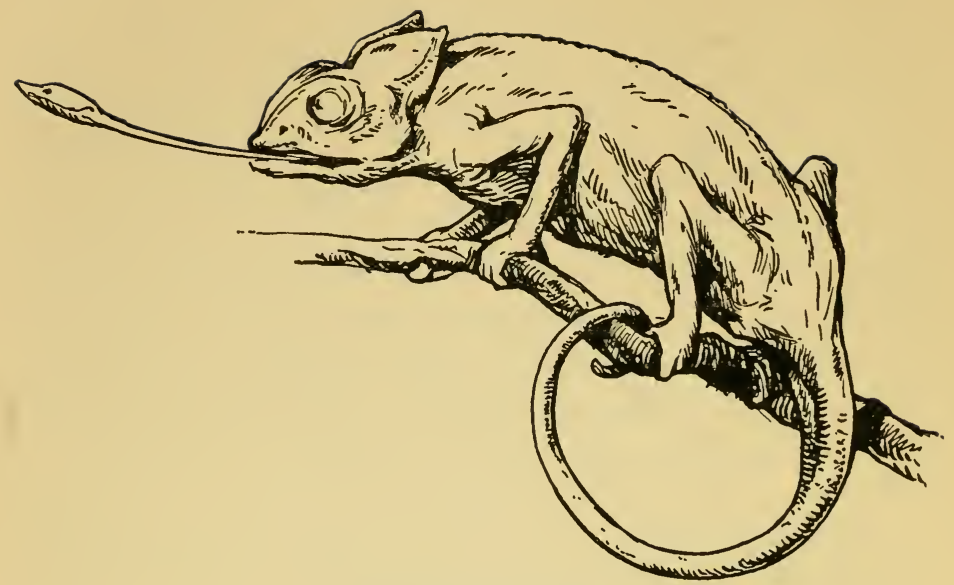

FIGURE NO. 21

\section{A CHAMÆLEON ON A BRANCH}

Chamæleons (Chamaleo) are lizards specialized for arboreal life. Many structures in the body are particularly well suited for the conditions of the chamæleon's life. This is a case where we may well say that the animal is a bundle of fitnesses or adaptations. Thus the tail is prehensile, and moves in an unusual way,dorso-ventrally, so that it can be readily coiled round the branch. The hands and feet are split in halves, the better to grip the support. The tongue is unusually long, and can be shot out from a distance on the insect booty. The color changes rapidly and is often a concealment; though the changes are also expressive of varying moods. There are many other adaptations. 
creatures-a parable for man's instruction. Somewhat different from the environmental sieve in general is that which is furnished by the inter-relations established between living creatures in the web of life. The system of linkages tends to become more and more intricate from age to age; it is often subtle enough to discriminate between Shibboleth and Sibboleth; it is stable enough, as in the inter-dependence of flowers and their insect visitors, to serve as an external security for progress. Along this line is Man's great opportunity.

\section{RECENT CRITICISM}

We do not share the view, often expressed in recent years, that Darwin's theory of Natural Selection has become outworn. If mutations have been common throughout the evolution-process, if a new position of organic stability has often been reached suddenly, if the Proteus has frequently been leaping as well as creeping, then the burden that the theory of Natural Selection has had to bear will be less than Darwin believed; but even De Vries, one of the founders of the "Mutation-Theory," declares that sifting must still be regarded as essential. "The origin of new species, which is in part the effect of mutability, is, however, due mainly to natural selection. Mutability provides the new characters and new elementary species. Natural selection, on the other hand, decides what is to live and what is to die." (Seward's Darwin and Modern Science, Cambridge, 1909, p. 1\%\%.)

Critics of Darwinism have in recent years made 
much of the fact that selection fails to effect progress in a "pure-line" - the inbred descendants of a single individual. Thus Johannsen has shown that if the descendants of an individual high-class bean are kept apart, no amount of selection will get beyond the mean of the line. There are, indeed, "fluctuations," such as tall plants and short plants, but if the talls are selected out and bred from, there is no establishment of a tall race. There is nothing to choose between the descendants of the talls and the descendants of the shorts. The reason for this is probably that the "fluctuations" in question within the pure and inbred line are "modifications" or individual indents, and not transmissible. There is no use trying to select from non-heritable characters.

But, apart from this, there are reasons why we should not allow these pure-line experiments to hurry us into a depreciation of the rôle of selection in natural wild conditions. Pure lines are not typical of wild stocks, in which cross-fertilization is frequent; it is dangerous to argue from brief experiments to the age-long processes of Nature; it is premature to deny the possibility of heritable variations or mutations occurring in a pure or inbred line. If one did occur, it might be the starting-point of a new advance. We have taken two modern criticisms of the selectionist position, and shown that they are not leading us to depart from an evolving Darwinism. The same might be done all along the line, and we do not believe that growing knowledge will lead to a depreciation of the rôle of Nature's sifting. 
The fact is, we are returning to an appreciation of the subtlety of Darwin's concept of selection. It is not one process, but many-lethal and reproductive, for instance; it operates in relation to an intricate web of life, and a Shibboleth may have survival value; there has been an evolution of sieves as well as of the material to be sifted. As we have seen, the struggle for existence, in the course of which selection occurs, includes not only competitive but symbiotic, not only egoistic but altruistic reactions, and both pay!

\section{§16. As Regards Heredity.}

IN two books recently published on evolution we find two extraordinarily divergent statements in regard to heredity. In one of them Professor Lotsy says : "Of heredity we know nothing." In the other, Professor 'T. H. Morgan says: "The problem of heredity may be said to be solved." What is the meaning of this discrepancy? Mainly this: that the first writer was trying to think of the almost unthinkable way in which all the manifoldness of a well-endowed creature is somehow telescoped-down into a microscopic implicit individuality - the germ-cell. An egg-cell is considered large if it is the size of a pin's head; a sperm-cell is often only $\frac{1}{100000}$ of the size of the eggcell. Darwin spoke of the brain of the ant as the most marvellous atom of matter in the world, but the eggcell of the ant is more wonderful still. For it implies the whole ant, brain included. We cannot picture to ourselves either the impliciting or the expliciting of 
the inheritance. What then did Professor T. $\mathbf{H}$. Morgan mean by saying that the problem of heredity has been solved? He meant, we take it, two things: (1) that the embryological discovery of the continuity of the germ-plasm, which is mainly due to the work of Weismann, has explained the fact that like tends to beget like; and (2) that the discovery of the behavior of the chromosomes-which carry the factors for many, at least, of the hereditary characters-has enabled us to understand the precise way in which certain characters of the parents are distributed among the offspring.

As is well known, the rediscovery and development of Mendel's work has made a change in the study of heredity so radical that it must be called a metamorphosis. It has been shown that many organisms consist, in part at least, of a great bundle of "unit characters" which behave in inheritance as if they were indivisible entities. They do not blend or intergrade; they are present in a certain proportion of the descendants; typically, they are either there in their entirety, or quite absent. But they may be in some degree masked in their developmental expression by other characters or by environmental conditions. Their germinal representatives in the chromosomes are called "factors," "determiners," or "genes," as we have mentioned; and one factor may affect several adult characters, while one adult character may be the outcome of several factors. It seems, for instance, that there are eight "factors" coöperating to produce the normal coloration of a wild rabbit's fur. As has 
been already implied, we do not know how a new factor comes to be, but we know a good deal about the-"sorting-out" of factors once they are there. The reality of "factors" is but little affected by their invisibility. There is no doubt as to the reality of the unseen virus of some diseases.

"Unit-characters" may be illustrated by eye-color (which never seems to blend), by night-blindness (which has persisted in the Nougaret lineage since Charles I was King), by the Hapsburg lip (in the royal houses of Austria and Spain), and by brachydactylism (having fingers all thumbs). To illustrate the heterogeneity, we may continue the list among plants and animals. It includes hornlessness in cattle, crests in poultry, Angora hair in rabbits, albinism and waltzing in mice, pink eye in fruit-flies, yellow seeds in peas, immunity to rust in wheat, six-rowed ears in barley, serrated margins in nettle leaves, besides subtle features like early ripening in cereals or broodiness in poultry. All these peculiarities illustrate Mendelian inheritance.

It is still an open question whether Mendelian inheritance is the universal mode, or whether the divergent characters of the parents may sometimes blend in the offspring so that intergrades result. There are cases which suggest this, but it must be recognized that an apparent "blending" may come about when an adult character depends on numerous factors. If some of the factors come from the mother and others from the father an appearance of blending may result. Another question, not to be closed as 
yet, is whether some of the more ancient and stable items in an inheritance may not have their vehicle in the cytoplasm of the germ-cells, for this would not be inconsistent with the proved fact that the genes of the more variable characters are carried by the chromosomes.

It is probable that the progress of biology will lead to a more generous appreciation of the evolutionary importance of nurture. Of its individual importance there is no doubt, for the degree to which factors in the natural inheritance find expression depends on the appropriateness of the nurtural conditionswhether of surroundings, food, or function. The wan and blind Proteus of the Dalmatian caves has the hereditary capacity of developing pigment, but it will not do so if it remains in the darkness which is now its normal environment. If it is brought into the light it soon darkens; if it is reared from its youth in the light, its eyes will be less degenerate than they are in the caves. In young forms reared in red light, the eyes may become seeing eyes. Numerous experiments justify a growing appreciation of the importance of nurtural conditions in individual development. A character is a function of nature and nurture. But there is still very little evidence to warrant belief in the transmissibility of an individually acquired "modification" as such or in any representative degree. Goldfishes kept in complete darkness for three years become blind, the retina undergoing serious degeneration. This is an instance of a somatic modification following directly on a peculiarity of nurture, 
and a hundred other examples could be given. But what we do not know is that the induced blindness of the-goldfishes has any effect on their offspring reared from eggs developed in the light. And it is at present illegitimate to say, except as a working hypothesis, that the blindness of certain cave fishes and salamanders is due to generations of darkness and disuse of eyes. Yet our impression is that increase of knowledge will lead us to discover that the experience of the individual may count as a factor in evolution by some entailment on the offspring. In other words, we are unwilling to foreclose the question as to possible transmission of at least some specific representation of an individually acquired modification. It is admitted by all that the individual experience may give the individual opportunities to play its new hereditary cards. But is there nothing more?

\section{§17. Habits and the Possible Entailment of Their Results.}

From everyday experience and from convincing experiments it is certain that the organism, especially when young, is modified by peculiarities of "nurture" -habitudinal, nutritional, and environmental. It runs the gauntlet of a successsion of influences which produce "dints" or "modifications." A modification may be defined as a bodily change induced in the individual's lifetime as the direct result of some peculiarity in habits, nutrition, and environment, and so transcending the limits of organic elasticity that it persists after the inducing conditions have 
ceased to operate. In illustration may be mentioned the tanning of the skin during many years of life in the tropics, the hardening of the skin under the influence of prolonged pressure, the alteration of the wall of the gull's stomach in consequence of a change of diet, the enlargement of a muscle in the course of exercise, the increase in the length and thickness of the fur in a cold climate, the fattening of a prize bullock or Strassburg goose, the acquisition of a rapidly working coördination as the reward of much practice.

The problem known by the unhappy phrase "the inheritance of acquired characters" may be stated thus: Can a structural change in the body, induced by some change in use or disuse, or by a change in surrounding influences, affect the germ-cells in such a specific or representative way that the offspring will, through its inheritance, exhibit, even in a slight degree, the modification which the parent acquired? Evidence leading to an affirmative answer would mean a retention of some form of the Lamarckian theory of evolution. But if there is no convincing evidence, then the raw materials of possible evolution are restricted to germinal variations which arise more or less spontaneously; endogenous, not exogenous; "blastogenic," as Weismann said, not somatogenic; outcomes rather than indents; expressions rather than impressions.

This is a question of far-reaching importance, and our answer must affect not only our theory of evolution, but our conclusions in regard to the possibilities 
of improving the human race. It therefore demands very careful consideration. (1) No doubt advantageous modifications are always useful for the individual who acquires them, and conversely. (2) These useful modifications can be hammered on to each successive generation. (3) They may perhaps serve as a protective screen until, happily, similar germinal variations may arise from within. (4) They may have indirect effects on the health of the organism, so that the general vigor of the germ-cells is improved, though there is not any entailment of a particular feature. (5) In cases like mammals and seed-bearing plants, where there is prolonged and close physiological connection between the parent and the offspring, before birth in the one case and seed-scattering in the other, it is possible for advantageous changes in the parent to saturate into the offspring. Thus there are some instances of the offspring sharing in a specific immunity acquired by the mother.

From the transmission of a particular modification or even some slight representation of it, we must distinguish changes produced in the germ-cells along with changes in the body. Alcoholism in males through successive generations may result in a deterioration of offspring, but this probably means that the germcells are poisoned as well as the body-cells. This is not a case of the transmission of an acquired character; it is rather what Weismann called "parallel induction." Modifications induced by $\mathrm{X}$-rays, radium, poisons, serum-treatment, and so on may be asso- 
ciated with the appearance of other peculiarities in the offspring, but this probably means that the agent that effected change in the body was also able at the same time to effect an independent change in the germ-cells. In short, the direct action of modifying agents on the germ-cells along with the body, is one thing, and the specific enregistration in the germcells of somatic modifications from the body, is another thing - as yet not demonstrated to the satisfaction of all critics.

Furthermore, deeply saturating modifications may influence the blood and other fluids of the body, or may alter the rhythm of metabolism so that the production of internal secretions is affected, and these internal changes in the somatic environment may act as liberating stimuli on the germ-plasm and provoke variations. Prolonged exercise-e.g., in dancingmay lead to an exaggerated production of muscleforming substance; the tendency to myogenic metabolism may spread to other parts of the body, as it often does; the influence may saturate through the body, and it is conceivable that it may eventually affect the germ-cells in a way so specific that there is increased muscular development of the offspring.

It must be clearly understood that, while it is very easy to give an account of certain steps in evolution on the Lamarckian assumption that functional and environmental modifications may be in some degree entailed on the offspring, the possibility of giving this account does not prove that the Lamarckian theory is valid. 
After careful consideration of all the evidence that we have been able to find, we personally remain unconvinced that there is at present any satisfactory instance of the transmission of a particular modification even in a representative degree. But others have come to a different conclusion, and, as we cannot prove a negative, we think that the Lamarckian door should be kept open. We wish to call attention to a few cases which suggest the desirability of keeping an open mind.

\section{HABIT FORMING}

The word "habits" is often used to include all the ways or behavior of animals, as when we speak of the habits of monkeys, or the habits of rooks, or the habits of spiders. But this usage is too wide to be profitable. For many of these "habits" are the expression of inborn ready-made aptitudes, such as those which are called instinctive; others, especially in the big-brained animals, are expressions of genuine intelligence which controls every step; and others are the result of individual habituation in the performance of an oft-repeated routine, for which, however, there was no precise hereditary pre-arrangement of nerve-cells and muscle-cells.

Miss Cunningham tells the following story of the young gorilla whose kind teacher she was. One day when a piece of fillet-beef came in from the butcher's, she cut off a tiny, rough piece and offered it to "John." He gravely handed it back, and gently taking her hand pressed it against a soft, juicy piece. 
This action, which there was no resisting, illustrates genuine intelligence. When another ape was given a difficult hammer with one end of the head very rounded, he felt the two ends carefully and then proceeded to use the flatter one for driving in the nails. This, again, was genuine intelligence.

When a spider constructs a beautiful web, true to the type of its species, the very first time it tries, that is one of its "habits" in the loose sense; but it is an expression of an inborn hereditary or instinctive capacity. The spider's deftness may increase with practice, but it is clear that this spinner and weaver does not learn its trade any more than we learn to sneeze. Both kinds of activity depend physiologically on preëstablished linkages of certain nerve-cells and certain muscle-cells, but the pre-arrangements (badly called mechanisms) involved in the spider's web-making are more complicated than those involved in our sneezing or coughing or any other reflex action. And besides the physiological prearrangements, there is, in the more complicated cases, a psychological side-a certain degree of awareness and a bent bow of endeavor or desire. But instincts are not habits.

We usually mean by a habit a chain of actions which follow one another in an easy sequence as the result of much individual repetition. A habit is the outcome of habituation! And we mean by habituation the engrained facility which comes from frequent individual repetition. The facility with which we wrote down the word "repetition" without even look- 
ing at our paper illustrates a habit. The ease with which the pianist plays a piece, the learning of which cost so much detailed attention and control, illustrates habituation. A habit is an individually acquired capacity for giving a certain answer without hesitation, or for pursuing a chain of actions without needing to attend to or control each step. It always implies some degree of automatization. The clever shunting-horse steps off the line at the appropriate moment and lets the truck it was pulling sweep past. It is said that some van-horses have continued to go their rounds quite effectively even after they became blind.

A habit is well illustrated by trained animals which learn to go through a performance or through a routine of work. In the course of time their activity becomes more and more facile- $\mathbf{a}$ habit has been established. We read of a famous performing chimpanzee that when at his best he went through a series of fifty-six separate acts without hesitation or mistake, and without visible direction. Even if there was some direction which the audience did not detect, and even if we allow for some degree of intelligent control on the performer's part, we are safe in concluding that the key to a considerable part of the remarkable exhibition was habit.

It is a pity that the word "habit" has been badly over-used. We speak of a mistaken habit of thought, of the apprentice's industrious habits, of the habit of getting up early (even when it does not become any easier), of the habit of cigarette-smoking, and so on. 
But it is plain that the word should not be used to describe consistency or ethical conduct or a methodical way of living. It is very doubtful whether it is profitably used in reference to a pathological state of affairs when an artificial "urge" or craving has been established in the body. The system calls out for the physiological satisfaction afforded by the frequent repetition of a stimulus or a sedative, such as a glass or a pipe or an injection. But this is not in the strict sense a habit.

When the tide is low hermit-crabs persistently avoid the light; when it is high they make for it. This periodic alternation has been engrained in the constitution of the creature, for it will be exhibited for about three weeks in an aquarium where there is no tide. Similarly the well-known green worm, Convoluta, common on the Roscoff beach, comes up when the tide goes down, and retires into the sand when the splash of the incoming tide is near; and it will continue for some days exhibiting this alternation in a tideless aquarium. A physiological periodicity has been established in the body, which lasts even when the accustomed stimuli are absent. This is verging on the habitual, but some term like "periodic rhythm" is probably more useful. It is well known that a man or a domesticated animal may be miserable because of some interruption of the accustomed periodicity of three meals a day. Yet many a man, with a different periodicity, is happy with two meals, and many a well-trained dog with only one.

In an ordinary act in any of the higher animals 
the physiological sequence is always in essentials the same, involving (1) sensory, receptor, or afferent nerve-cells (the scouts), (2) associative or internuncial nerve-cells (general headquarters), motor or efferent nerve-cells (the executive officers), and (4) muscle-cells that do the work (the "common soldiers"). If we are humble enough to use the metaphor we cannot be foggy in regard to the general sequence of participants: (1) Scouts, (2) G.H.Q., (3) Executive Officers, and (4) Men; but it need hardly be said that in a given operation there may be many representatives of each of the four kinds of participants. In ordinary reflex actions the linkage is preëstablished, it is part of the hereditary makeup. In learning a new game of skill or a new piece of work we have to establish the linkage by eliminating errors and by frequent repetition. A line of least resistance is established; the message comes to travel along one particular line rather than along any other; and various improvements may be effected, such as not troubling more than subordinate members of the general headquarters. But all but the very simplest instances of behavior involve a sequence or simultaneity of actions, each with its four links. Thus (I) S-A-M-E (sensory, associative, motor, effector) leads on to or is associated with (II) s-a-m-e, and this leads on to or is associated with (III) $s-a-m-e$, and so forth. What habituation does is to make it easy for II to follow or conjoin with I, and for III to follow or conjoin with II, and so on. In some manner that is still very obscure, even on its physiological side, II 
is linked to I, and III to II, and IV to III, so that one follows or accompanies the other with great facility. As they say, "paths of low resistance" are established in the nervous system. The linkage becomes stronger in proportion to the number of repetitions, plus in many cases the influence of certain psychological factors, such as the pleasure of success and the determination to succeed. The path becomes more beaten the more it is trodden. Habituation means the making of paths, the forging of linkages.

There are habits and habits, differing in complexity and in origin. There are simple one-act habits in which the creature learns to associate a particular signal with a particular experience and acts accordingly with ever-increasing facility. At the sound of a particular bell the cat darts upstairs to a room where it is fed; but that is simpler than what we see when a well-instructed dog obeys the command to go to a certain room and fetch its master's slippers or newspaper or walking-stick. After a few lessons a frog learns to avoid disagreeable objects, such as hairy caterpillars or doped worms; and the habit lasts for a week or more. Habits that are in a line with the creature's everyday behavior are most quickly learned, but the acquisition of very artificial habits is quite common. Triplett divided an aquarium into two with a glass screen, and placed minnows in the one compartment and two perch in the other. For a month the perch continued butting their beads against the glass in obeying the impulse to seize the 
minnows, but they learned to avoid this. Even when a minnow was placed in their own compartment the habit of inhibition continued. Yet when worms were dangled in the other compartment the perch bumped their heads as before. For their habit of inhibition was formed in regard to minnows, not in regard to worms.

More worthy of the name of habits, however, are those which involve a chain of many links. In a few days an elephant in a zoo learned to receive a penny from a visitor's hand, open the lid of a cash-box on a shelf, deposit the coin, shut the box, and ring a bell. In another well-known case it took a different elephant longer to learn to accept a penny (rejecting halfpennies), put it into the slot of an automatic machine, and receive delivery of a biscuit, which was its reward. As there was a directly associated pleasure in this habit it should have taken the elephant a shorter time to learn it, but elephants vary in educability, and there was a snag in the possibility of the coin being a halfpenny. It is unnecessary, however, to suppose that the elephant understood that only pennies would work the automatic biscuit machine. But among the best examples of habits with diverse acts in a chain are those afforded by maze experiments. It is well known that monkeys, white rats, squirrels, and the sparrow can master a maze of the Hampton Court pattern, which sometimes puzzles human beings. After a sufficient number of lessons the animals referred to get quickly into the center of the maze and out again without making any mistakes. 
Many other animals can master simpler labyrinths and can retain their mastery for a month or more without further practice. It has been proved that a rat can master a labyrinth without any cues from sight, smell, or touch; but in ordinary cases various sensory hints, especially those of touch, seem to be of great importance in the establishment of the habit. What eventually happens, however, when the habit is perfect and the creature moves rapidly through the passages, is that the guiding cues derived from outside (through "extero-ceptors") are replaced by guiding cues from inside (through "proprio-ceptors"). That is to say, the linkages are kept right by hints from the muscles, tendons, and blood-vessels. A habit has taken a firm grip when cues from within replace cues from without.

Habits may be graded in other ways, and most important of all, were it not so difficult, is a classification from the psychological side. There are some habits, say the elephant's routine in putting the penny into the cash-box, which owe their establishment to mere repetition. But in many cases the animal recognizes some measure of significance in the sequence of events, and this recognition, say of rewards and punishments, helps the habit-forming. In many cases, also, as when an animal learns to do a certain thing on hearing a certain sound, there is associationmemory, and in other cases, perhaps, higher forms of memory. When the first links in a habituationchain have been activated, it is easy for other links to follow, and in this sense there is a certain inertia in 


\section{Habituation among Wild Animals 161}

habit, to which people sometimes refer when they speak of the force of habit. But it is very improbable that a habit (unless pathological) has in itself any motive power or "drive"; it is but the instrument of some appetite or urge, some appetency or purpose.

Keeping habits (in the strict sense) separate from instinctive routine on the one hand and controlled intelligent behavior on the other, some authorities have held that habituation does not count for much in the everyday life of wild animals. Our impression is different. For we think that among birds and mammals there is often in the individual lifetime a habituation of activities which were learned either by the help of parental tuition or by serving an apprenticeship in the school of trial and error, testing all things and holding fast that which is good. We refer especially to chains of actions exhibited in locomotion, food-capture, construction, and the like, some of which, intelligently learned, look as if they became habitual. But the question whether an individual habituation in the present may become a racial instinct in the distant future, leads us now to some interesting experiments, which deserve careful consideration.

\section{ALCOHOLIZED RATS}

Many experiments have been made in America in the way of treating animals like rats and guinea-pigs with alcohol. The object has been to discover how far subsequent generations were affected by the alcoholic habits of their parents or ancestors. It cannot be 
said that the results are as yet altogether in agreement, but they are very interesting and sometimes surprising. We wish to refer to a few.

In the early stages of the experiments, some of which have been continued for a dozen years, the mistake was made of giving the animals alcohol along with their food or drink. The effect on the treated individuals was very bad and their progeny were also deteriorated. It soon became plain, however, that the experiment was hopelessly complicated by the digestive disturbances that set in, which wrecked the health of the animals and influenced the vigor of their progeny. It is true that the digestive disturbances were due to the alcohol, but the point of the experiment was too blunt. It did not discriminate between the intoxicating and the dyspeptic influences.

Thus there arose the method of administering the alcohol by inhalation. The food and drink were left uncontaminated, but the animals were subjected several times a day to fumes of alcohol which rose through the floor of their cage. They inhaled the fumes in breathing, and though they became intoxicated, they did not become dyspeptic. In some cases, indeed, they did not seem a whit the worse for their daily doses.

Yet the remarkable result became evident that, while the treated guinea-pigs showed no injury to their health, or impairment of their vigor, or shortening of their life, their offspring were distinctly different from those of individuals that had not been treated. And the differences (to be afterwards re- 
ferred to) were in the direction of inferiority in the case of guinea-pigs. Here we face an interesting fact, that while no deleterious effect on body or life was discernible in the treated parents, such an effect was clearly observable in their untreated offspring.

But the complexity of the problem grows when we pass from Professor Charles R. Stockard's treated guinea-pigs to Professor Raymond Pearl's treated fowls. For it was found that after alcohol treatment the fowls produced offspring which were superior in a marked degree to those produced by non-treated controls. Professor Pearl accounts for this by the ingenious theory that the alcoholic treatment killed off or eliminated all the inferior germ-cells in the fowls, leaving the coast clear for the superior ones to produce the next generation. That there actually is this process of germinal selection or germ-cell sifting seems to have been proved by the investigations of Dr. Danforth.

Experiments on rats conducted for half a dozen years by Dr. MacDowell did not reveal any appreciable structural damage as the result of the alcoholic treatment, but they yielded a result of high interest -namely, a reduction in the capacity for learning in the treated generation, and a persistence of this effect to the next generation, even when the animals were kept strictly "dry." The capacity for learning to do certain things, such as getting out of a maze, can be tested quantitatively, and the figures show that it is not improved by sniffing alcohol.

Some interesting experiments on white rats are 
recorded by Dr. F. B. Hansom. He made them inhale alcohol fumes in an air-tight tank, and he kept careful watch on four generations. Brother and sister "controls" were started, they and their descendants were reared in normal conditions, and precautions were taken to exclude every difference except that the one set breathed normally while the other set inhaled alcohol. The members of the first generation were treated for a whole year from the age of sixteen days, which covers the period of the rat's most rapid growth. Measurements of weight and length were taken every ten days, and the treated were compared with the "controls." There was no observable difference. Hence it cannot be said that the narcotic influence of the alcoholic inhalations had any effect on the growth of the rats. Similarly the treated offspring of the treated parents were indistinguishable from their first cousins, the untreated offspring of the untreated parents!

In the third generation, however, a difference showed itself. At an age of twenty days, prior to the first treatment, the members of the treated lineage showed themselves inferior, in body weight, body length, and tail length, when compared with their counterparts on the untreated line. When treatment began the difference increased, as if the animals were responding to the alcohol with a new susceptibility. It reached a maximum of nearly ten times the probable error. The natural inference at this stage would have been that the previous generations of alcoholism were telling, and that, as the effects were observable before 
treatment began, there was definite inheritance. At this point, however, we must learn once more the scientific lesson of caution, for in the fourth generation there was a marked improvement! "The treated side of this generation for the first half of its growth curve is back in the fold with the first two generations. Later there is some response to the treatment and a consequent dropping off in the curve." This is a remarkable result. It suggests that some process of germinal selection was at work, an alcoholic elimination of the inferior germ-cells. It also suggests caution.

Very careful experiments have been made on guinea-pigs by Professor Charles R. Stockard. They have been continued for thirteen years, and more than a hundred animals have been treated with fumes of alcohol to the point of intoxication for six days per week for various lengths of time. Several have been treated for six years-a long life for a guinea-pigand some have lived to be seven years old, which seems to be a record. This shows that the individual guinea-pigs were none the worse as far as length of life is concerned. On the other hand, the deteriorative influence on immediate offspring and on later descendants was well marked up to a certain point. The deterioration was shown in weakness, short life, and arrest of development, but there was no evidence of the transmission of any particular character. There can be little doubt that the alcohol, saturating through the body of the parent, poisoned the germcells along with the body, and affected the constitu- 
tion of the offspring in a general rather than in a specific way. The prejudicial influence may come from treated father or from treated mother, but, as one would expect, it is most marked when it operates through the mother. But in Professor Stockard's experiments, as in some others, the remarkable fact emerges that after three generations of treating, there is a marked improvement. The members of the fourth filial generation of alcoholics were actually superior in vitality to the controls! This striking result may be due to the elimination of the weaklings and defectives, and this may operate not on the individuals only but on the germ-cells as well. The same kind of elimination has probably occurred in many races of mankind.

\section{RATS ON A ROUNDABOUT}

When the distinguished Russian physiologist, Professor Pavlov, was in this country a short time ago one of the many interesting things he alluded to was his experiment with white mice. He trained a lot of them to run to their feeding-place when he rang a bell. Three hundred lessons were needed before the association was established. But in the second generation only one hundred lessons were required, in the third only thirty, in the fourth only five. If this is a correct report, the result of Pavlov's experiment is very interesting, for it suggests the hereditary entailment of a somewhat subtle "acquired character." In the course of the lessons a neuro-muscular associative linkage was established between bell and food; in the fourth 
generation the aptitude to association-forming had been so much increased that five lessons were enough. Perhaps future generations will answer the bell without any lessons at all. But apart from this possible climax the experiments suggest that individual experience may have a specific and representative influence on the race. We refrain, however, from basing any conclusion on Pavlov's experiment until we have before us a full account of the circumstances and a precise statement of the numbers. It may be noted, however, that recent experiments on white rats by Dr. E. C. MacDowell led emphatically to the conclusion that offspring of trained parents or of trained grandparents as well, take as long to learn the secret of a maze as did those that were first trained.

We wish, however, to refer to some other experiments on this important question-whether individually acquired bodily modifications can be transmitted to the progeny in a specific and representative fashion. It will be understood, of course, that the rather unfortunate term "acquired character" has a perfectly definite meaning, and that it is not open to any "argufier" to use it in some other way. An acquired character is "an exogenous somatic modification"-a bodily change directly induced in the individual lifetime by some peculiarity or novelty in environment, nutrition, or function, and so transcending the limit of organic elasticity that it persists after the inducing conditions have ceased to operate.

Two psychologists in Philadelphia, Dr. Bentley and Dr. Griffith, made the experiment of rotating 
rats for a long time in circular cages revolving at speeds of 60-120 revolutions per minute, some in a clockwise and some in a counter-clockwise direction. The animals tried at first to adjust themselves, as we do on a so-called "merry-go-round" or to the rolling of the ship at the beginning of a voyage. Eventually, however, they became accustomed to their turn-table world, and would eat, and sleep, and play, just as we do on the rotating and revolving earth. Some of them endured from six million to eighty million rotations, which, put into terms of time, means from two to eighteen months. They suffered from it, however, for when they were liberated they exhibited long-continued readjustments to a more prosaic environment, just as we do when we leave the rolling ship or the garish roundabout. Some of them showed serious locomotor disorders, and fell into a decline and died. Others pulled themselves together, and appeared normal, yet after some months showed disturbed locomotion and eye-movements, which differed, it is interesting to note, according to the direction of rotation, whether clockwise or counter-clockwise. Some of these disturbed individuals were allowed to mate with one another or with normal stock, and the results were rather startling.

Dr. Griffith found that rats with a long history of roundabout rotation in their lineage showed among their descendants a high proportion of "disequilibrated" individuals, although these were brought up in a normal way. Moreover, the type of disequilibration exhibited by these descendants corre- 
sponded precisely to the type induced by clockwise or by counter-clockwise rotation in the ancestors.

Evidently this is an important contribution to the question whether a modificational change can affect the progeny in a specific and representative way. We must remember Herbert Spencer's emphatic declaration: "A right answer to the question whether acquired characters are or are not inherited underlies right beliefs, not only in biology and psychology, but also in education, ethics, and politics." For some years the trend of opinion among zoölogists has been on the whole in favor of a negative answer, but the results of the experiments we have referred to point towards the affirmative. In such cases the proper course is to repeat the experiments, and that has been done by Dr. J. A. Detlefsen in his laboratory in the Wistar Institute in Philadelphia, where the psychologists had also worked.

What Dr. Detlefsen has to say is already sufficient to suggest the need for great caution. It had been noted that there was much mortality associated with the previous experiments, and also a frequent occurrence of serious ear troubles. It is suggested by Dr. Detlefsen that the abnormal rotation injured the labyrinth of the ear and made it susceptible to microbic invasion. There might be an inflammation of the labyrinth due to a pathogenic microbe, and this might be passed on to the progeny by direct contact. Moreover, less resistant offspring might be expected from seriously infected parents. Dr. Detlefsen obtained twenty rats suffering from "spontaneous" 
labyrinthine disturbance, which had arisen apart from any rotation. He found that they answered back to tests much in the same way as the descendants of Dr. Griffith's rotated rats. The tests brought out two types of head and eye movement, corresponding to those exhibited by the descendants of clockwise and counter-clockwise rotated rats in the psychologists' experiments. Thus the possibility is that the rotation of the rats had induced numerous cases of inflammation of the ear; and that there were many cases of discharges from the ear is admitted. It might therefore be that what was exhibited in the offspring was due to an infection and not to the transmission of an acquired character in the strict sense. For no one who thinks precisely can suppose that the reappearance of the same microbic condition in successive generations is in itself a phenomenon of inheritance. Dr. Detlefsen does not say that he can explain all that the previous experimenters observed, but he has indicated a probable fallacy, and he is continuing his experiments. In regard to a matter so important as this there must be no hurry.

There are several other fresh experiments somewhat similar to those just indicated, and they suggest the desirability of keeping an open mind. Darwin was uncommonly shrewd, and it should be remembered that while he had his own theory of the indirect origin of adaptive changes, he did not abandon the Lamarckian theory that the direct effects of use and disuse might be transmitted. He attached secondary importance to the Lamarckian view, but he did not 
refuse its aid. In his Variation of Animals and Plants under Domestication he contrasts, for instance, the skeletons of wild and domestic ducks, and explains the relatively smaller size of the bones of the wing in the domesticated forms as due to the fact that they have been reared for generations during which the wings have been used little, if at all. Whether Darwin's retention of the Lamarckian view is an illustration of prescience or of acquiescence remains doubtful, and we shall have one reason to be grateful to rats if they assist in answering this question.

\section{EXPERIMENTS ON LENSES}

Very remarkable experiments have been made by Professor M. F. Guyer and E. A. Smith on the eyes of rabbits. Lens tissue from rabbits was pulped, made into an extract, and injected into fowls. It excited in the blood of the fowl the production of specific "anti-bodies"-that is to say, chemical counteractives to the deleterious intruded material. Now, if the serum of the fowl's blood be injected into pregnant rabbits, the contained anti-bodies sometimes attack the lenses of the unborn young and produce serious deterioration. But the injurious effects on the lens were also observed in very pronounced form in a second generation of rabbits which had not been subjected to any interference. The eye defects may be transmitted for several generations, by males as well as by females; and the defects may even increase in amount. The explanation may be that the deterioration or degeneration of the eyes of the first 
generation of young rabbits (the offspring of those that had received injections) had the effect of inducing the formation of anti-bodies in their blood, which in turn had a specific effect on their germ-cells, especially on the "factors" concerned in lens development. This repercussion may go on generation after generation. The experimenters have also brought forward evidence that suggests that there may be an entailment of an acquired immunity to typhoid bacilli.

\section{HORMONES AND HEREDITY}

One of the most far-reaching of modern discoveries in physiology concerns the rôle of the ductless or endocrine glands, such as the thyroid gland and the supra-renal body, in the body of Vertebrates. They produce stimulating hormones and quieting chalones which are distributed throughout the body and exert specific influences on particular parts. The chemical messengers thus sent forth exert a regulative action on the functions of the body, securing their orchestration. If the activity of the thyroid gland is perturbed there may be a serious loss of bodily and mental health, which can be counteracted for the time being by utilizing in diet or injection the thyroid glands of sheep and calf. A substance called "secretin," discovered in 1902 by Professors Bayliss and Starling, is produced in the presence of acid by the cells lining the beginning of the small intestine; it is carried away by the blood-stream, and the particular lock for which it is the key is the pancreas or 
sweetbread. It excites this gland to secrete its very important digestive juice, which is poured into the food-canal. Thus, when a meal is in process, or it may be in pleasant prospect, there is by means of the hormone secretion a preparation for its digestion. This illustrates what is meant by physiological coordination or correlation, for it is plain that the beginning of the intestine and the pancreas work into one another's hands.

Of great interest are the hormones which pass from the reproductive organs throughout the body and awaken adolescent changes in many parts. The male frog's swollen first finger, the nuptial adornments of many cock-birds, the antlers of the stag, may be mentioned as familiar masculine features which are activated by the reproductive hormones. In many cases the female organism has the masculine characters lying latent, inhibited by chalones from the ovary. Thus we understand why a duck from which the ovary has been removed should put on the precise livery of the drake, and assume some of his ways as well. Not less important are the hormones which prepare the mammalian mother for the gestation and nurture of the offspring, and an interesting light is shed on the intimacy of the ante-natal partnership or symbiosis by the discovery that there is not only a passage of hormones from the mother to the unborn offspring, but a passage of useful hormones from the offspring to the mother. It is probable that there are hormones to be discovered in plants, and their discovery among backboneless animals has begun, but 
what we have said refers to the hormones of backboned animals.

There are, as we have seen, a number of experiments which must be taken seriously in connection with the transmissibility of individually acquired bodily modifications. Speaking for ourselves, we are convinced by none, but that may be due to prejudice. And why this prejudice? It is partly engendered by the difficulty of thinking out a method by which an extrinsic structural change in, let us say, the eye, or the skin, or the skull, could specifically repercuss on the germ-cells, changing them in a manner so representative that the offspring not subjected to the peculiar outside influence that played upon the parents might yet show a peculiarity similar to that which their parents acquired. Darwin suggested that "gemmules" might pass from a modified corner of the body to the germ-cells and serve as the vehicles of specific change-producing stimuli, which would have their effect when the germ-cells developed into offspring. Herbert Spencer had an analogous theory, but both remained in the air and hypothetical. More than that, they were hypotheses invented to explain what was not known to be a fact.

But in 1908 a notable step was taken by Mr. J. T. Cunningham, who published the suggestion that bodily modifications due to peculiarities of nurture might liberate specific hormones which would be carried by the blood stream to the reproductive organs, and there specifically affect the germ-cells in such a way that the offspring reproduced something 
in the nature of the parental modification. The chain would be like this: (1) An extrinsic change in surroundings, food, or habits; (2) a dint or imprint on a particular structure in the organism; (3) the liberation of specific products (of the nature of hormones), due to the modification in question, and their transport to the germ-cells; (4) a representative resultant in the offspring, due to the specific influence of the hormones on the relevant "factors" in the germ-cells. This theory, which obviously deserves careful consideration, has been made available in elaborated form in Mr. Cunningham's Heredity and Hormones (1921).

What distinguishes Mr. Cunningham's suggestion from Darwin's "provisional hypothesis of pangenesis" is that, while we know nothing about gemmules, we know a little about hormones. They are "chemical messengers," stirrers-up and soothers-down, produced in ductless glands and tissues of internal secretion. They are liberated into the blood, where they circulate like keys seeking the particular locks which they fit. Gemmules are hypothetical, but hormones are real, and the potency of those formed by such structures as the thyroid gland, the supra-renal capsule, the pituitary body, and the gonads is well known. It has been proved up to the hilt that the influence of the hormones from the male reproductive organs in birds and mammals is necessary for the actualizing of masculine characters like decorative plumage, wattles, spurs, and antlers. Similarly, the influence of the hormones from the ovary tells on the develop- 
ment of such feminine organs as the milk glands, and plays an important part in keeping latent masculine characters in abeyance. As we have seen, when the ovary is removed from a duck, she puts on the drake's plumage.

Mr. Cunningham believes that new characters in animals have arisen in one of two ways. They may be expressions of changes in the germ-cells (in the "factors" or "genes" of the nuclear chromosomes); or they may be due to bodily modifications induced by extrinsic changes in environment and function. This is the old contrast between "variations" in the strict sense and bodily "modifications," between Weismann's "blastogenic" changes and his "somatogenic" changes. It is, in easier words, the contrast between expressions and imprints, between outcomes and indents. According to Mr. Cunningham, however, all adaptive characters (structural fitnesses for particular uses and surroundings) have arisen from bodily modifications, while non-adaptive characters are due to "spontaneous" changes in the germ-cells.

According to Mr. Cunningham, "no character whose development is dependent in greater or less degree on the stimulation of some substance derived from the gonads can have originated as a mutation, because the term mutation means a new character which develops in the soma as the result of the loss or gain of some new factor or determinant in the chromosomes." But the argument in support of this important conclusion appears to us little more than assertive. There is surely no difficulty in supposing 
that a bodily character arising intrinsically in the germ plasm, and expressed as a mutation, should come secondarily under the influence of the gonadial hormones, so that it is not activated in development without that stimulus.

The antlers of stags are traced back by Mr. Cunningham to the butting habit, which stimulates an upgrowth from the frontal bone; the increased growth results in products which act as a hormone on the germ-cells, stimulating and affecting the germinal "factors" for the frontal bone and adjacent tissues. So, as generations pass, the outgrowth from the frontal bone becomes stronger and stronger. There is a centripetal hormone action from the exaggerated antler-tissue to the corresponding factor in the germcells, and there is a centrifugal hormone action from the male reproductive organ to the tissues associated with the growth of the antler. This is desperately ingenious, but is it not in the air? In the same way the primary origin of the milk glands is found in the mechanical stimulus of sucking; centripetal hormone action accounts for their hereditary entailment; centrifugal hormone action accounts for their appropriate development in the individual mammalian mother. But do we know anything definite in regard to hormones formed by modified tissues? Are we even sure that they exist? If we venture to suppose that there really is an occasional transmission of individually acquired bodily modifications, Mr. Cunningham offers an ingenious theory of the way in which the hereditary entailment might come about. But is 
his theory more than a hypothesis to explain what we do not know to be a fact?

\section{§18. Evolution Not a "Chapter of Accidents."}

IT seems justifiable to say that the range of the fortuitous has shrunk since the early days of Darwinism. As we have seen, when Darwin called variations or new departures "fortuitous," he meant little more than to acknowledge that they arose from conditions too complex for his analysis. We know that some variations arise from what might be called a shuffling of the hereditary cards contained in the chromosomes of the germ-cells, and there is in this a certain fortuitousness. It appears to be by a chance distribution that some of the chromosomes in the nucleus of the egg-cell are removed in the first polar body. On the other hand the permutations and combinations of hereditary factors that result in new patterns must be in some measure congruent with the already established architecture. "Anyhow variations" cannot take hold, and this is one of the reasons why constitutional diseases so rarely show face in Wild Nature. They are incongruities, and it seems to be a fact not only that they are prevented by selection from taking root, but also that they very seldom occur. When variations are definite or orthogenic - that is to say, additions to or subtractions from previously existing steps of change-they are obviously far removed from the fortuitous. We have admitted our ignorance of the origin of mutations or brusque qualitative new departures, like a calculating boy or a musical genius 
in mankind, but it is possible that the implicit organism or germ-cell is unconsciously "experimenting" with its material as the synthetic chemist deliberately experiments with combinations of carbon-compounds. In any case, as regards variations in general, such fortuitousness as there may be is restricted within certain limits.

So when we pass to the sifting or selection of the variations that crop up, the fortuitousness appears to be less than was formerly believed. For it must be recognized that animals do in varying degrees play the hand of cards with which they have been hereditarily endowed. They trade with their talents; they seek out circumstances in which their idiosyncrasies - for that is what variations are-can be turned to good account. Often indeed the environment selects the organisms, but it is also true that organisms sometimes select their environment. In short, living creatures are not passive pawns; they play their own game, they take a share in their own evolution. Whenever this is true, fortuitousness has markedly shrunk, though it never disappears. We cannot give a scientific account of some of the "chances" that have meant much in our own life.

Perhaps what has been said may be put in the more generalized form of the statement that the vital tends to transcend the mechanical. Some variations may be due to the shuffling of "genes" or hereditary factors in the manœuvres of the chromosomes. The new pattern is somewhat like what we see in a kaleidoscope. It is suggestive of the mechanical. But in other cases 
the variation seems to be the outcome of more than the permutation and combination of factors; it looks as if the factors themselves had changed. This is suggestive of the vital, something beyond mechanism. Similarly, when Darwin compared the fashioning of the beautiful hinge of some bivalve shells to the formation of snow-wreaths in stormy weather, he was perhaps deviating a little from his usual shrewdness. For in proportion to our knowledge of the wind, the surface-relief, the texture of the snow, and other factors, we can give a satisfactory mechanical account of the larger phenomena in the making of a snowwreath, whereas we can only go a little way with a mechanical account of germinal variations, hereditary entailment, the influence of function, and the intricate processes of Natural Selection. One must not make too much of an argumentum ad ignorantiam, but increasing knowledge of evolutionary processes lessens the range that one is inclined to allow to the fortuitous and strengthens the emphasis which one is inclined to lay on activities that transcend mechanism.

\section{§19. Evolution in Its Religious Aspect.}

How should our knowledge of Organic Evolution enter into our all-round philosophical and religious picture?

(I) The evolutionist discloses a sublime cosmic process, continuing without rest, without haste, for millions of years, with what might be anthropomorphically called a patient progressiveness. Not by a 
sudden fiat has Animate Nature come to be as it is, but by a long-drawn-out proving or testing and holding fast that which is good.

(II) We discern progressiveness in the long history - a movement towards greater integration and differentiation, towards a fuller and freer life, towards more dominance of mind. There are trends in Organic Evolution which are in the direction of man's highest ideals-truth-seeking, beauty, and goodwill. No doubt there are strange blind alleys-e.g., in Sponges and some Corals - with an extraordinary exuberance of sheer complexity and yet without any great advance; no doubt there are what might be called eddies and retrogressions, simplifications and even degeneracies; but on the whole Life has advanced and evolution has been integrative. That is its main trend, and its momentum is behind us, intrinsic to our nature and in some measure dynamic in our social heritage.

(III) One idea must be given up-that of the "Divine Artificer" of the "Special Creation" theology. In scientific honesty we are bound to leave behind us Paley's idea that these beautiful fitnesses are the direct outcome of Divine skill. But when we surrender an old idea because we know it cannot be true, we get something in return, not always in the individual lifetime, but eventually. And in exchange for Paley's argument from Design we get a wider Teleology. The Institution of the Order of Nature was such that living creatures when they emerged were able to evolve in ever-improving adaptedness, 
in a growing mastery of their environment, and with an increasing explicitness of mind.

The process of evolution from invisible animalcules has a magnificence that cannot be exaggerated. It has been a process in which the time required has been, as it were, of no consideration, in which for many millions of years there has been neither rest nor haste, in which broad foundations have been laid so that a splendid superstructure has been secure, in which, in spite of the disappearance of many masterpieces, there has been a conservation of great gains. It has had its outcome in personalities who have discerned its magnificent sweep, who are seeking to understand its factors, who are learning some of its lessons, who cannot cease trying to interpret it. It looks as if Nature were Nature for a purpose, and as we cannot predicate purpose in a vast system, we must reverently ascribe it to a Creator. We plead that the evolutionist picture is in harmony with the Vision of God.

\section{Summary.}

1. Sometime, somewhere, somehow there was an emergence of simple living creatures upon the earth. Perhaps the problem is beyond scientific solution; perhaps the best answer is "Ignoramus"; perhaps germs of life came to the earth from elsewhere, safely ensconced in the crevices of a meteorite; perhaps the living arose by natural synthesis from the non-living — from a colloidal carbonaceous slime activated by ferments. The last answer is in line with evolutionist 
thinking in general and is suggested by the triumphs of the synthetic chemist, who builds up complex carbon-compounds from simple materials. Very striking are the recent experiments of Professor Baly and his colleagues, who have been able, with the aid of light only, to build up formaldehyde from carbon dioxide and water, and to bring about a union of nitrites with the formaldehyde. The problem of the origin of living creatures upon the earth remains admittedly very obscure, but the probability of a natural integration has certainly increased. While there is no known exception to the experimental induction omne vivum $e$ vivo, we are not warranted in making this into a dogma.

2. The most important process in the world is the photosynthesis that occurs in the green leaf. Utilizing part of the radiant energy which shines through the complex green pigment (chlorophyll), the green leaf is able from carbon dioxide and water to build up formaldehyde, which becomes the basis for sugars and starch. A continuation of the synthetic process results in proteins, which are essential parts of the physical basis of life (protoplasm). The carboncompounds thus built up furnish materials for the plant's growth and energy for its activities; and they form the fundamental food-supply of the animal world. Moreover, by the utilization of the carbon dioxide of the air, and the return of oxygen, green plants have for ages been making a breathable atmosphere, and they continue to keep it "good." It is this fundamental process of photosynthesis that has 
now been mimicked in the laboratory by Professor Baly and his colleagues.

3. An outlook on Animate Nature discloses an immense world of living creatures-multitudinous and yet orderly, balanced and yet changeful, plastic and yet insurgent. After we have paid a tribute of admiration and wonder, we have to face the question: How did it come to be as it is? The transcendental or religious answer is, "By the Will of the Creator"; but to rest satisfied with that answer is an impiety. It is denying our birthright as inquiring minds to refrain from trying to understand the concrete ways in which the birds and beasts, the flowers and trees, have come to be as they are. The more thoroughly we can answer the scientific question, the more truth we shall see in the religious interpretation.

4. The general idea of evolution is that the present is the child of the past and the parent of the future. Evolution means a racial movement in a definite direction as the result of which new types emerge, take root, and flourish, either in place of or alongside of those from which they arose. The evolution formula is a modal formula of becoming. It fits all the facts and is the only scientific descriptive formula in the field. It is to be distinguished from particular theories as to the factors that effect the evolutionary change. In regard to these factors (e.g., variation, selection) there is and should be much uncertainty, but the fact is accepted by all competent naturalists. It cannot be demonstrated like the Law of Gravitation, but it is 
justified of its children. So far as it goes, it fits all the facts.

5. The rock record shows that as age succeeded arge there was an advance in differentiation and integration, an emergence of finer and nobler forms of life. From among Fishes there arose Amphibians, from Amphibians came Reptiles, and these gave origin to Birds and Mammals. The most ancient of the extinct birds, Archæopteryx, that lived in Jurassic times, had several reptilian features. There are some archaic living animals, like the New Zealand "Lizard," Sphenodon, which may be called "living fossils," for they are the sole survivors of ancient races, otherwise quite extinct. There are generalized extinct types-e.g., among crocodilians-which link together more specialized extant types. Some very satisfactory palæontological pedigrees have been worked out, as in the case of horses. The pedigree of modern elephants may be taken as a test case.

6. Geographical evidences of evolution may be illustrated by the occasional correspondence between the extinct and the extant in the same area; by the history of Marsupials; by the contrast between Oceanic and Continental Islands as regards their fauna and flora. The very interesting facts in regard to the Galápagos Islands, notably as regards Giant Tortoises and Giant Lizards, cannot be accounted for except in terms of evolution.

7. Anatomical evidence may be illustrated by homologies - the same materials twisted and moulded into a great variety of result; by the transformation 
of very old structures into something quite new; by the frequent occurrence of useless vestigial structures; by the existence of annectent and synthetic types; and by the possibilities of "natural" classification.

8. In a general way the development of the individual reads like a condensed recapitulation of the racial evolution. In a general way the animal climbs up its own genealogical tree. Gill-slits in the higher Vertebrates are never used for respiration, and most of them are of no use at all; but they are never absent; they are historical relics. The persistence of the notochord in the development of Amphibians, Reptiles, Birds, and Mammals is another instance of embryonic recapitulation, for this primitive skeletal axis is of no permanent use for support above the level of Fishes. In most cases it is very transient and is represented in the adult only by traces. The development of important organs like brain, heart, and kidney follows lines of historical evolution. Often there is a remarkable circuitousness. The life-history of the bony flat-fishes illustrates admirably the interpretative value of the evolution idea.

9. That the past lives on in the present is an evolutionist conclusion with abundant corroboration. It is well illustrated in some of the habits of domesticated animals, which are revivals of the ways of wild ancestors. The story of the Common Eel is taken as a vivid instance of the illumination of the present by the past, for it becomes intelligible on the hypothesis that this fish was originally at home in the deep sea 
and took secondarily to exploring and exploiting the fresh waters.

10. Domestication and cultivation have been longcontinued experiments in evolution, showing how much Man has been able to achieve in fixing and increasing the raw materials or variations which Nature supplies. Recent Mendelian breeding shows Man as transformist with more precise methods than before. There are a few interesting experiments indicating that it is possible to induce heritable variations by artificial stimuli; but in most cases man has simply to take what comes. Striking blood-transfusing experiments afford demonstration of literal bloodrelationship.

11. The evidence from many fields points clearly to the validity of the evolution formula. Organic evolution may be defined as a continuous natural process of racial change in a definite direction whereby distinctively new individualities arise, take root, and flourish, alongside of or in place of the originative stock. The difficulty is to develop this modal formula into a causal theory. Little is certain in regard to the origin of the great classes, such as Vertebrates; little is certain in regard to the causes that operated in the great steps in evolution, such as the establishment of the Vertebrate brain. We are not even clear how discontinuous species arise. The fact of evolution is undeniable; the factors in the process are still being investigated.

12. The first great idea in Darwinism is the correlation of organisms in a web of life. No creature lives 
or dies to itself ; each is a retainer to some other part of Nature. Organisms are linked together into a system. This is a central fact in Natural History. It also helps us to understand the fineness of Nature's sifting, for the meshes of the sieve are between the threads of the web of life. The interlinking of lives in a progressive inter-relationship, like that between flowers and their insect visitors, tends to make retrogression more difficult, gives additional security to integration. The idea of the web of life may be illustrated all through Organic Nature, as in the linkages between various insects and their partner yeasts, the association of ants and acacias, the utilization of a caterpillar by an ant.

13. The second great idea in Darwinism is the Struggle for Existence. This is a formula for all the manifold efforts and answers-back that living creatures make when they find themselves up against environing difficulties and limitations. It includes all the reactions which secure the welfare not only of the self but of the offspring, and even at times the kin. It rises from internecine competition to an endeavor after well-being; it includes the improvement of the nest and the elaboration of parental care as well as sharpening teeth and claws. Darwin realized the subtlety and many-sidedness of "struggle" more clearly than most of his followers have done, and modern ecology justifies his breadth and depth of view. Love is a factor in evolution just as much as hunger.

14. The central problem in evolution is the origin 
of the distinctively new. Some important steps of progress have been made. (a) It is clear that most of the variations that count have a germinal origin; tiıey find expression in the body of the offspring; but they begin as permutations and combinations or changes in the hereditary "factors" or genes in the germ-cells of the parent. (b) Mutations or discontinuous variations are not uncommon, and when they come they come to stay. (c) Variations are often correlated with other variations. (d) In some cases there is evidence of orthogenetic variation-that is to say, steady change in some definite direction. (e) In any case, a variation-if viable at all-must be congruent with the organization already established.

15. The theory of Natural Selection suggests that Nature's sifting of heritable variations in the struggle for existence consistently results in the survival of those variants that exhibit some character or quality giving them an advantage over their neighbors. The advantage may be a firmer foothold, better food, greater success in evading enemies, longer life, a larger family, more success in launching the offspring on the voyage of life, and so forth. It is interesting to consider the evolution of sieves from age to age and from type to type. The oldest sieve is the quest for food; another not less primordial is the physical environment with its vicissitudes; then there is the animate environment of competitors, neighbors, partners, parasites; in some cases there is the gregarious or social life; there is also the sieve of courtship, or, more generally, of preferential mating; and 
then there is the sieve of the web of life with its changing pattern, becoming on the whole more and more subtle, and therefore more discriminative. Darwin's theory of selection does not pretend to account for the origin of variations or mutations; but as a theory of sifting it works well.

16. Heredity is the relation of organic continuity between successive generations. It has become the subject of precise experimental inquiry. We know why like tends to beget like and how the contrasted "unit characters" or Mendelian characters of two parents will be distributed in their offspring. There is a rapidly increasing knowledge of the topography of the hereditary factors or "genes" in the nuclear rods (or chromosomes) of the germ-cells! It is possible to predict with accuracy what the result of certain crossings will be in the first and second filial generations, and it is possible to use Mendelism as a method of transferring advantageous characters from one variety to a neighboring one.

17. Each of the characters of the individual organism is the resultant of the vital coöperation of the hereditary "nature" and the appropriate "nurture" -meaning by nurture the whole complex of environmental, nutritional, and functional influences to which the developing organism is susceptible. A peculiarity in the nurture may induce a definite change in the organism. Such changes are called "somatic modifications" or "acquired characters." They are of very frequent occurrence and they often mean much to the individual. The important question 
is whether these "indents" or "impressions" can be, even in a minutely representative way, entailed on the offspring. The Lamarckian theory of evolution assumes that this is possible, but the experimental demonstration of this is inconclusive. But it would be premature to foreclose the question.

18. Since Darwin's day the range of the "fortuitous" in evolution has been much reduced. Many variations have a notable definiteness; many are correlated with others; many are congruent with what has been previously established. The facts of heredity are much more orderly than was previously supposed. Even in Natural Selection there is less fortuitousness than might be thought, for the sifting is in relation to an established Systema Natura, and organisms often play an active part in their own evolution. They play their hand of hereditary cards; they often select their environment.

19. The evolutionist picture discloses on the whole a progressive integration. The advance has been towards increased fineness, fullness, and freedom of life. Often the organic trend is like an anticipation of man's best endeavors. There is a strong suggestion of purposiveness. The evolutionist picture is in harmony with the religious vision. 



\section{CHAPTER III}

\section{THE EVOLUTION OF MAN}

$\S 1$. The Tax on Nerw Knozeledge.

§. What Darwin Proved.

§3. Factors in Man's Origin.

\$4. Recoil from the Evolutionist View.

§5. Emergent Evolution.

\$6. Man's Emergence.

§. Factors in Man's Evolution.

§. Neanderthal Man.

\$9. The Continuance of Man's Evolution.

$\S 10$. The Danger of Biologisms.

§11. Religious Interpretation. 



\section{THE EVOLUTION OF MAN}

\section{§1. The Tax on Nere Knorwledge.}

T seems that we have often a tax to pay on our 1 advances in knowledge. This is partly because a new conclusion is apt to bulk disproportionately large in our intellectual firmament. It is a new star, whose brilliance we exaggerate, and we have afterwards to pay for our exaggeration. To change the metaphor, there is trouble because we are so insistent that our goose is a swan. The moral is to accept conclusions with critical calm.

The other tax is one that cannot be evaded. The new conclusion has to be fitted into our thought system, sometimes like a steel girder into a stone and lime house, and the new adjustment involves architectural risks. Sometimes we are afraid that our whole house will come tumbling about our ears. To vary the metaphor, the new wine sometimes bursts the old bottles.

The tax on new ideas is well illustrated by what followed or follows the acceptance of the Darwinian doctrine of the Descent of Man. Some minds give it overhearty welcome, exaggerating its value. Man a product of evolution-why, that clears up all our difficulties!

Others receive it without effusive hospitality, as a guest accepted for the Truth's sake, out of a sense of duty, rather than with joy. There is friction 
before the new idea, which always comes to stay, becomes a harmonious and integral part of the household. We cannot pick and choose our science; it is a case of all or nothing. If seeking the Truth seems easy, we may be sure we have lost our way.

There was an old man in a little German town who did not believe in railways, declaring them to be impossible. He shook his head when his neighbors told him of journeys they had made. But in the course of time- this was long ago-the railway line was extended, and there was a station at the town. So the old man had to restrict his walks to remote places from which he could not see any trains. He died an unbeliever in railways. It is the same with some people and the Descent of Man.

\section{§2. What Darwin Proved.}

What Darwin proved, so far as proof is possible, was Man's solidarity with the rest of creation. Whatever Man was and is and will be, he is zoölogically affiliated with the highest order of Mammals, to which apes and monkeys also belong. Not that any living creature is his ancestor; no one supposes that Man sprang from any living Simian. The theory is that he emerged, probably as a mutation or saltatory variant, from a stock common to the anthropoid apes and to him. The ape voyage has been in one direction, man's in another, but the vessels sailed from the same port; their keels were laid down in the same shipbuilding yard. 
What evidence is there in support of a conclusion so momentous? Anatomically, there is, to use Sir Richard Owen's phrase, an "all-pervading similitude of structure" between the higher apes and man. Man has indeed his distinctive features-his erect figure, his big brain, his chin and regular teeth; but bone for bone, muscle for muscle, nerve for nerve, there is an all-pervading similitude. In some features man is nearer one ape, in other features nearer another; anatomically regarded, he is their distant cousin.

Man is a walking museum of relics, vestiges of mammalian and of remoter ancestry. Professor Wiedersheim, in his Structure of Man, an Index to his Past History (1895), discusses over fifty of these relics; and everyone knows the little third eyelid in the inner upper corner of the eye and the vestigial muscles of the ear-trumpet which a few exceptional individuals can activate, thus emulating the donkey. If these vestigial structures are not relics of the past, indices of history, like the unsounded letters in words, what are they? We recall Darwin's fine sentence:

"We must, however, acknowledge, as it seems to me, that man, with all his noble qualities, with sympathy which feels for the most debased, with benevolence which extends not only to other men, but to the humblest living creature, with his God-like intellect, which has penetrated into the movements and constitution of the solar system - with all these exalted powers-man still bears in his bodily frame the indelible stamp of his lowly origin" (the closing words of The Descent of Man, 1871). 

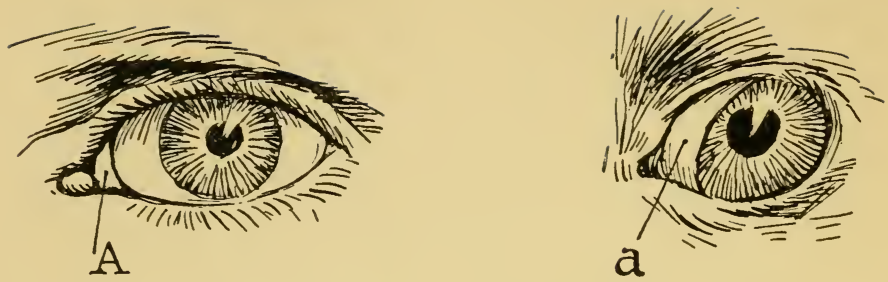

FIGURE NO. 22

\section{THIRD EYELID IN MAN AND BIRD}

In the inner upper corner of man's eye (to the left) there is a vestige of a third eyelid or nictitating membrane (A). It is larger in some races than in others, but it is of no use. In most mammals, however, as in rabbit and dog, it is well-developed and is drawn over the front of the eye for cleaning purposes. Its absence in man and monkeys is compensated for by the frequent movements of the upper eyelid. Its absence in whales is compensated for by the continual washing of the front of the eye. In birds it is usually an important membrane ( $a$, in figure to the right), used in cleaning the front of the eye. It is drawn down by special muscles and goes back spontaneously when they relax. 
The individual development of man is in its early stages closely like that of the higher Primates. No doubt there is specificity; from first to last Homo sapiens is himself and no other. Yet he does seem to climb up his own genealogical tree; and arrests of human development-in times of famine, for instance - -sometimes show Simian features.

The everyday functions of the body are closely alike in man and ape, and the disturbances of these are sometimes similar. Certain diseases, like tubercle and rheumatism, occur on both lines. The blood of man mingles harmoniously when transfused into that of an anthropoid ape (chimpanzee), but it does not mingle harmoniously with the blood of a monkey, showing that degrees of blood-relationship, in a very literal sense, can be defined by blood-mingling experiments.

Finally, we must remember that there were "tentative men" before Homo, vaguely known intermediate beings that are in various ways "connecting links" between man and the anthropoids; we must recall the fact that Neanderthal man had Simian features swarming in his body; we must recognize the fact that not all the living races of mankind are on the same level. We can still see our "contemporary ancestors."

We have considerable sympathy with the impatience of the critic who says: Your language is of the earth earthy; you speak as if man was only a divergent mammal; you are begging the whole question by ignoring all that is most distinctive of Man- 


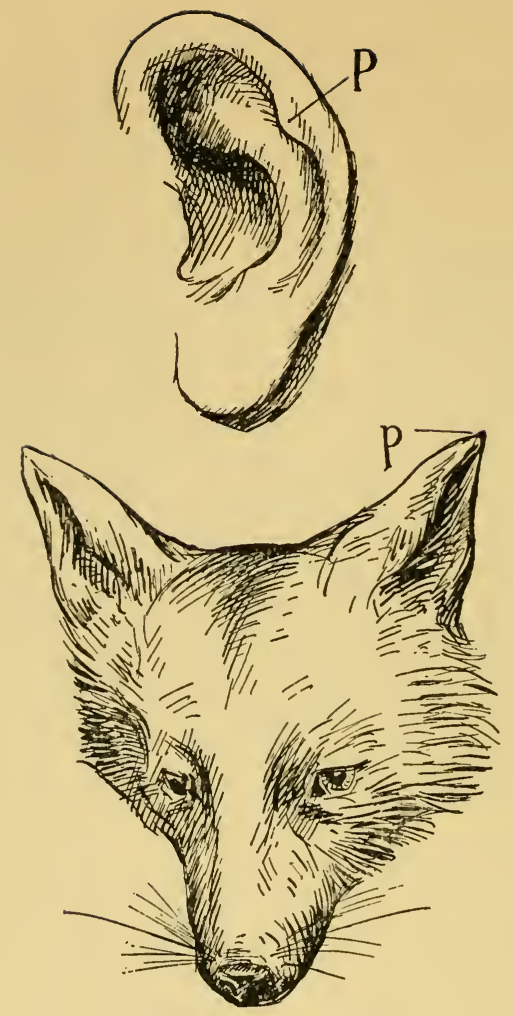

FIGURE NO. 23

\section{DARWIN'S POINT IN MAN'S EAR}

The upper figure shows at $\mathrm{P}$ what is called "Darwin's point" on the pinna or ear-trumpet of some men. It is the original tip of the ear and corresponds to the tip in ordinary mammals, shown as at $p$ in the fox below. In the developing human off spring the region corresponding to $P$ is actually at the tip, but the pressing backwards of the whole pinna and the infolding of the margin (or helix) brings the original tip to the position shown at P. Darwin's point is an interesting relic, very clearly marked in some individuals. 
his speech, his reason, his morality, his personality. But we must be patient, and when we speak of speech, reäson, morality, and personality, we must remember Frimitive Man and the least evolved human races of to-day. Man cannot ignore his poor relations-and there is little reason why he should be more ashamed of them than of himself. It is impossible, we think, to split man into two-bodily frame and personalityand the evidence is cumulative in support of the conclusion that man is solidary with the rest of creation.

\section{§3. Factors in Man's Origin.}

DARwIN stated the case for regarding man as affiliated to the Primates, but he did more. He made contributions to the problem, still before us, of picturing the factors that may have operated in man's emergence. What were these factors? There were new departures or variations-still an abundant crop; there were processes of sifting or selection which were prompted by love as well as by hunger, and winnowed a capacity for mutual aid as well as the strenuous "will to live"; there were conditions of isolation that favored endogamy (or in-breeding) and of dispersal that favored exogamy (or out-breeding); and there were of course the conditions of hereditary entailment. The factors in man's emergence and ascent remain very obscure, but to use this frank admission of ignorance as an argument against the general idea of the Descent of Man is bad thinking. It is unconscious dishonesty of the intellect. 


\section{\$4. Recoil from the Evolutionist Viere.}

MAN's solidarity with and affiliation to the rest of creation-that is the Darwinian conclusion. What is the tax to pay? The first instalment is in our tendency to think less nobly than we ought to think of Man and the height of his calling. If he is not a great exception, a "special creation," but the latest of a succession of evolutionary masterpieces, some would think less worthily of Man. If he is no "moral Melchizedek," but the long result of time, the child of the ages, affiliated to the stock of the Primates, some would think that Man has lost in dignity and in promise. But this is altogether fallacious. The real apartness of man remains, whatever be his ancestry. Shakespeare is not less great because he was once a silly child, nor are Newton's achievements lessened when we read that he was one of the most miserable infants ever born. Value is independent of origin. Whatever be his pedigree Man's apartness remainshis big brain, his language, his reflective self-consciousness, his power of conceptual inference, his moral judgments, his ability to envisage and control his own evolution. He remains, in Emerson's words, "the man-child glorious," "the summit of the whole."

But the second part of the tax is more serious. It is not man's affiliation merely that is difficult to harmonize with other convictions : it is the idea of his natural evolution. The discord is expressed in the reproach that Darwinism has done away with God, which is not perhaps such a shallow saying as it seems. For it was 
in part the unaccountable marvel of Man's origin that led him to cry out for God. A sense of the mysterious on being confronted with a baffling problem has often prompted religious interpretation.

The stirrings of my heart were of Thee;

Thou didst knit me together in my mother's womb.

My frame was not hid from Thee,

When I was made secretly and richly wrought in the deep of the earth.

My spirit awaketh and still I am with Thee.

(Psalm exxxix.)

But according to Darwinism man is the long result of time, an "antiquity," the outcome of a natural process which has been in progress for millions of years and still continues. And not only was evolution the mode of man's becoming, but we can say a little - just a little as yet-in regard to the factors of variation and selection, isolation and entailment, that may have operated.

The plain fact must be recognized that it is not open to us to pick and choose scientific conclusions. If we have a quarrel with the Law of Gravitation, it will prove the stronger. If we resolve to ignore the Descent of Man because we do not like it, we shall be left behind. There is no alternative to accepting the well-established results of scientific inquiry, and we have no right to say: The consequences of this or that scientific conclusion will be troublesome. At the same time, biologists are not infallible, and the question arises whether their mode of presenting their 
conclusion has always been perfect. The question of the Descent of Man is in a realm somewhat beyond exact science, and philosophical criticism should be welcome, especially in its scrutiny of the terms in which the scientific verdict is stated.

Put somewhat bluntly, the question is whether the scientific descriptive statement that Man is the outcome of a process of evolution is incongruent with the religious interpretation that Man is the child of God. Without yielding anything on either side, can we see the interpretation to be supplementary to the description?

When we say that Man is an outcome of evolution, we mean that he is the highest expression of a process that began with simple forms of life and has continued for many millions of years, a process in which novelties are continually emerging and being sifted. There is no reason to suppose that it was "a chapter of accidents," as someone has said. There is no reason to suppose that mind evolved out of what was devoid of the primordia - the raw materials, so to speak, of mind. There is no reason to believe that the mind of the living creature was not operative throughout, through all the spires of form, testing all things and holding fast that which is good or fit-for that is the evolutionary process. The firmer our grasp of the idea of continuity, the more we must allow to the original endowment of the simplest organisms. Not that evolution has been an unpacking of a wellpacked portmanteau, any more than the finest work of a great artist is just the development of his early 
scribblings. All through, evolution has been creative. From first to last, the organism has been trading with time and trafficking with circumstance, taking a hand in its own evolution.

\section{§5. Emergent Evolution.}

There is something to be gained by considering what Professor Lloyd Morgan calls "emergent evolution." The whole ascent of life, not to speak of the genesis farther back still, is studded with puzzling "emergences"-outcrops of genuine novelties. In the field of mechanics we can say with a clear intellectual conscience: "This movement is the resultant of its components : causa aquat effectum." But in the realm of organisms, our knowledge of the causal nexus is often dim. No zoölogist doubts that birds evolved from an extinct reptilian stock, from amidst the Ornithischian Dinosaurs. But we cannot even imagine how the reptile, creature of the earth, gave origin to the conquerors of the air, the emblems of freedom. Birds emerged; we are sure of that, but of little else.

Let us take an illustration of a simple kind from the domain of things. Everyone knows that in certain conditions a combination of hydrogen and oxygen spells water. No alien influence intervenes; all is approximately known-the raw materials and the stimulating conditions that bring about their union. There is no joukery-pawkery. And yet a novelty results-at least it would have been a startling novelty if we had not been familiar with it before. Water results, with unpredictable properties very different 
from those of the two gases from which it is compounded. Some day, perhaps, as chemistry deepens, it may be possible to account for the properties of water in terms of the properties of hydrogen and oxygen, but this does not seem practicable at present. Water emerges. A new internal and external relatedness of molecules of oxygen and hydrogen has afforded opportunity for the emergence of new intrinsic qualities and new extrinsic properties. Using the word "emergence" does not explain anything, but it lays emphasis on the difference between an additive resultant and an outcome that is a new synthesis.

But the fact of emergent evolution, so brilliantly expounded by Professor Lloyd Morgan, is more conspicuous in the realm of organisms than in the domain of things. All the great steps in evolutionthe making of a body, the establishment of a brain, the beginning of the blood, the differentiation of sense-organs, and so on-were new syntheses, with new intrinsic qualities and new extrinsic properties. Professor Lloyd Morgan illustrates his point by an apt quotation from Browning's Abt Vogler:

And I know not if, save in this, such gift be allowed to Man That out of three sounds he frame, not a fourth sound, but a star.

"By 'star' Browning lays poetic stress on the emergent character of 'chordiness,' which is something more than the additive resultant of the constituent tones-something genuinely new." There is the summation of constituent notes, but Browning 
"asserts that there is more in the chord than can be interpreted as the outcome of summation only."

Every distinctively new type of living creature is like Browning's chord. More prosaically, it is like one of the new carbon-compounds made by the synthetic chemist-a creator in his way. Something startlingly novel emerges out of the new concatenation. So the new emergent animal type-whether it be fish or frog, bird or mammal-is more than an additive summation. Every one of them meant a Columbus voyage - the discovery of a new world. Indeed, every one of them meant the making of a new world, for the new type is an agent that turns on its environment with a new lever.

What has been taking place throughout the ages of ascent resembles what we see when a number of men of diverse gifts unite to form a firm or some similar association. Each member of the firm is admirable by himself, yet not extraordinary. But when they unite their forces and work into one another's hands they create an integrate that may have unpredictable efficiency. It is much more than the additive sum of its parts; it illustrates the mystery of the esprit de corps.

Now the same idea applies $a$ fortiori to the ascent of man. He was a new synthesis, if ever there was one; no mechanical resultant, but a vital new creation; not involving any breach of continuity, or any interpolation of supra-mundane influence, but making a fresh disclosure of the unending riches of 


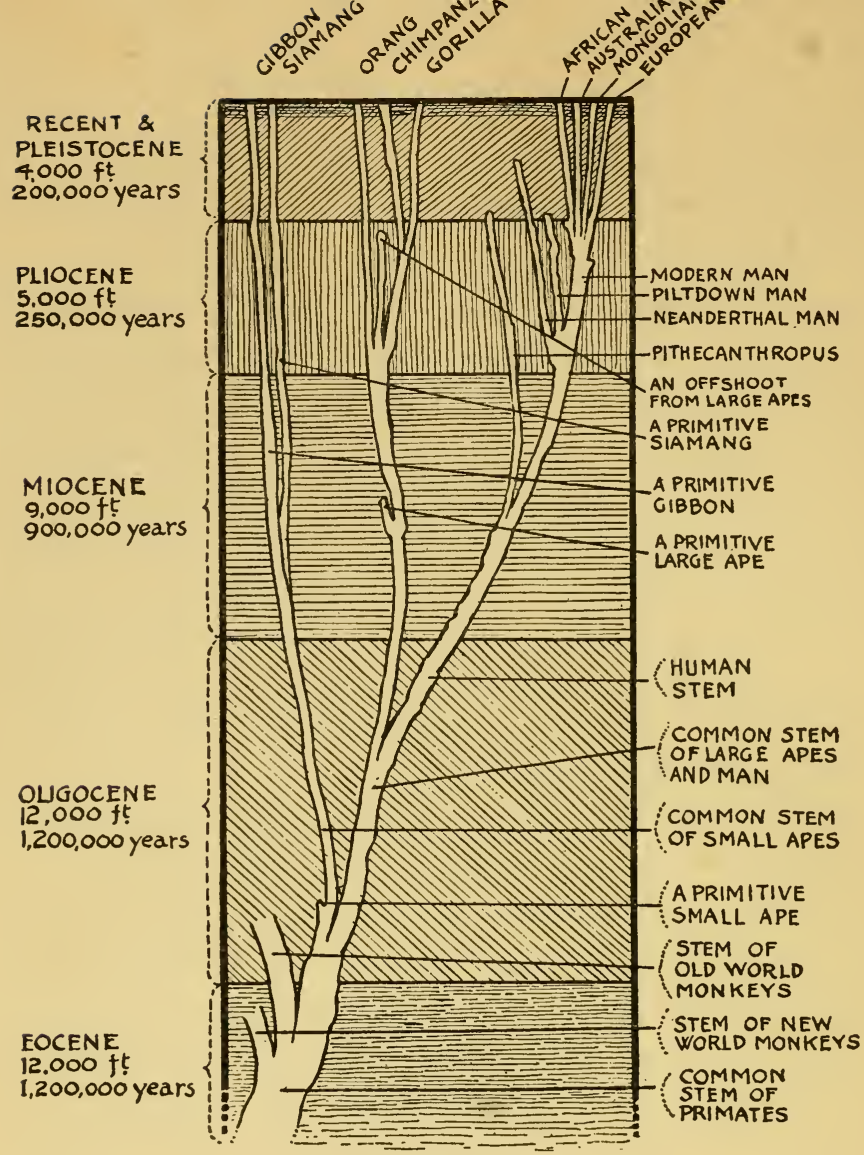

FIGURE NO. 24

\section{MAN'S GENEALOGICAL TREE}

(By kind permission of Sir Arthur Keith and Messrs. Williams \& Norgate, publishers)

From a generalized "Primate" stem there were separated off first, the New World Monkeys; second, the Old World Monkeys; third, the smaller Anthropoid Apes; fourth, the larger Anthropoid Apes. From a generalized Humanoid stem there were separated off various 'tentative men,' like Pithecanthropus. From the stem of Homo there was separated Neanderthal man (Homo neanderthalensis); the line is continued by Homo sapiens. The estimates for the duration of Eocene, Oligocene, etc., are of course approximate and subject to criticism. 
reality. In Browning's sense, he was not a new sound, but a star.

The evolutionist does not interpret the higher in torms of the lower, the man in terms of the beast, for that would be to deny the newness of the emergence. He sees antecedent pre-human stages with less of certain characteristics, such as intelligence and selfconsciousness; out of these emerges Man, a new creature, not rising at once, of course, to the height of his calling, but with a new chord that is a fresh start in what Lotze called "the onward advancing melody." Into the new fabric there pass no doubt strands of the old, but some threads are new and the pattern is new. Explain it who can, but that is the way the loom of time works. The religious interpretation is a reverent acknowledgment of God as the spiritual source of all, as "the nisus through whose activity emergents emerge, and the whole course of emergent evolution is directed" (Lloyd Morgan).

\section{§6. Man's Emergence.}

THE story of man's evolution, so far as we can picture it, has never been told better than in Yale. In the series of masterly lectures by Professors Lull, Ferris, Parker, Angell, Keller, and Conklin, coöperation has achieved a breadth and depth probably beyond individual attainment. We have neither criticism nor addition to suggest. All that we can do is to lay emphasis on certain points in the story which have some bearing on religious interpretation. 
There is great interest in what might be called the sifting-out process in man's pedigree. In early Eocene times, the Primate stock of big-brained arboreal Mammals was differentiated from other Mammalian orders, such as Carnivores and Insectivores. From this generalized monkeyish stock there diverged first the New World Monkeys, and later on the Old World Monkeys. But the main stem, we believe, grew on. In the Oligocene Ages there diverged the branch of small apes, the gibbons; and later on, probably in the Miocene, the large apes, the gorilla and the chimpanzee, while the orang was apparently on a line of its own. The main stem, vaguely known, we must confess, grew on as a humanoid stem. From this, as ages passed, there diverged the tentative men, the Hominidæ, but not yet Homo.

So it is not merely that Man is a scion of an ancestral stock common to him and to the higher apesthe humanoids and the anthropoids parting company between a million and two million years ago-but there is what we might call a trend towards finer and bigger brains. Scientifically, we can only say that Man was the outcome of a natural evolutionary process; in a larger light, may we not see something like the working out of a divine idea? It looks as if certain steps were made and qualities gained, and that while many settled down at this or that level, the remnant pushed on and repeated the process on a higher turn of the spiral. As it is written in Emerson's Song of Nature: 



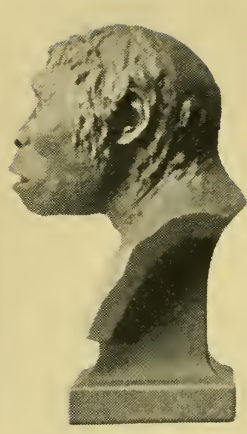

PITIECANTHROPUS ERECTLS

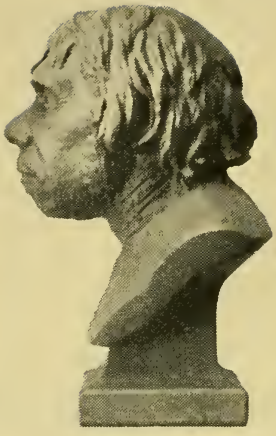

HOMO

NEANDERTHALENSIS

FIGURE NO. 25

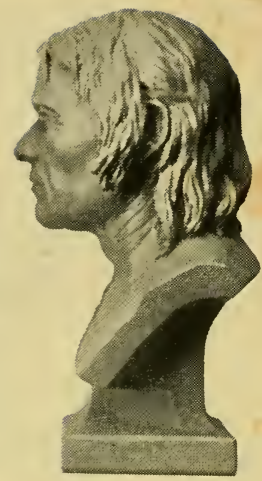

CRô-MAGNON MAN

PITHECANTHROPUS, NEANDER'THAL MAN AND CRÔ-MAGNON MAN

By Professor J. H. McGregor, Columbia University.

OriginaIs in American Museum of Natural History.

Reproduced by permission of Professor McGregor. 
I travail in pain for him,

My creatures travail and wait;

His couriers come by squadrons,

He comes not to the gate.

This at any rate is clear: that when we think of the length of the pedigree, of the millions of years through which the lineage stretched, of the sifting out of side-tracks, we feel the unutterable vulgarity of saying "Man sprang from a monkey." The scientific statement is that Hominids sprang from a stock common to them and to the Anthropoid Apes.

What happened before the separation of the humanoid from the anthropoid stems continued to happen afterwards. Many are called, but few are chosen. The sifting process continues, without haste, without rest. We know of the shadowy figures that hold the stage for a little and are gone-the tentative men-the vague Pithecanthropus the Erect, perhaps half a million years ago, "human in stature, human in gait, human in all his parts, save his brain"; the Heidelberg Man, Palceanthropus heidelbergensis, perhaps 400,000 years ago, a very strong fellow if he used the eoliths found beside him, but we only know his lower jaw ; the Piltdown Man, of the Sussex Weald, Eoanthropus darosoni, a remarkable mixture of ape-like and man-like characters. Everyone admits that our knowledge of these forms is vague, but there seems little doubt that they represent tentative menHominidæ but not Homo. We are reminded again of Emerson's lines: 
Twice I have moulded an image, And thrice outstretched my hand, Made one of day, and one of night, And one of the salt sea-sand.

It will be understood that the same sort of trying and testing can be discerned in the story of the evolution of other types, but the persistent pressing-on past side-tracks and blind alleys touches us more when the result is Man.

\section{\$\%. Factors in Man's Evolution.}

THE not unfriendly criticism is sometimes made that while the evidence undoubtedly suggests man's derivation from a pre-human stock, the picture of what may actually have occurred is very vague. This is true in regard to most of the important big lifts in evolution. We know very little about the factors that were operative.

It is not illegitimate to suppose that Homo arose as a mutation, especially in the direction of a great increase in the cerebral cortex. We do not know the causes of mutations, but we know that they frequently occur, and that when they appear they usually come to stay. It is quite likely that the humanoid mutation was associated with some great change in one or more of the ductless or endocrinal glands, such as the thyroid.

There seems good sense in the idea that arboreal apprenticeship on the part of Man's ancestors would lead to very important changes. It led to the emancipation of the hand, a new pose of body, a recession 
of the snout, a correlated increase of the brain cavity, a shunting forward of the eyes and more stereoscopic vision, a greater mobility of the head, a greater emphasis on touch, a decrease in the olfactory region of the brain, and an increase in the region where the sensory tidings from hand and eye and ear come streaming in-a region, moreover, according to the experts, towards which the originative seats of the motor impulses tend to become approximated. (See Thomson, What is Man, 1923.)

Professors R. Anthony and F. Wood Jones have independently emphasized the probable importance of the arboreal apprenticeship, but the likelihood is that it affected man's ancestors rather than man himself. It is obvious that we see its results in monkeys and apes, which have nevertheless been side-tracked, having remained more or less arboreal. We therefore follow Professor R. S. Lull in thinking that the crucial step was when the shrinkage of forests, owing to aridity in the Miocene or early Pliocene, led the humanoids to come to earth. It was facing the difficulties of life on terra firma that meant so much in Man's emergence. He needed his big brain and his free hand to save him in his struggles with Carnivores and with a callous physical environment.

We should also remember that man belonged to a clever social stock; that the prolonged ante-natal life, as Robert Chambers suggested, might be correlated with a high degree of cerebral development; that a prolongation of infancy and of the play-period would favor educability of mind, as contrasted with early 
fixity; and that the prolonged infancy would also favor the development of gentleness in the individual and its evolution in the race.

It is sometimes said that evolutionists argue in vicious circles. Prolonged infancy favors gentleness; but it was gentleness that made the prolonged infancy practicable. Language makes greater social integration possible, but it was the gregarious life that abetted the evolution of language. Language is associated with improved intelligence, but the higher flights of intelligence are impossible without language.

This is, we think, very characteristic of evolution, the existence of what one might venture to call virtuous circles. Strong parental care makes prolonged infancy possible, and the prolonged infancy acts as a sieve favoring variations in the direction of increased parental care. As long as Natural Selection operated powerfully in the winnowing of mankind there would be a tendency to eliminate parentally careless types and favor the parentally effective. The evolutionary movement of a character is, as it were, on a spiral that ascends and then bends down again, lifting a correlated character on to a higher level.

\section{§8. Neanderthal Man.}

IT may tend to focus our reflections if we consider in more detail the men of Neanderthal, who seem to represent a collateral species now extinct. They lived in Europe towards the end of the last glacial invasion, in the period termed Mid-Pleistocene. It was a time 
of severe cold and frequent floods. There was competition for suitable caves which could be warmed with fires. How severe the cold was we can judge from the thick coat of hair on the mammoth, and from the extension of northern and Alpine animals, such as reindeer and musk-ox, ibex and chamois, into the low grounds of Central and Southern Europe.

The primitive men who lived in those hard times have been named Neanderthal Men because one of the early, though not earliest, discoveries of their remains was made in a grotto in the valley called Neanderthal, through which the river Düssel flows into the Rhine. But many other remains have been found in widely separated places-at Gibraltar, at Spy in Belgium, at Krapina in Croatia, at La Chapelle-aux-Saints in France, and elsewhere. About fifteen good sets of skeletal specimens are accessible, and they are homogeneous and distinctive. As Professor Boule says in his Fossil Man (Translation by Dr. and Mrs. Ritchie, 1923), the Neanderthal type is better known than many living types.

Can we form any picture of this primitive man, who was once the highest of created beings, but did not enter into the promises? He was a man of small stature, perhaps 5 feet 1 inch on an average, and he slouched forwards. Stature is a composite character, with diverse elements (for neck, back, loins, and so forth) which may be separately inherited; and it should be noted that Neanderthal Man was very short in the legs. But he was thick-set, almost massive, and very strong. Professor Lull speaks of him as "a 
clumsy, shuffling, loose-jointed being of great muscular power."

Neanderthal Man had a big head, spoilt from our point of view by the prominence of the facial region, which projected almost like a snout. The forehead was very receding and the occiput protuberantneither of them very agreeable features in modern eyes. There was a very prominent continuous ridge above the large orbits. The nose was also big and prominent. The strong lower jaw is impressive, but there is no chin. The teeth are massive, but in some ways primitive. He was a true man, but his anthropoid ancestry is revealed in skull, vertebral column, and limb bones. Sir Arthur Keith speaks of the "simian characters swarming in the details of his structure." In Walt Whitman's words, he was stuccoed all over with quadrupeds.

But what of his brain? The average brain capacity of Neanderthal Man, calculated by Professor Boule from five intra-cranial casts, was 1450 cubic centimeters, and thus is about the same as the average in some of the inferior races of mankind living to-day. But we cannot base much on the size of the brain-case, for Raphael's brain capacity was only 1420 cubic centimeters, and that of a distinguished anatomist was 100 cubic centimeters less. It is quality, not quantity, of brain that counts, after we pass a certain limiting line.

But while Neanderthal Man was human enough as regards the amount of his cerebral matter, a careful investigation of the inside of his skull shows that he 
had not attained to the organization of brain that marks the Modern Man type. Professor Boule speaks of the brain of Neanderthal Man as "presenting numerous primitive or simian characters, especially in the relatively great reduction of the frontal lobes and the general pattern of the convolutions." The probability is that Neanderthal Man was a very silent person, and partly because he had not much to say. Intelligent he doubtless was, but in a somewhat simple fashion. He was notably "eye-minded," not "ear-minded."

This picture, based on anatomical facts, may have some color added to it by what is known of the activities of this primitive kind of Man. He found shelter in caves, but he probably wandered about a good deal. Among his contemporaries were reindeer, bisons, ibexes, and the like, but it is not certain that he was able to make any of these his booty. He seems to have lived on coarse food, largely of a vegetable nature, and sometimes gritty, as his teeth plainly show. He seems also to have caught small mammals and sucked the marrow from their bones. According to Professor Boule, he sometimes suffered from inflammation of the gums and worse; and this may have given him food for reflection. There is nothing very remarkable about his stone weapons and implements, for though it would puzzle most of us to make them, they were simple and rude- of the style called Mousterian. There is just a trace of the use of bone. The evidence of fires in the caves seems to be clear, but it is not so certain that there is warrant for the statement often 


\section{Neanderthal Man Extinct Species}

made that Neanderthal Man buried his dead reverently, and gave them not only food for their journey, but ornaments which could not have been relinquished without a pang.

Huxley regarded Neanderthal Man as an extreme variant of Homo sapiens, the Modern Man type, but Professor William King, a quiet worker at Queen's College, Galway, challenged this conclusion in 1864, and maintained that it is necessary to recognize a distinct species, Homo neanderthalensis. This is the view generally accepted to-day. Neanderthal Man differs from modern man of any race much more than modern races differ among themselves. Professor Boule writes: "The Neanderthal type clearly represents a species different from Homo sapiens, taken collectively, existing or fossil, because it presents a certain number of constant characters which are not met with, normally and in association, in any human race or species existing at the present day."

But this is not all. The facts are entirely against the view that Neanderthal Man was any ancestor of ours. He represents a collateral line that came to an end. But the noteworthy fact is that our ancestorsthat is to say, representatives of the Homo sapiens species-were living synchronously with Neanderthal Man in the later millennia of his species-life. $\mathrm{He}$ was older and he had his innings, but he dwindled into extinction, while the progressive newcomers became dominant. The two species doubtless sprang from a common stock, and they must have diverged long before the last Glacial Epoch. But, as has 
happened so often in evolution, the one race, after having had a strong grip for a long time, disappeared, while the other race survived and made headway. Neanderthal Man had his day and then shuffled off the stage. He left no descendants whatsoever. Even if the two species occasionally crossed when they were living synchronously-a possibility that cannot be dogmatically denied-there is no foundation for the hypothesis of blending. Some isolated features suggestive of the Neanderthal type are occasionally seen to-day in secluded places, but these rehabilitations of the primitive are probably due to a re-awakening of certain structural items characteristic of the remote ancestral stock of Homo, in which the Neanderthal Man and the Modern Man had a common origin.

Two impressive facts stand out. In the first place, in the divergence of Neanderthal Man from the Homo stem and his subsequent elimination we have a vivid illustration of what we have called "the sifting-out process." It is a common method in organic evolution, but we realize it more when it comes near ourselves. Considered in the light of the whole, it is suggestive of "an increasing purpose." In the second place, our picture of Man's emergence must include the fact that for a time the highest living being was the Neanderthal species. The Neanderthal men were at the top of the genealogical tree. They lasted for a long time, took a strong grip of things, and then, somewhat suddenly, vanished, perhaps only 20,000 years ago. Who can help asking whether from amidst our 
variable human race there may not emerge (or may not be emerging!) a new species, destined to progress as far beyond the average Homo sapiens as the Modern Man type did beyond that of the Neanderthalers? This question of the continuance of human evolution is of great interest, and may be briefly considered by itself.

\section{\$9. The Continuance of Man's Evolution.}

MAN has a long ascent behind him, but is he still on the way up? Is he continuing to evolve as an organism? Does he show an organic racial change in definite directions? It is plain that his external or social heritage is changing, but is man himself changing? He suffers dints and he puts on veneer; he fattens himself and makes himself lean; he develops Sandowian muscles and dulls his sense of smell: but are these and similar changes more than superficial modifications? Do they in any direct way grip the race? It does not seem easy to prove that man as an organism is evolving either up or down, either progressively or retrogressively. It seems as if animal species often took a rest after a period of marked variability and progress. Perhaps man is in one of these periods of stability. Perhaps human evolution has passed from being mainly organismal, as in the days of primitive man, to being mainly outside the body-that is to say, in the social environment.

We can prove the reality of continued evolutionary change in a race of domesticated animals or of cultivated plants when we have definite records of the 
state of affairs at successive periods. We are sure that dogs are continuing to evolve-for the worse as well as for the better. We are sure that wheats are still evolving; finer and finer races continue to emerge. Similarly in Wild Nature, if we measure a set of characters year after year under similar conditions of life, and find an emphatic increase or decrease in certain measurements, we may safely conclude that the species is moving in a certain direction as regards particular characters. The difficulty of doing this for man is that a human generation means a long time and that the habit of taking exact measurements is very young: The anatomist knows well that little variations are always cropping up in man's body, but it is another thing to prove that any of these is taking racial grip.

It is easy to suggest theoretical improvements in man as an organism. His thirty feet or so of foodcanal is probably far too long for the requirements of civilized dietary. The appendix vermiformis seems a troublesome relic which might be dispensed with. The teeth are often inconveniently crowded, and as a matter of fact the wisdom tooth often fails to cut the gum. The little toe does not seem to be of much account. Now it may be that some of the desirable improvements are going on at present, but so slowly that their advance is hardly to be discerned. There is not, however, much convincing evidence that man is adding in any marked way to his bundle of adaptations, as an evolving organism should do.

Man is an antiquity, the long result of time; he 
is in many ways highly specialized; and a high degree of specialization tends to limit further evolution - the balance of an intricate organization will not admit of any great change. No doubt there are some parts of man's body that are not highly specialized, the hand being a notable example. It is a generalized hand compared with a horse's hoof, or a bat's wing, or a mole's shovel, or a whale's flipper. Why, then, should we not find signs of evolution in man's hand? The answer must be in part this, that for man's purpose a generalized hand is far and away the best. It is a universal tool with which man can do a hundred things well.

In the ordinary course of Nature advantageous variations or novelties have a good chance of persisting. When they come, they come to stay. Professor Punnett has calculated that "if a population contains .001 per cent. of a new variety, and if that variety has even a 5 per cent. selection advantage over the original form, the latter will almost completely disappear in less than a hundred generations." This is in Wild Nature. Why does it not continue to occur in mankind? Because man has rebelled against Nature's method of drastic sifting for health, vigor, and efficiency. By many artificial devices he has brought it about that valuable new departures (in artistic talent, for instance) do not find their due reward, whereas deteriorative changes (extreme short sight, for instance) are not visited with their natural penalties. This is probably the deepest 
reason for the sluggishness of organic evolution in mankind.

The probability is that some improvements in adaptation, such as a shortening of the food-canal and immunity to certain diseases, are in slow progress in mankind; but even if this be so, there must be put on the other side of the account the likelihood that disadvantageous changes, such as short sight and neurasthenia, are taking racial grip because of the inadequacy of the sifting processes that remain at work.

Two lines of possible evolution seem to be particularly promising. The first is an increase in the complexity of the inter-relations amongst the 9200 millions of nerve-cells in the cerebral cortex. The size of the brain has not increased since the days of the CrôMagnon men, who lived some 20,000 years ago, but without increase of size there might be increase in complexity; and that would mean the improvement of intelligence. The second possibility is an extension of the youthful period and an abbreviation of the time of senescence. This might come about by variations in the endocrinal or regulative system of the body.

Man stands apart in his reason and language and morality, but also in the degree to which he enregisters the gains of the past in the social heritage. This is only incipient among animals, as in the permanent ant-hill or the beaver village; it means half of evolution to man. To the enrichment and increased utilization of the social heritage no limits can be set. 
But there is more than that. Every vigorous animal that is an agent does in some measure share in its own evolution; and so it has been a fortiori for all men who have been swimmers, not drifters, in the stream. But there is more than that. To modern man there is coming a growing awareness that he can, in ways previously undreamt of, control not only the individual life, but racial evolution as well.

\section{§10. The Danger of "Biologisms."}

IT is convenient to use the term "a materialism" to denote the attempt to give a false simplicity to the activities of living creatures by trying to fit them into the descriptive frameworks of chemistry and physics, thus depreciating the distinctiveness of "life" and "mind." Much progress has been made in the chemistry and physics of organisms, but these do not exhaust what is observed, which requires special biological categories. Thus, to take a single instance, a migrating bird is a "historic being" in a degree far transcending anything that is known in the domain of not-living things.

Similarly, it is convenient to use the term "a biologism" to denote the attempt to give a false simplicity to the activities of man, by trying to force them into the descriptive framework of zoölogy. This unduly depreciates man's apartness.

This tendency may be illustrated, for instance, by too fatalistic theories of heredity. It may be allowed that a man cannot add to the number of his distinctive hereditary talents, yet he can trade with them so that 
they accumulate interest. By control of "nurture," which includes all manner of environing influences, man can determine the degree of unfolding of a hereditary bud, and can even, if it be an undesirable quality, ensure that it remains more or less dormant.

It is a "biologism" to underestimate the power of "nurture" in determining the expression of hereditary "nature," and it is another to forget the importance of the external heritage in which man can register racial gains apart from any germ-plasm. What is only adumbrated in the animal kingdom has come to be of paramount importance to man.

The recoil of many religious minds from the Darwinian view of man is partly because it has become wrapped up with ways of regarding man which suffer from false simplicity; but another reason is to be found in the somewhat too easy-going way in which it has been assumed that the factors which seem approximately adequate in the animal world will likewise serve in the kingdom of man. It is plain that man became at an early stage more or less aware of the history behind him, and that he has insisted on taking part in his evolution to a degree far more marked than is exhibited by even the highest animals. Man has, for instance, insisted on throwing off the yoke of Natural Selection, and has suffered in the dilemmas of civilization for doing so without substituting sufficiently testing modes of rational and social selection. In modern times the idea of purposively controlling not only individual development 
but racial evolution as well is growing rapidly in men's minds, and this opens up great possibilities.

Perhaps we may make the fallacy of "biologisms" more vivid by taking the particular case of the influence of the ductless glands on human development and activity. This influence is indubitable and farreaching, but it may be exaggerated into a fallacy which pictures man as the slave of his hormones.

There is a strong tendency nowadays to shirk personal responsibility. If things are not well with us, we blame our heredity. If that won't work, we blame our "unconscious mind." When the worst comes to the worst, we blame our "glands." When things are going well with us, however, we are quite willing to take the credit to ourselves.

Apart from some earlier guesses at truth, the first glimpse of the idea of internal secretions, which are not got rid of on a free surface, nor carried away by ducts, may be found in the work of the great French physiologist, Claude Bernard, especially in his discovery that the liver was a maker of glycogen or animal starch. The second great step was due to Brown-Sequard, who gave some experimental evidence in support of his brilliant idea that glands (and other organs) make definite contributions to the blood, and that these have a profound influence on the whole system. The third step was taken by Professors Bayliss and Starling, who put the theory of internal secretions on a firm basis, and proved, for instance, that a specific chemical messenger, called secretin, is manufactured by glands on the wall of 
the small intestine, and that when this is swept away in the blood stream, and comes in due course to the pancreas or sweetbread, it stimulates in that organ an increased flow of digestive juice.

The body is made one by the nervous system and also by the circulation of the blood-that common medium from which all the cells take, and to which they all give. But the new idea, that has changed the whole aspect of physiology, is that the regulative function is effected by these hormones which put on speed or put on a brake, as circumstances require. The organs and tissues of internal secretion have complex and subtle influences, still imperfectly investigated, and they work into one another's hands in a wonderful way.

The thyroid gland acts like an accelerator of the transformations of energy that go on in our bodies; the pituitary body has much to do with the regulation of growth; the supra-renal bodies, under the influence of emotion, secrete an increased amount of adrenalin into the blood, and the results are manifold—raising the blood-pressure, increasing the sugar-content and coagulability of the blood, quickening the heart-beats and the breathing movements, toning up the nervous system, and so forth. It is the gland of emergencies.

The cretin child, whose bodily development is arrested, is also more or less of an imbecile. What is wrong is thyroid-deficiency, and when that is medicinally compensated for by injections of thyroid secretion, say from sheep, or by a thyroid diet, there is an immediate improvement in the state of the mind 
as well as of the body. Whatever we may think of the body-and-mind relation, the activities of the two are in mundane experience inseparable. Perhaps the mind plays on the body as the musician on his instrument, and will naturally be affected if the body is out of tune. Perhaps the inner and the outer life, the psychical and the protoplasmic, the mental and the metabolic, are two aspects of one activity.

Perhaps and perhaps; but the certainty is that the reality we call "mind" and the reality we call "body" are in intimate correlation. The cat is excited by the impertinence of the dog; its emotion, akin to anger, affects the sympathetic nervous system; this stimulates the supra-renal bodies to increased production of adrenalin; this affects the whole of the cat's bodyfrom its heart to its hair, which stands on end. But if this be taken as an instance of mind affecting body through the mediacy of the endocrine (or internal secretion) glands, we must also recognize that the activity of the glands may influence the mind. Excessive thyroid activity may be the background of boasting; thyroid insufficiency may be the cause of mental depression. An animal with a relatively large suprarenal cortex is likely to be aggressive and courageous, whereas one with a relatively small supra-renal cortex is likely to be timid and self-effacing.

In an interesting, if sometimes impetuous, book, The Glands Regulating Personality, Dr. Louis Berman pictures a number of types of men who are in the sway of particular endocrine glands. There is the adrenal personality - vigorous, efficient, forceful, apt 
to overdo it unless the adrenal spur is counteracted by some other endocrinal bridle. "An adrenal type will probably be the first woman President of the United States." There are two pituitary personalities. The one is determined by the rule of the anterior lobe of the pituitary body, usually a big-brained man. The other is determined by an excessive activity of the posterior lobe of the pituitary body, usually a very emotional, tender-hearted woman. The thyroid personality is "the ruddy live-wire, recognized everywhere as bubbling with vitality, the life of any group."

In Dr. Louis Berman's vivid thesis of glandular personalities there is much that must be kept in mind if we are to understand human life. But the details of it seem to be ahead of the secure facts. We must always welcome the flapping of the wings of the scientific imagination, but we are not compelled to follow their flight. Science must hasten slowly. Details apart, we must correct the over-emphasis on the glands. It still remains a man's business to try always to be captain of his soul and master of his fate. To acquiesce in being an endocrinal slave means relinquishing a birthright.

\section{§11. Religious Interpretation.}

What seems to us to be the sound position is to maintain that there cannot be any radical antithesis between scientific description and religious interpretation. There may be clashing as regards details, or as regards the form in which conclusions are expressed, 
but there cannot be any fundamental opposition. For science and religion use incommensurable categories. If the religious man has attained to the vision of God, nothing that science can say will affect that reality, save in increasing the wonder of it. For it is plain that communion with the Divine, which lies at the heart of religious experience, is beyond the scientific universe of discourse. It is possible that the scientific sceptic may regard the religious vision of the unseen universe as an illusion, just as it is possible that the philosophical sceptic may regard the naïve view of the seen universe as an illusion; but there is no possible way in which science could disprove God. Thus, writing as a student of science from the naturalistic point of view, which excludes in description any extra-natural power (force, entelechy, or élan), Professor Lloyd Morgan maintains in his Emergent Evolution (1923) that there is nothing in scientific cosmography that precludes an acknowledgment of God. The same applies to other transcendental concepts to which we are led by experience which cannot be called scientific. The only proviso is the avoidance of self-contradiction. We cannot have idea-tight compartments in our mind; our synoptic or all-round view, which includes not only science but what we gain from feeling and doing, must be consistent. We say, tritely enough, that it must be consistent, yet the difficulty is that we must not try to look out of two windows at once! We must not mix our concepts. If we are trying to give a scientific description of man, we must not speak of him, in the same breath, 
as a child of God. If we are trying to give a religious interpretation of man, we must not fall into the error of Dr. John Lightfoot, an eminent Hebrew scholar in his day-the time of the Westminster Confessionand likewise Vice-Chancellor of the University of Cambridge, who maintained that man was created by the Trinity on October 25, 4004 в.c., at nine o'clock in the morning.

What is wrong is not so much that 400,004 B.c. is nearer the facts than 4004; the larger error is in mingling with the transcendental idea of man's relation to the divine purpose a particular concrete description. For the latter cannot be given except by science. In short, we must not try to speak two languages at once. Empirical formulæ we know, and transcendental concepts we know, but they will not blend.

We had some years ago the pleasure of a short talk with a well-known poet who is not less remarkable as a man of practical affairs. He has done big things for his day and generation. In the course of conversation he said, if we understood him aright, that when he disciplined his spirit he could see fairies and sojourn in fairyland. The environment of which he became eye-witness was different from that of our everyday life, and was not even a reconstruction of it on a new pattern. In any case, fairies were as real to him as microscopic little people are to us in our zoölogical laboratory. As we listened to his story we felt that, as naturalists, we had nothing to say; for the poet did not obtrude his fairies into the universe 
of our discourse. Perhaps psychologists might have proved the fairies an illusion, but we, as naturalists, had no objection to offer. Our dominant feeling, as a matter of fact, was envy. But had the poet proceeded to explain that the manufacture of nectar in the honeysuckle was entirely a matter of fairies' distilling, we should have been up in arms at once. We should have pointed to the naturalistic "Notice to Trespassers : No fairies allowed to encamp here." But the poet was much too wise to mix his concepts. He did not offer us the alternative-botany or fairies. The question was botany plus fairies (guaranteed not to meddle) or botany alone. Perhaps the question was really in regard to what Robert Bridges has called "the necessity of poetry."

The point of the analogy will break if it is pressed, and we have not ourselves found the right-of-way to fairyland; but what we wish to suggest is that our poet was wiser in his generation than some children of greater light. For he did not obtrude his fairies into our science. Nor did he argue about their reality; he accepted them with "natural piety"; and he contrived to make one feel that one was missing something.

Similarly, there is no alternative_- "God or Darwinism"; no alternative_- "Man as child of God or man as highest mammal"; no alternative_- "divine creation or cosmic evolution." For all these express confusion of thought. The alternative is- "Science only or science and the vision of God."

Apart from the fact that the evolutionist conclu- 
sion must be accepted as the inferential scientific description of what actually occurred in the irrecoverable past, there are several reasons why it should be welcome. It gives the world a new unity when we recognize man as the crown of Nature, the copingstone (for the time being) of the great edifice. It gives more meaning to the prolonged groaning and travailing of creation when we see that the outcome was man-in whom Nature became articulate and selfconscious. There is fresh interest in the elaborateness of the intricate economy of Nature when we understand part of it at least as the foundation which has rendered man possible. Moreover, there are discomfiting features in every man which become more intelligible when we recognize them as anachronisms inherited from distant ancestry-still disquieting, no doubt, but less perplexing parts of what is, on the whole, a goodly heritage. "The web of our life," Shakespeare says, "is of mingled yarn, good and ill together." The evolutionist interpretation makes both more understandable.

The evolutionist view has a gospel for man, inasmuch as evolution has been on the whole an integrative process, making more and more for the emergence of individuality and personality. It is an encouraging fact that it is an ascent, not a descent, that we have behind us. There are, no doubt, retrograde possibilities, but evolution has been on the whole in a direction which man at his best has always known as best. The momentum of the past is with men who will 
continue this trend, who will continue the work of those-

Who toiling hard against the stream

Saw distant gates of Eden gleam

And did not dream it was a dream.

If we realize what is meant by speaking of man's "emergence," we are saved from the fallacy of taking either a simplicist or a depreciative view of human nature. This is so important that we must be allowed to quote a paragraph from Professor Lloyd Morgan's Gifford Lectures on Emergent Evolution (1922), a very valuable contribution to science and philosophy alike.

"Emergent evolution works upwards from matter, through life, to consciousness which attains in man its highest reflective or supra-reflective level. It accepts the 'more' at each ascending stage as that which is given, and accepts it to the full. The most subtle appreciation of the artist or the poet, the highest aspiration of the saint, are no less accepted than the blossom of the water-lily, the crystalline fabric of a snowflake, or the minute structure of the atom." The theory of "Emergent evolution" urges that the "more" of any given stage, even the highest, involves the "less' of the stages which were precedent to it and continue to co-exist with it. It does not interpret the higher in terms of the lower, "for that would imply denial of the emergence of those new modes of natural relatedness which characterize the higher and make it what it is." Nor does it interpret the lower in terms 
of the higher, e.g., physical changes in terms of life, for that is not in accordance with the rules of scientific description. But Professor Lloyd Morgan seeks to show that it is not inconsistent with his evolutionist science to acknowledge God as the immaterial source of all change and "the nisus through whose activity emergents emerge, and the whole course of emergent evolution is directed."

As our knowledge increases, we realize more of man's debt to his pre-human ancestors. There is an evolutionary momentum behind him, making for kindliness and integration. It is an ascent, not a descent, which science discloses; and the doctrine of "the Fall" must be adapted to the facts. As our knowledge increases, we realize that there is little justification for thinking of primitive man as brutal or brutish; there is reason for thinking of him as clever and kindly, adventurous and inventive. Here, again, it is a rise, not a fall which science discloses.

In any case, the apartness of man remains, whatever be his pedigree. Man is not less great because a scion of a stock common to him and to the gorilla. We must look on the rock whence we were hewn and the depth whence we were digged, but there are other directions in which we must also look. "What a piece of work is a man! How noble in reason! How infinite in faculty! In form and moving how express and admirable! In action how like an angel! In apprehension how like a god!" Part of the truth lies here and Natural History must keep in tune.

Some people seem never to get past talking of 
man as if he were no more than a bipedal mammal with an unusually big brain and a strong herd-instinct. Of course, that is true, so far as it goes, but how far from expressing the whole truth, even from the scientific point of view! For man at his best discovers the secret motions of things and uses his knowledge to bend nature to his purposes. He seeks after the true, the beautiful, and the good. He sends his tendrils to the stars. All these are facts which must enter into the scientific description, which in turn admits of religious interpretation.

What is man, that thou art mindful of him?

And the son of man, that thou regardest him?

\section{Summary.}

1. There are apt to be taxes on new knowledge, for it is difficult to avoid exaggeration in the glow of discovery, and the incorporation of large new facts and new ideas into the framework of our thinking often means disturbance. Thus in connection with the Descent of Man, some imagined that to say "Man evolved" cleared up all difficulties, while others felt that the new way of regarding Man's emergence was subversive of his dignity and destructive of his value. Both views are obviously misunderstandings.

2. What Darwin proved was Man's solidarity with the rest of creation. He demonstrated Man's affiliation to an extinct stock common to him and to the anthropoid apes. The evidence of this may be found in the close anatomical similitude, in Man's numerous vestigial structures, in Man's individual develop- 
ment, for a time so like that of the higher Primates, in the similarity of humanoid and anthropoid functions, and in the existence of "tentative men" who came before Homo. We may recognize all this solidarity without abating in the least our appreciation of Man's apartness-in reason, in language, in vivid self-consciousness, and in moral agency.

3. But Darwin also sought to show how demonstrable factors of variation, heredity, and selection may have operated in Man's emergence. Our knowledge of these factors remains confessedly slight and vague, but the inquiry is still young, and it is bad thinking to use our confession of ignorance of the factors as if it implied any dubiety as to the fact of Man's natural evolution-a fact in the sense that all the scientific evidence points to that mode of emergence.

4. The tax to pay on the Darwinian conclusion is twofold. There is a tendency to think less nobly than we ought to think of Man and the height of his calling. But value is independent of origin, and Man remains "the summit of the whole." Secondly, the idea of Man's natural evolution is repugnant to some to whom it seems inconsistent with the idea of his being "the child of God." But it is not permissible to pick and choose our science according to our liking, and the idea of God as the Will behind a process of evolution is not less conceivable than the idea of God as acting by special creation.

In any case, there can be no radical antithesis between the scientific description of Man as the outcome 
of a process of natural evolution and the religious interpretation of Man as the child of God.

5. The idea of "emergent evolution" is useful. By an "emergence" is meant a genuine novelty, not a mere additive resultant. All the big steps have illustrated "emergent evolution," the appearance of new syntheses; and this is particularly true of Man. Just as the remarkable properties of water are the unpredictable, though now familiar, outcome of combining oxygen and hydrogen, so, but more subtly, birds emerged from reptiles, and man from a simian stock.

6. The pedigree of man illustrates a sifting-out process-successive divergences of New World monkeys, of Old World monkeys, of small apes, of large apes, of tentative men (Hominidæ), until at last what we may call the progressive main stem is represented by Homo. There was a persistent pressing on past lower levels of existence, past side-tracks and blind alleys, until at last there emerged the Man.

7. Mutations often occur in Nature, transilient or discontinuous variations. It is probable that Man arose as a mutation. In his ancestry the period of arboreal apprenticeship probably counted for much -e.g., in the emancipation of the hand, the recession of the snout region, the enlargement of the braincase, the shunting forward of the eyes, and changes in the brain. But the critical time was probably when climatic changes brought about a shrinking of the forests, and the humanoids came to earth. That involved a struggle for existence in which the premium was on wits rather than on strength. Account must 
also be taken of the social predisposition, the prolonged ante-natal life, the prolonged infancy, the growing language, and other factors. Attention is directed to a method characteristic of progressive evolution, in which the ascending spiral of one character bends down, as it were, and lifts a correlated character on to a higher level. Sociality prompts language, but language reacts on social organization. Parental care makes economized reproduction possible, but the reduction of the family makes a higher form of parental care possible and creates a milieu that sifts variations in the direction of better parents. Evolution works in virtuous circles.

8. Neanderthal Man was for a time the highest living creature, but he disappeared without leaving descendants. He appears to represent a distinct species, Homo neanderthalensis, different from the Modern Man type, Homo sapiens. Both diverged from a Homo stock, but Neanderthal Man was not ancestral to Modern Man. This illustrates again "the sifting-out process" characteristic of evolution, and raises strange questionings in our minds. Is the same process being continued in our midst? Is a new type emerging?

9. Why should Man cease to evolve? Has human evolution passed from man's body to his social environment or external heritage? Modifications of the body are common, but their entailment has not been proved. Germinal variations are always cropping up, but it is uncertain whether any of them are taking grip. It is probable that some parts of man's body are 
in process of more perfect adaptation; perhaps some new immunities are being evolved; but little is certain. Two lines of possible evolution seem to be particularly promising, an increase in the complexity of cerebral inter-relations and a change of the rhythm of life so that the youthful period is extended and the senescent period abbreviated. Modern man is becoming aware of new methods of controlling not only the individual life, but racial evolution.

10. A "materialism" is an attempt to give a false simplicity to the ways of organisms by trying to fit them into the descriptive frameworks of chemistry and physics, without recognizing the distinctiveness of "life" and "mind." So a "biologism" is an attempt to give a false simplicity to the life of man by trying to fit it into the descriptive framework of zoölogy. This may be illustrated by fatalistic theories of heredity which depreciate the extent to which man can trade with his talents; by an obtrusive physiology which insinuates that the ductless glands altogether determine the personality; and by an evolutionism that makes little of man's apartness and fails to realize the part he plays and may play in directing his own evolution.

11. There cannot be any radical antithesis between scientific description and religious interpretation. There may be clashing as to details and forms of expression, but not in principle. Science and religion work with incommensurable categories. The outcome of natural evolution may be religiously interpreted as "the child of God." 
The evolutionist picture gives the world a new unity; the groaning and travailing of creation finds a new meaning when Man is discerned as its outcome; the elaborateness of the foundations is more intelligible when recognized as in part a foundation for the lofty superstructure; perplexing anachronisms in our nature receive historical elucidation. The evolutionist view is encouraging and strengthening, for evolution is on the whole integrative and makes for the emergence of mind and personality; its momentum is with us at our best; it is an ascent, not a descent, that lies behind us. This is more heartening than the theological doctrine of the Fall. Perhaps, after all, the God of Evolution is no new concept, for the scholars tell us that the word Jehovah meant not only "I am that I am," but "I will be what I will be." 



\section{INDEX}

Acquired characters, 125, 150, 174

Ambrosia beetles, 106

Anatomical argument, 69

Anthony, R., 213

Antlers, 128, 177

Ants and acacias, 109

Ants and caterpillars, 114, 117

Appendix vermiformis, 85

Arboreal life, 213

Archæopteryx, 58

Atom, structure of, 18

Balanoglossus, 78

Baly, 45, 48, 50

Barnacles, 138

Bateson, 99

Bayliss, 172

Becquerel, 43

Beebe, W., 64, 107

Belt, Thomas, 109

Bentley, 167

Berman, Louis, 228

Birds, ancestor of, 98

Blood, salts of, 95

-, transfusion of, 93

Boule, 215, 216

Boyden, 81

Bracken, 102

Browning, 206

Buchner, 108

Butterfly, "Large Blue," 117

Cats, 100, 101

Chamæleon, 142

Chamberlin, 23

Chamberlin and Moulton, 8, 10

Chlorophyll, 49

Colloidal state, 25

Convoluta, 156

Cosmology, 32
Cunningham, J. T., 86, 174, 175, 176

Danforth, 163

Darwin, 58, 69, 118, 124, 196

Darwinism, 101

Darwin's point in ear, 200

Death-watch, 108

Delpino, 110

Descent of Man, 196, 197

Design argument, 181

De Sitter, 15

Detlefsen, J. A., 169

De Vries, 143

Dipnoi, 64, 74

Ear, Darwin's point in, 200

Earth, fashioning of, 20

- , origin of, 23

Eel, life-history of, 87

Einstein, 15

Electrons, 18

Elephant, pedigree of, 59

Embryological evidence, 80

Emergent evolution, 205

Emerson, 211, 212

Energies, transformation of, 19

Evolution, evidences of, 53

-

_- gospel of, 233

- , inorganic, 20

- , organic, 41

- , religious aspect of, 180

Evolution of matter, 18

Eyelid, third, 198

Factors in inheritance, 146

Feather-star, 88

Flat-fishes, 83

Flounders, 86

Fortuitousness, 179

Friedenthal, 93 
Galápagos Islands, 64

Geikie, Sir Archibald, 21

Genes, 126, 146

Gill-clefts, 81

Glands, endocrine, 226

Goldfishes, 148

Gorilla, 153

Graham, Thomas, 25

Gregory, Sir Richard, 14

Griffith, 167

Guinea-pigs, 165

Guyer, M. F., 171

Haas, Arthur, 15

Habit-forming, 153

Habits, 149

Habituation, 158

Hansom, F. B., 164

Heather, 104

Henderson, 23

Heredity, 145

Homo sapiens, 218

Hormones, 172, 226, 227

Hunger and love, 119

Hutton, James, 21

Huxley, 118

Hyphænosymphily, 114

Iguanodon, 56

Inflammation, 131

Islands, 63

Jeans, 7, 9

Johannsen, 144

Jones, F. Wood, 213

Jungle-fowl, 91

Kallima, 134

Kant, 3

Keith, Sir Arthur, 208, 216

Kemner, N. A., 113

Lamarckian theory, 170

Lamarckism, 152

Lancelet, 62
Laplace, 3, 11

Leaf-butterfly, 134

Leaf-cutting ants, 107

Leaf-insect, 136

Leiper, 103

Lenses, experiments on, 171

Leucochloridium, 103

Life, origin of, 42

Lightfoot, John, 231

Lizards, giant, 66

Lotsy, 145

Lull, R. S., 60, 213, 215

Luminescence, 105

MacDowell, E. C., 163, 167

Man, evolution of, 193, 202, 203 - continued evolution of, 220

- genealogical tree, 208

Man's evolution, factors in, 212

Marsupial, 61

Maxwell, Clerk, 15

Mendeléeff, 29

Mendelian inheritance, 147

Meteorological cycle, 27

Mind and body, 228, 229

Modifications, 150, 151

Morgan, C. Lloyd, 205, 209, 230, 233, 235

Morgan, T. H., 145, 146

Mudfish, 74

Mutations, 125

Myrmecophily, 110

Napoleon, 11

Natural Selection, 122, 132

Nature-Psalms, 12

Neanderthal man, 214

Nebula, spiral, 6, 7

Nebular hypothesis, 3

Nerve-cells, 82

New Zealand "Lizard," 54

Newton, 16

Notochord, 81

Nuttall, 93 
Ontogeny, 83

Order of Nature, 9, 23

Order of Universe, 15

Owen, Sir Richard, 197

Paludina, 96

Pathology, 127

Past in the present, 87

Pavlov, 166

Pearl, Raymond, 163

Peripatus, 76

Photosynthesis, 45

Phyllium, 136

Phylogeny, 83

Pigeons, evolution of, 94

Planetesimals, 10

Poincaré, 16

Poultry, evolution of, 92

Preparations for life, 27, 29

Proteus, 148

Protons, 18

Punnett, 133, 222

Radium, 18

Rats, 161, 162, 163

Rats on a roundabout, 166

Recapitulation, 81

Reflex actions, 157

Religion and science, 229

Religious wonder, 12

Rhythms, 156

Rock record, 57

Root-tubercles, 105

Rutherford, Sir Ernest, 20

Salmon, 130

Saturn, 4

Schimper, 111

Schwalbe, G., 93

Sea-Lizards, 66
Selection, 137

Sex-hormones, 173

Simpson, J. Y., 139

Skene, MacGregor, 49

Smith, E. A., 171

Soddy, Frederick, 18

Specificity, 83

Spencer, Herbert, 120, 169

Sphenodon, 54

Spiracle of skate, 73

Spontaneous generation, 47

Starling, E. H., 172

Stars, distance of, 14

Stickleback, 129

Stockard, C. R., 163, 165

Struggle for existence, 117, 137

Sun, distance of, 14

Synthetic types, 75

Tennyson, 20, 22

Tidal theory, 8

Tortoises, giant, 65

Uhlenhuth, 93

Unit characters, 147

Universe, circumference of, 15

Uranium, 18

Variability, 124

Variations, 125

Vestigial organs, 71

Virchow, 127

Wallace, Alfred Russel, 63, 100

Water, 26, 28

Web of life, 101

Wegener, 21

Weismann, 150, 151

Whale, 71

Wiedersheim, R., 197

Wild cat, 100 




